\title{
AXISYMMETRIC AIR AUGMENTED METHANOL/GOX ROCKET MIXING DUCT EXPERIMENTAL THRUST STUDY
}

\author{
A Thesis \\ presented to \\ the Faculty of California Polytechnic State University, \\ San Luis Obispo
}

\author{
In Partial Fulfillment \\ of the Requirements for the Degree \\ Master of Science in Aerospace Engineering
}

by

Kyle Jacob Johnson

March 2013 
(C) 2013

Kyle Jacob Johnson ALL RIGHTS RESERVED 


\section{COMMITTEE MEMBERSHIP}

TITLE:

AUTHOR:

DATE SUBMITTED:

COMMITTEE CHAIR:

COMMITTEE MEMBER:

COMMITTEE MEMBER

COMMITTEE MEMBER:
Axisymmetric Air Augmented Methanol/Gox Rocket

Mixing Duct Experimental Thrust Study

Kyle Jacob Johnson

March 2013
Dr. Dianne DeTurris, Professor Aerospace Engineering Department California Polytechnic State University, San Luis Obispo

Dr. Jin Tso, Professor Aerospace Engineering Department California Polytechnic State University, San Luis Obispo

Dr. Eltahry Elghandour, Lecturer Aerospace Engineering Department California Polytechnic State University, San Luis Obispo

Trevor J. Foster, Industry Advisor Empirical Systems Aerospace Pismo Beach, California 


\section{ABSTRACT \\ Axisymmetric Air Augmented Methanol/GOX Rocket \\ Mixing Duct Experimental Thrust Study}

Kyle Jacob Johnson

A hot-flow axisymmetric Air Augmented Rocket (AAR) test apparatus was constructed to test various mixing duct configurations at static conditions. Primary flow for the AAR was provided through a liquid methanol-gaseous oxygen bipropellant rocket. Experimental thrust measurements were recorded and propellant mass flow rates and chamber conditions were calculated using an iterative solver dependant on recorded propellant line stagnation pressures. Primary rocket flow produced thrust ranging from 14 to 17.9lbf. Primary mass flow rate through testing ranged from 0.071 to $0.085 \mathrm{lbm} / \mathrm{s}$ with calculated chamber pressures between 298-362psia. Calculated primary flow velocity ranged from $6,600 \mathrm{ft} / \mathrm{s}$ to $8,000 \mathrm{ft} / \mathrm{s}$ depending on propellant pressure inputs and calculated chamber conditions.

The AAR test apparatus was capable of testing various mixing duct geometries and measuring the axial thrust of the mixing ducts separately from the total thrust of the system. Two mixing duct geometries, a straight wall mixing duct and diverging wall mixing duct, with identical exterior dimensions and inlet geometry were tested for a range of air/fuel mixture ratios from 0.82 to 2.2 spanning the stoichometric mixture ratio of 1.5 . Mixing duct thrust did not vary greatly with primary flow characteristics. Straight mixing duct thrust averaged $0.97 \mathrm{lbf}$ and diverging mixing duct thrust averaged $0.18 \mathrm{lbf}$. Total system thrust decreased by an average of $0.62 \mathrm{lbf}$ with a straight mixing duct and $0.74 \mathrm{lbf}$ with a diverging mixing duct. Decreases in total thrust are attributed to low pressure flow interaction between the mixing duct and the primary rocket assembly.

Visual flow comparison between mixing duct configurations and fuel ratio cases were carried out using high definition video recording with a grid reference for comparison. The diverging mixing duct produced the greatest variation in visible flow when compared to a straight mixing duct and no mixing duct configuration. This indicated that the diverging mixing duct had a greater influence on primary and secondary flow field mixing than the straight mixing duct. 


\section{Acknowledgments}

I must first thank my family for their incredible support throughout this project and my entire academic career. Their continual encouragement and generosity made this possible.

I must thank Dr. DeTurris for providing the opportunity to expand my knowledge of propulsion systems and supporting my research interests. Her enthusiasm and guidance has kept this project on track and moving forward. Cody Thompson has been instrumental in the construction of this test apparatus, his commitment of time and access to equipment made timely construction possible. Daniel Wait provided invaluable instrumentation assistance and continual motivation for the completion of this project. I must thank Joey Sanchez and Chaz Moarantz for their initial work on the SMORE, which served as a baseline for this test apparatus.

Thank you to all of my roommates and friends who put up with long hours and provided support and entertainment when needed. 


\section{Table of Contents}

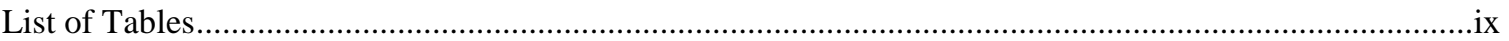

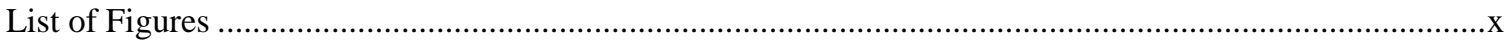

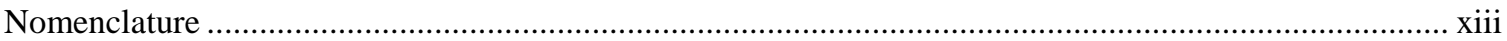

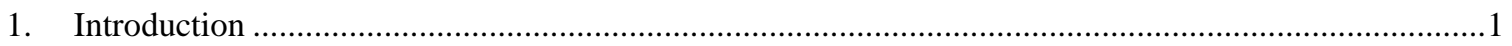

1.1 Rocket Based Combined Cycle (RBCC) Background ..............................................................

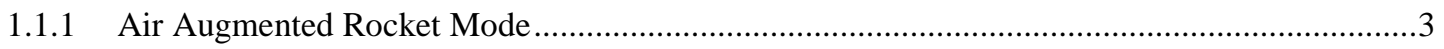

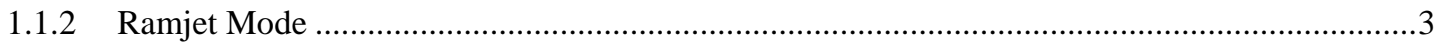

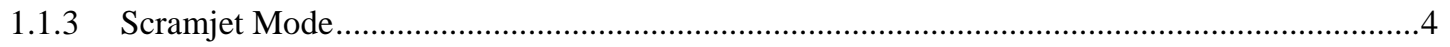

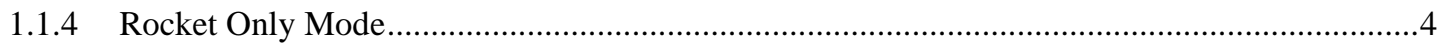

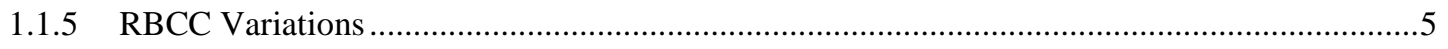

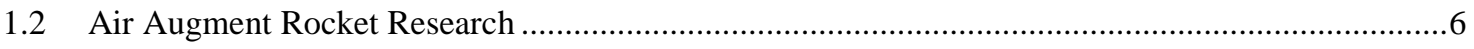

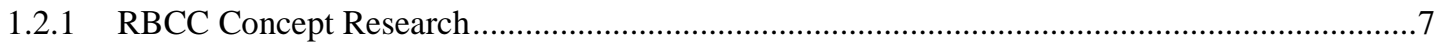

2. Previous Cal Poly Experimental Research …….........................................................................

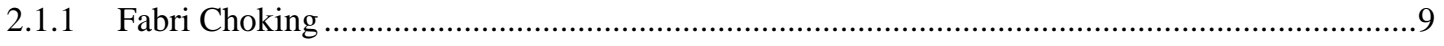

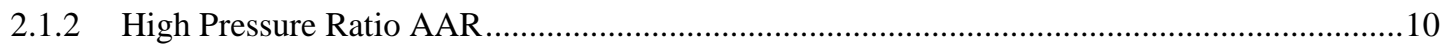

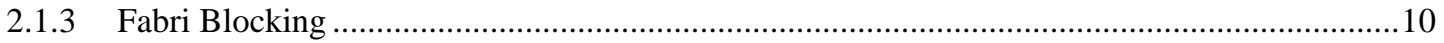

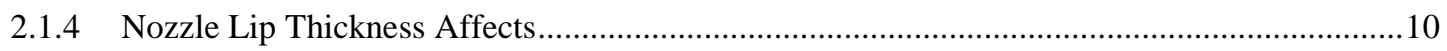

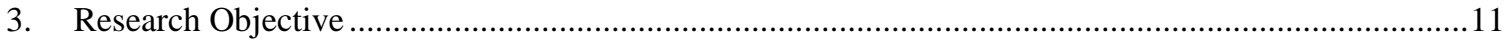

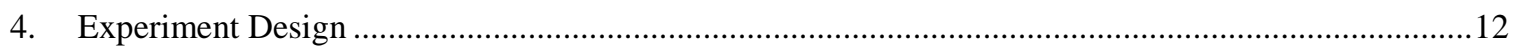

4.1 Static Methanol/Oxygen Rocket Engine (SMORE) ………..........................................................12

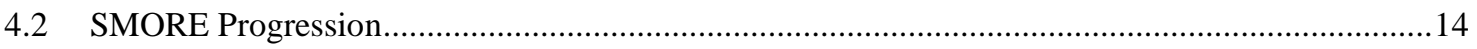

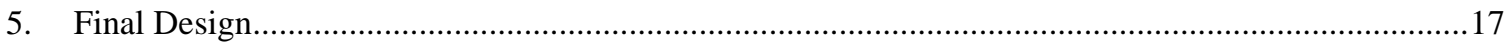




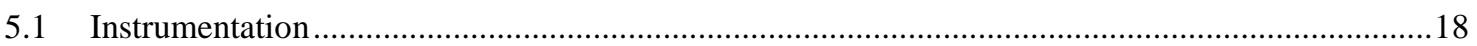

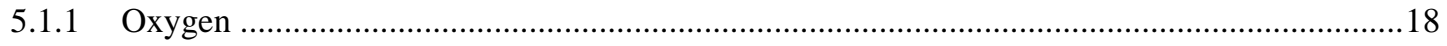

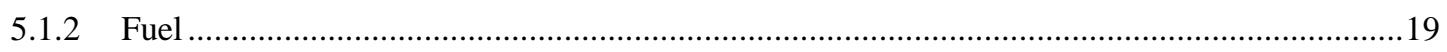

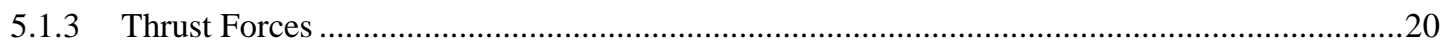

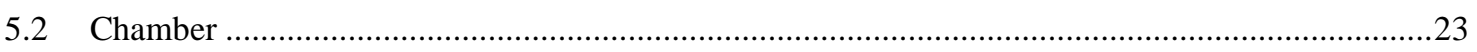

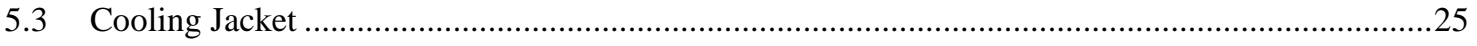

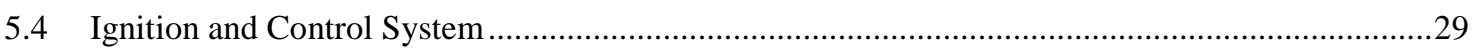

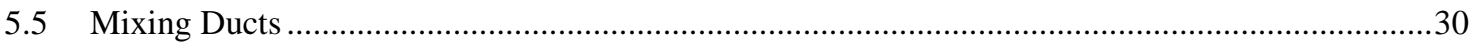

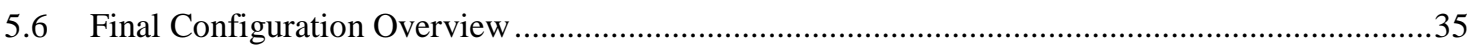

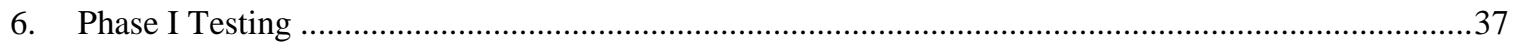

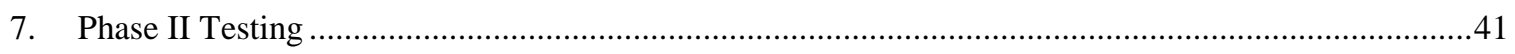

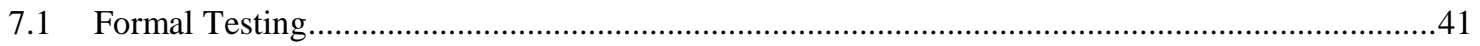

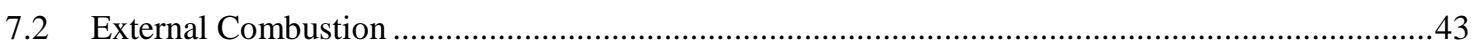

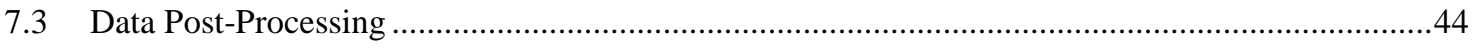

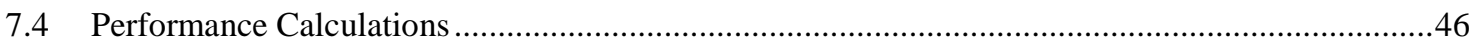

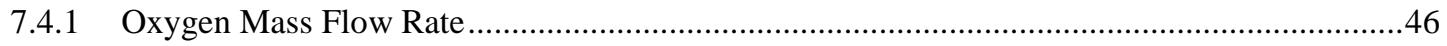

7.4.2 Fuel Flow Rate and Chamber Conditions .............................................................................

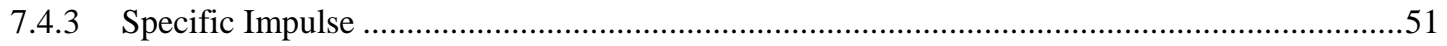

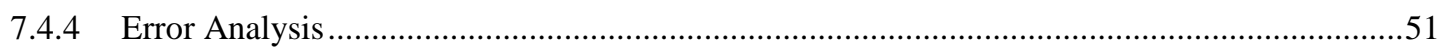

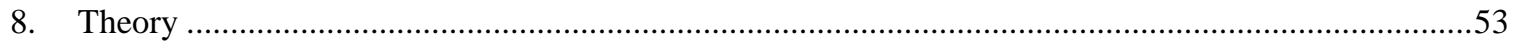

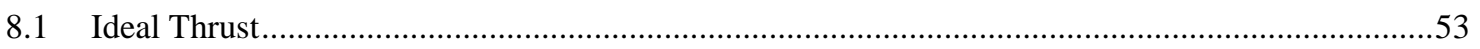

8.2 Mixing Duct Lip Thrust and Incompressible Theory ……..............................................................54

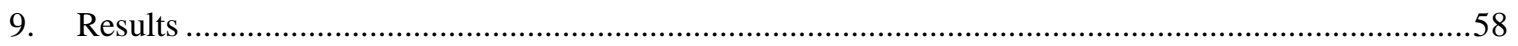




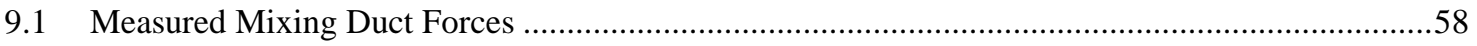

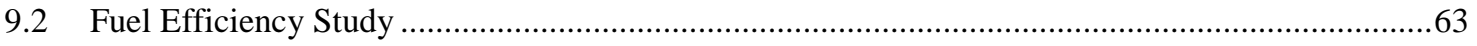

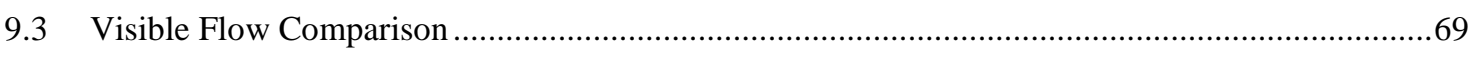

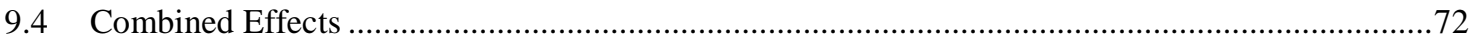

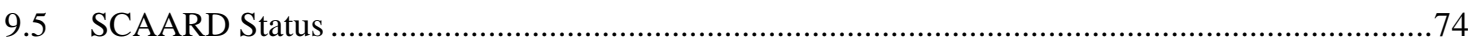

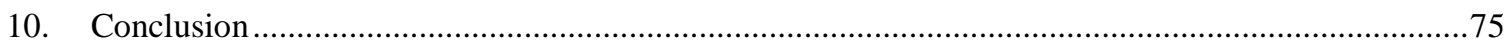

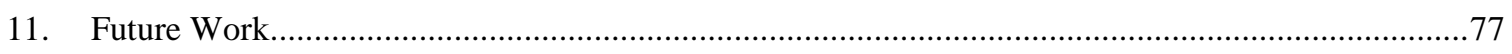

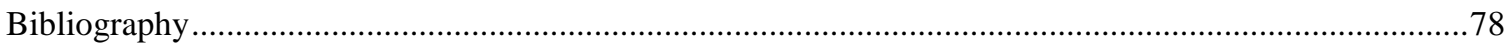

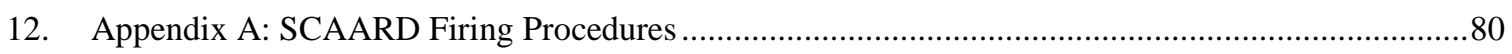




\section{List of Tables}

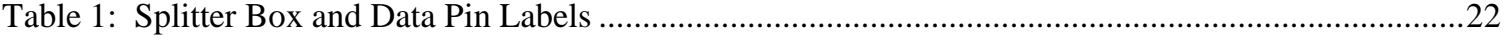

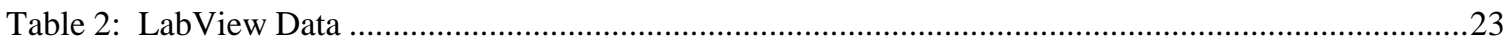

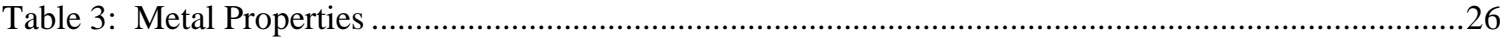

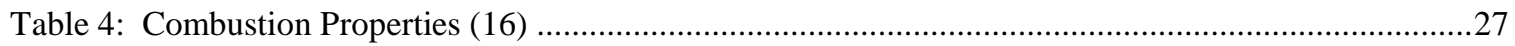

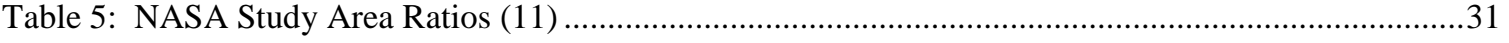

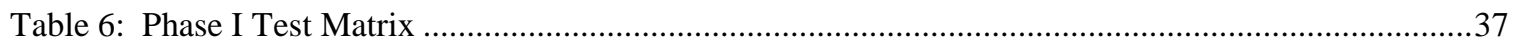

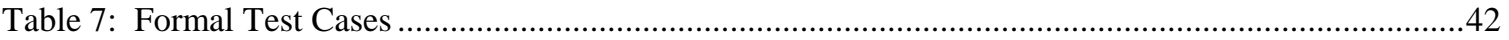

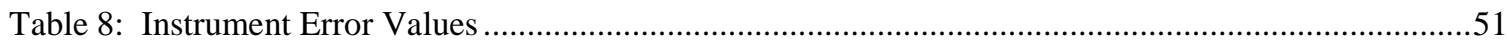

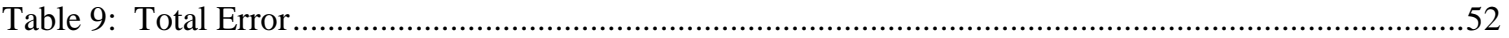

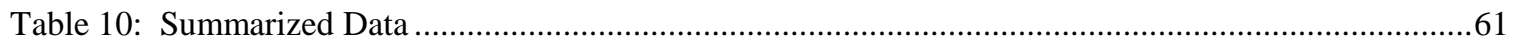




\section{List of Figures}

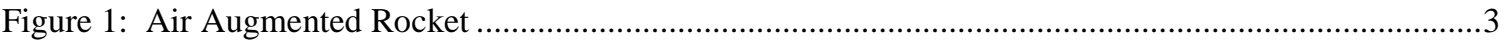

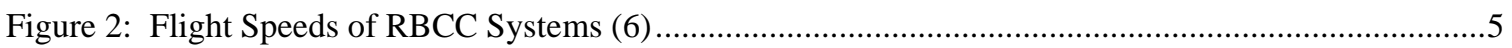

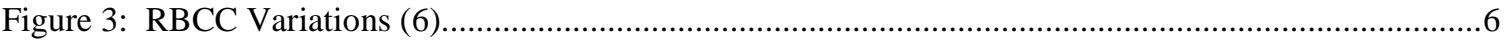

Figure 4: AAR Variations a) Rocket Ejector b) RENE c) SMC d) DAB e) AAR with thermal choke..........8

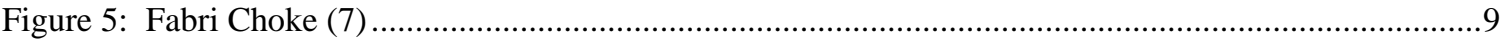

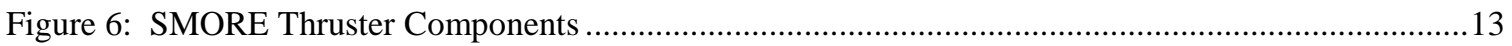

Figure 7: SMORE Counterweight Thrust Measurement .............................................................................14

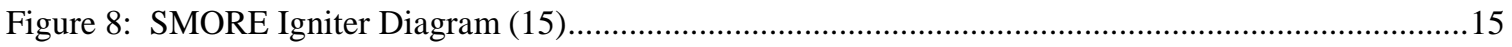

Figure 9: Final SMORE test frame

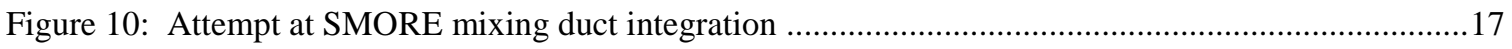

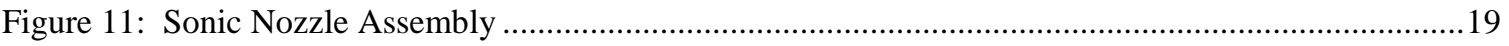

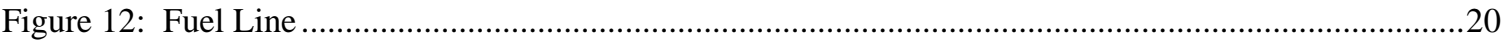

Figure 13: Top, SMORE Chamber; Bottom, SCAARD Chamber .........................................................2

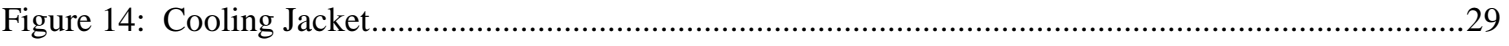

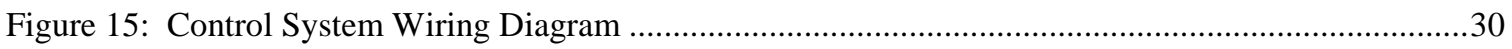

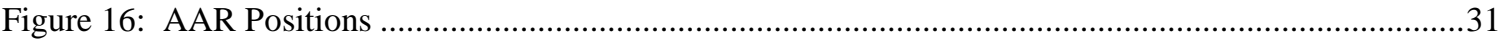

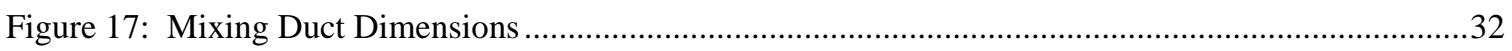

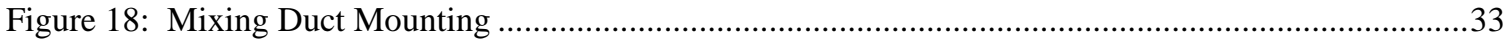

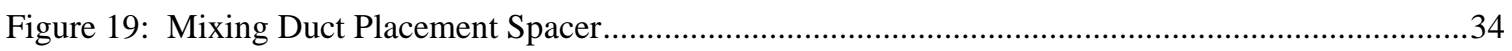

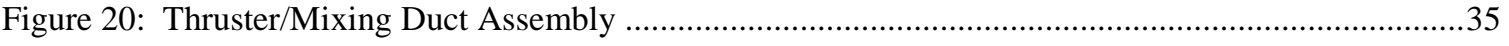

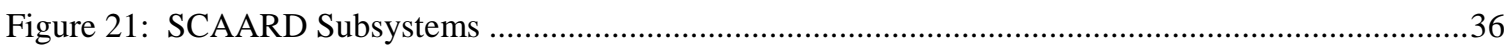

Figure 22: Steady Run: Regulated Fuel Pressure 350psi, Regulated Oxygen Pressure 350psi ....................38 
Figure 23: Unsteady Run: Regulated Fuel Pressure 330psi, Regulated Oxygen Pressure 430psi

Figure 24: Hysteresis Comparison ……………..........................................................................

Figure 25: a) Internal Combustion b) External Combustion ...................................................................4

Figure 26: Regulated Fuel Pressure 350psi, Regulated Oxygen Pressure 370psi: a) External

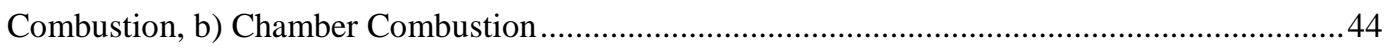

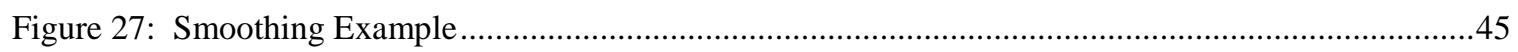

Figure 28: Sonic Nozzle Relationship past Critical Pressure Ratio (24) ....................................................48

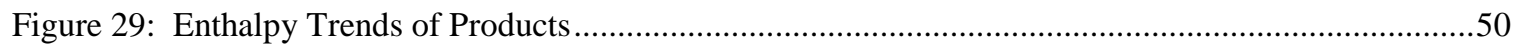

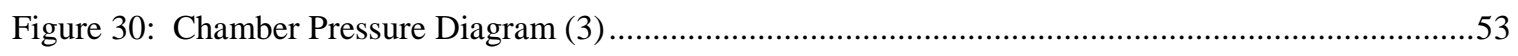

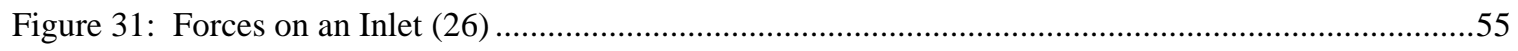

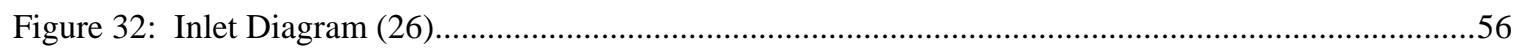

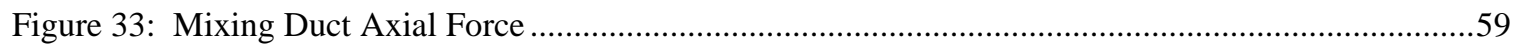

Figure 34: Mixing Duct Wall Pressure Explanation................................................................................62

Figure 35: Variations in Fuel efficiency: a) 50\% b) 60\% c) 70\% d) $80 \%$ e) $90 \%$ f) $100 \% \ldots \ldots \ldots \ldots \ldots \ldots \ldots \ldots . . . . .64$

Figure 36: Effect of Fuel Efficiency on a) Chamber Pressure b) Chamber Temperature...............................65

Figure 37: Effect of Fuel Efficiency on Mixture Ratio ............................................................................66

Figure 38: Ideal Exhaust Velocity Variation with Fuel Efficiency ............................................................67

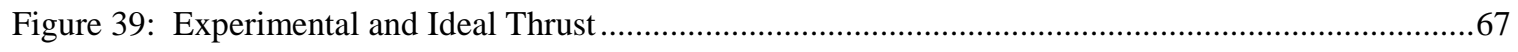

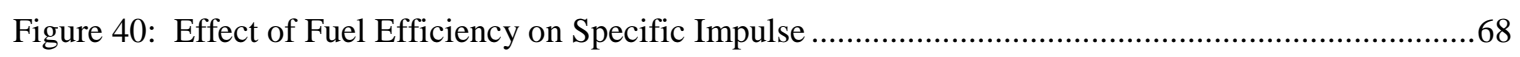

Figure 41: Rich Exhaust Visualization a) No Mixing Duct b) Straight Mixing Duct c) Diverging

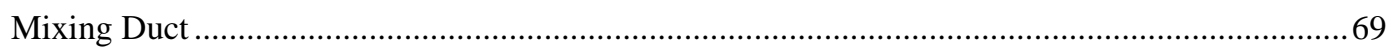

Figure 42: Lean Exhaust Visualization a) No Mixing Duct b) Straight Mixing Duct c) Diverging

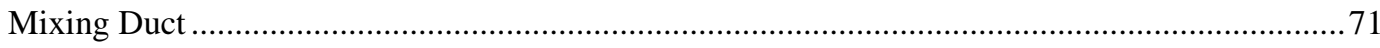

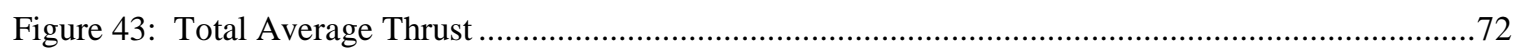


Figure 44: Low Pressure Acting on Assembly..

Figure 45: SCAARD Chamber: a) Combustion Chamber b) Nozzle ..........................................................74 


\section{Nomenclature}

$\begin{array}{ll}\text { A } & \text { Area } \\ \text { C } & \text { Critical Flow Factor } \\ \text { Cd } & \text { Discharge Coefficient } \\ \text { chL } & \text { Characteristic Length }\end{array}$

D

F

FE

GW

$\mathrm{g}_{\mathrm{c}}$

$\mathrm{H}$

$\mathrm{H}_{\mathrm{f}}{ }^{\mathrm{O}}$

Isp

$\mathrm{M}$

$\mathrm{Mw}$

$\dot{\mathrm{m}}$

$\mathrm{P}$

$\mathrm{p}$

$\mathrm{R}$

$\mathrm{Rd}$

rt

SG

$\mathrm{T}$

V

$\dot{\mathrm{W}}$

\section{Greek}

$\gamma$

$\mu$

$v$

$\underline{\text { Subscripts }}$

c

e

f

$\mathrm{s}$

$\mathrm{p}$

$\mathrm{pr}$

$\mathrm{R}$

$\mathrm{t}$

nt

$\mathrm{x}$

3

4

$\underline{\text { Superscripts }}$ $\left(\mathrm{in}^{2)}\right.$

-

(in)

(in)

$\left(\mathrm{lb}_{\mathrm{f}}\right)$

- $\left(\mathrm{b}_{\mathrm{m}}\right)$

$\left(\mathrm{ft} / \mathrm{s}^{2}\right)$

(KJ/mol)

(KJ/mol)

(s)

Specific Impulse

Mach Number

Molecular Weight

Mass Flow Rate

Stagnation Pressure

Static Pressure

Universal Gas Constant

Reynolds Number

Residence Time

Specific Gravity

Temperature

Volume

Weight Flow rate

Ratio of Specific Heats

Absolute Viscosity

Velocity

$\left(\mathrm{lb}_{\mathrm{m}} /\left(\mathrm{ft}^{*} \mathrm{~s}\right)\right)$

$(\mathrm{ft} / \mathrm{s})$
Chamber

Nozzle Exit

Fuel

Secondary

Primary

Products

Reactants

Primary Nozzle Throat

Sonic Nozzle Throat

Oxygen

Mixing Duct Inlet

Mixing Duct Exit

Sonic or Throat Condition $\left(\mathrm{lb}_{\mathrm{m}} / \mathrm{lb}_{\mathrm{m}}-\mathrm{mol}\right)$

$\left(\mathrm{lb}_{\mathrm{m}} / \mathrm{s}\right)$

$\left(\mathrm{lb}_{\mathrm{f}} / \mathrm{in}^{2}\right)$

$\left(\mathrm{lb}_{\mathrm{f}} / \mathrm{in}^{2}\right)$

$\left(\left(\mathrm{lb}_{\mathrm{f}} * \mathrm{ft}\right) /\left(\mathrm{lb}_{\mathrm{m}}-\mathrm{mol}^{* 0} \mathrm{R}\right)\right)$

(s)

$\left({ }^{\mathrm{o}} \mathrm{F},{ }^{\mathrm{o}} \mathrm{R}\right)$

$\left(\right.$ in $\left.^{3}\right)$

$\left(\mathrm{lb}_{\mathrm{f}} / \mathrm{s}\right)$ 


\section{Introduction}

Sputnik I, the first man made satellite to orbit the Earth in October of 1957, was boosted into orbit on a Russian R-7 rocket. (1) The Russian R-7 was a bipropellant rocket using liquid Oxygen and Kerosene for oxidizer and fuel. It represented the beginning of the space race between the United States and the Soviet Union. In the next twelve years the payload capabilities for achieving orbital spaceflight increased from 183.9lb Sputnik I on the R-7 to the giant Saturn V of the United States capable of placing 260,0001bs into Low Earth Orbit or 96,000 lbs to the moon. (2)

While the sizes of the R-7 and the Saturn V were vastly different, their propulsion methods were not. Rocket efficiency is measured in specific impulse, which is the total impulse per unit weight of propellant as seen in $1-1$.

$$
I_{s p}=\frac{F}{\dot{m} g_{c}}=\frac{F}{\dot{w}}(s)
$$

1-1

Higher specific impulse indicates a more efficient propulsion system. High efficiency does not always correspond to higher thrust. In the case of the R-7 and the Saturn V first stage, both systems had a specific impulse of around 250s with the R-7 producing 880,000lbf of takeoff thrust and the Saturn V producing 7,648,000lbf takeoff thrust. Since 1969 there have been relatively small increases in the efficiency of rockets, specifically the first stage launch vehicles. Modern launch vehicles have become more reliable but the overall method of achieving orbit is still the same brute force rocket approach with slight increases in the efficiency of the engines. For example the most efficient chemical rocket engine used in launch applications is the Space Shuttle Main Engine (SSME) which has a sea level specific impulse of 366s. (4) By contrast jet engines have developed from a specific impulse of 4,500s on the Boeing 707 in 1963 to 6,463s on a Boeing 777 in 1997. (5) In percentage increase the two systems have developed almost equally, yet the jet engines maintain a specific impulse that is an order of magnitude higher than that of bipropellant rockets. 
Rockets do have distinct advantages to make up for the lack in specific impulse. For example: thrust increases with altitude, thrust is independent of flight speed and air temperature, and there is no altitude limit on rockets. (3) Jet engines, on the other hand, behave in almost the opposite fashion to rockets: thrust decreases with altitude, increases with flight speed, and most importantly there is a definite altitude limit on jet engines. (3) Limits on altitude result from the use of atmospheric air as the oxidizer in the combustion reaction. This use of atmospheric air is also the reason for the order of magnitude increase in specific impulse over rockets. Air breathing propulsion systems such as turbojets, turbofans, ramjets, and scramjets maintain an inherent advantage over rockets. Carrying only the fuel required for combustion drastically increases the specific impulse due to oxidizer generally being the larger mass fraction of propellants in a combustion reaction. Rockets carry both the oxidizer and fuel internally allowing them to operate at any altitude and achieve orbital velocities. With current technology the only option for achieving orbital velocities $(7.8 \mathrm{~km} / \mathrm{s})$ is the use of chemical rockets.

Since the 1950 s there has been a desire to combine the efficiency benefits of an air breathing propulsion system with the high velocity performance of a chemical rocket. (6) Combining multiple propulsion systems is called a combined cycle system. There are typically two types of combined cycle systems for

flight use; Turbine Based Combined Cycle (TBCC), and Rocket Based Combined Cycle (RBCC). Each of these systems results in a single propulsion system capable of high speed, high altitude flight with increased system specific impulse compared to their individual components. TBCCs utilize an engine such as a turbofan or turbojet to provide thrust from static up to supersonic conditions where a ramjet or scramjet can operate. While TBCCs are a very interesting field of study their application in space launch is limited due to the continued requirement of rocket propulsion for orbital insertion. RBCCs on the other hand are capable of orbital velocities. This research will focus on a specific aspect of the RBCC system.

\subsection{Rocket Based Combined Cycle (RBCC) Background}

Rocket Based Combined Cycle systems generally consist of a shrouded chemical rocket to be operated in four different modes: air augmented rocket, ramjet, scramjet, and rocket only mode all sharing a common flow path. 


\subsubsection{Air Augmented Rocket Mode}

Air Augmented Rocket (AAR) mode is used to achieve higher static thrust and specific impulse compared to an identical rocket operating independently. An AAR is, in its simplest form, a rocket contained within a shroud or "mixing duct". AARs vary in complexity from a simple ducted rocket to supercharged liquid air collection variable geometry with thermal choke and afterburning. In order to understand the basics of AAR operation the simple form of a rocket ejector with constant area mixing will be examined. When a rocket is confined within a duct it operates as a mixer-ejector. High speed primary flow (rocket exhaust) entrains a low speed secondary flow (ambient air). The two flows mix and the resulting mixed fluid is ejected creating thrust. Shear layers caused by the velocity gradient between the high speed primary flow and low speed secondary flow accelerates the secondary flow. Acceleration of the secondary flow entrains more secondary air into the system to be used as a reaction mass or oxidizer for further combustion. This mixer-ejector principle is used in many applications: water pumps, refrigerants, steam ejectors, and RBCC systems. Figure 1 is an example of a generic AAR and its associated components. (7) Contained interaction and mixing of the primary and secondary flows occurs in a region called the mixing duct.

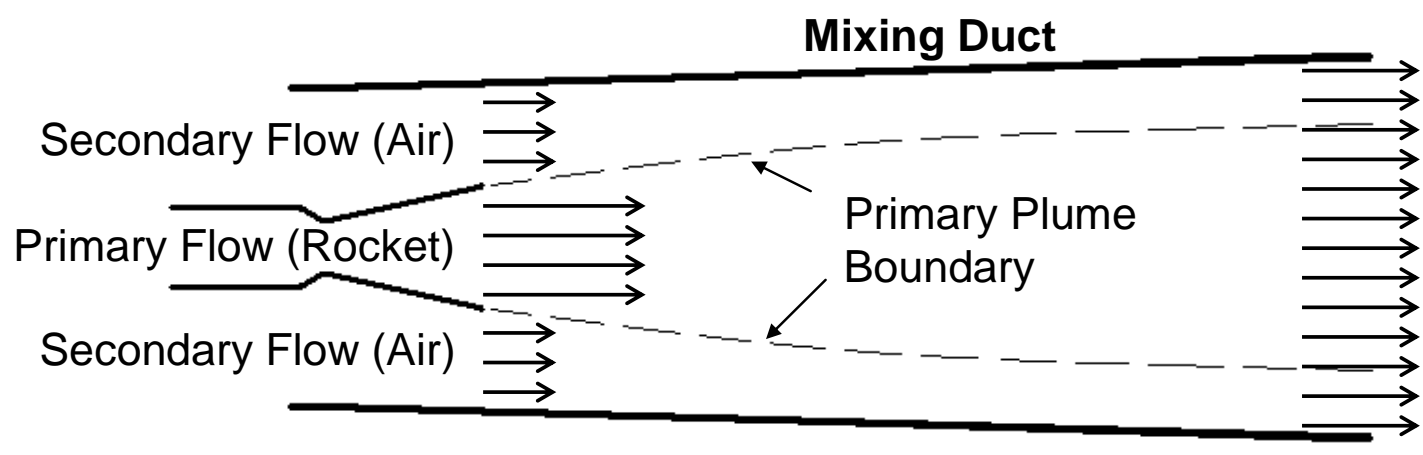

Figure 1: Air Augmented Rocket

\subsubsection{Ramjet Mode}

Ramjet mode in an RBCC utilizes the inlet geometry oblique shock design to compress the freestream air to high pressures and temperatures suitable for combustion. At the conclusion of the inlet oblique shock train 
a normal shock creates subsonic flow within the combustion area. Fuel is then added to the high temperature, high pressure flow where it combusts and is then expanded through a converging diverging nozzle creating thrust. In an RBCC, fuel can be provided to a ramjet through dedicated injectors, or in the case of a bipropellant rocket through the rocket itself.

\subsubsection{Scramjet Mode}

Ramjets are incredibly simple propulsion systems but current material limitations restrict ramjet flight speed to less than Mach 6 due to the high temperatures created by a normal shock at high flight speeds. (8) Increasing flight speeds above Mach 6 requires supersonic combustion to reduce the temperatures in the combustion chamber. Supersonic combustion is attained by changing the inlet geometry such that the inlet shock train does not terminate in a normal shock; this creates supersonic flow throughout the propulsion system. Complex design challenges arise in the design of a scramjet system such as: inlet design, flame holding, combustion cooling, and propulsion system integration. Even with design challenges programs such as the X-43 and X-51 have demonstrated sustained scramjet operation and net thrust. (9) (10)

\subsubsection{Rocket Only Mode}

Rocket only mode utilizes the same rocket as the AAR mode for high altitude orbital insertion. Due to the high altitude and extremely low density of ambient air, there is no ambient air capture cycle in this stage. If designed efficiently the mixing duct that shrouds the rocket can be used as an extremely high area ratio expansion nozzle improving the vacuum Isp of the rocket. (11)

Transitions between RBCC modes are dictated by the flight speed, Figure 2. 


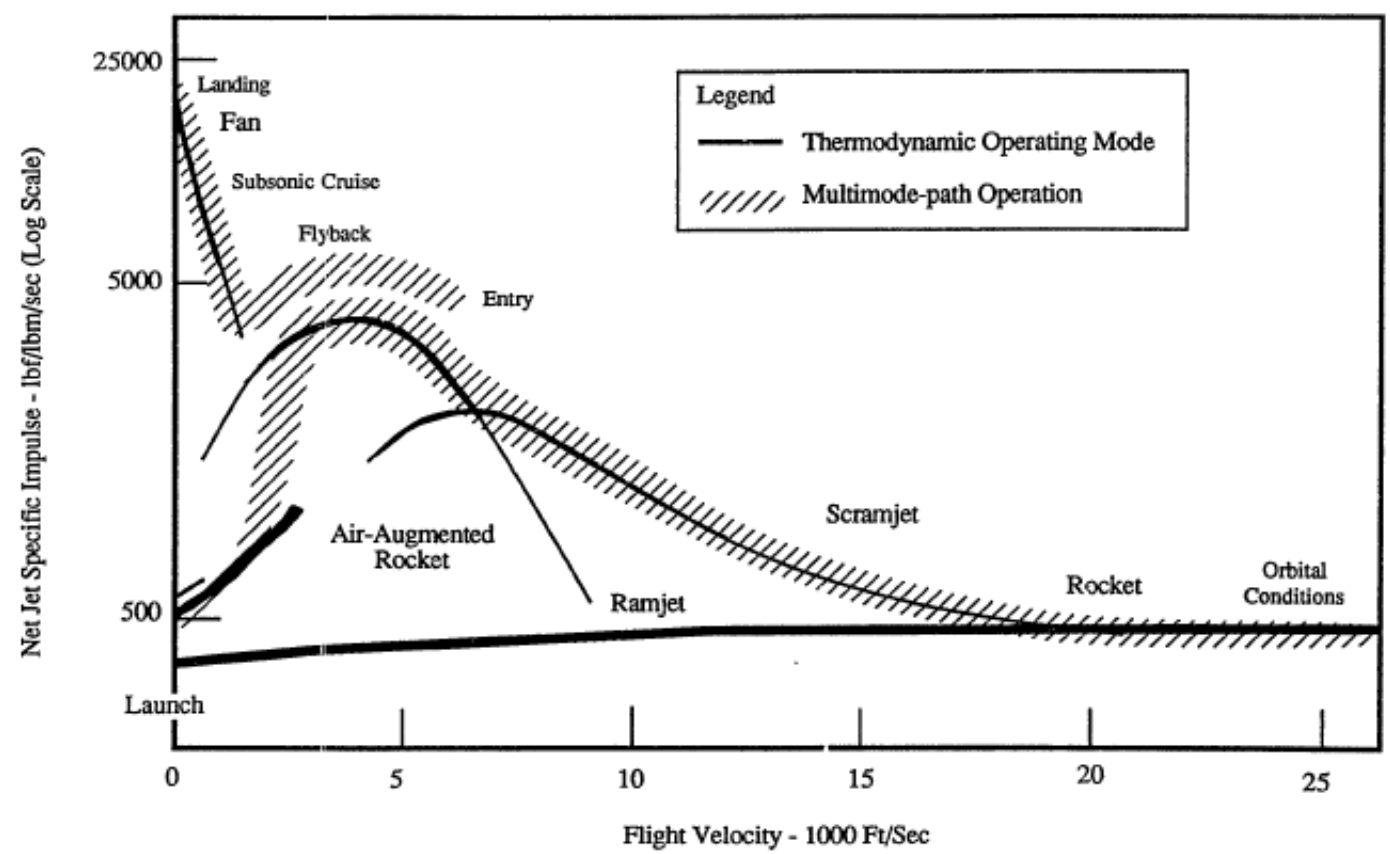

Figure 2: Flight Speeds of RBCC Systems (6)

Theoretically a well designed RBCC system would incorporate each stage into a single propulsion system capable of a much higher combined Isp compared to a rocket. Rockets are the only other system capable of operating over the entire flight regime. This research focuses solely on Air Augmented Rockets operating in static conditions.

\subsubsection{RBCC Variations}

RBCC is a title that can apply to a number of variations on the four modes of an RBCC. For example a conceptual study completed by Foster, Escher, and Robinson in 1989 focused on RBCC single stage to orbit (SSTO) applications. (6) This conceptual study was a more detailed look at 5 RBCC configurations out of 36 that were initially examined in the 1960s by Escher and the Marquardt Company. (12) Over the course of the SSTO study the five RBCC designs examined were, Supercharged Ejector Scramjet, ScramLACE, Non-Recycled Supercharged ScramLACE, Recycled Supercharged Ejector ScramLACE, and Ejector Scramjet, (Figure 3). Supercharged Ejector Scramjet includes a compressor stage increasing the compression of ambient air at low flight speed which increases the efficiency of the AAR mode as well as low speed static thrust. ScramLACE incorporates an oxygen collection device through the condensation of 
ambient air to liquid to be used in the primary rocket. Non-Recycled and Recycled Supercharged ScramLACE add a compressor stage to the ScramLACE system. Ejector Scramjet is the simplest form of RBCC in the Foster engine study and one of the simplest conceivable RBCC systems. Ejector Scramjet is a basic ducted rocket with ramjet and scramjet operational modes.
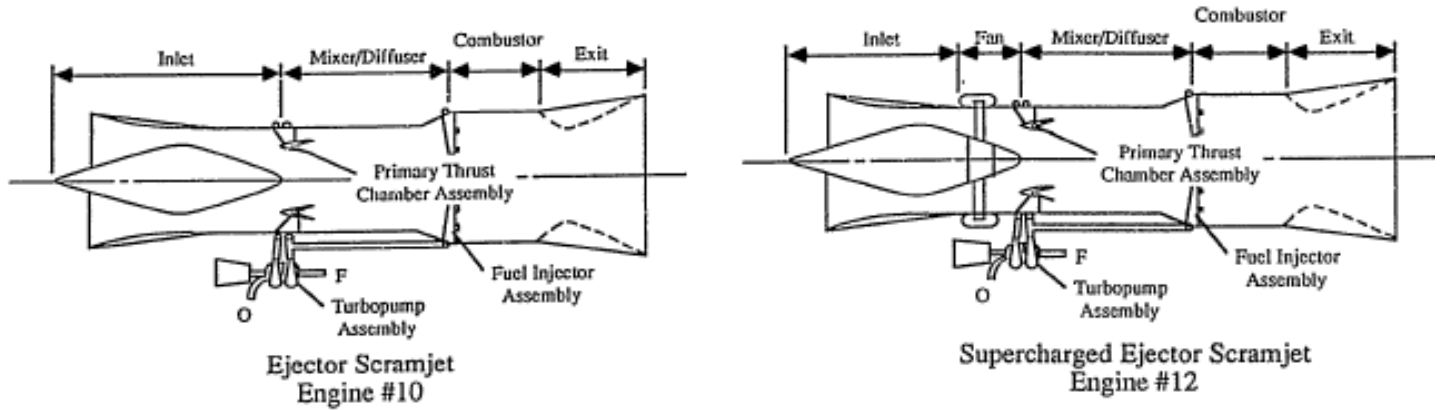

Supercharged Ejector Scramjet Engine \#12
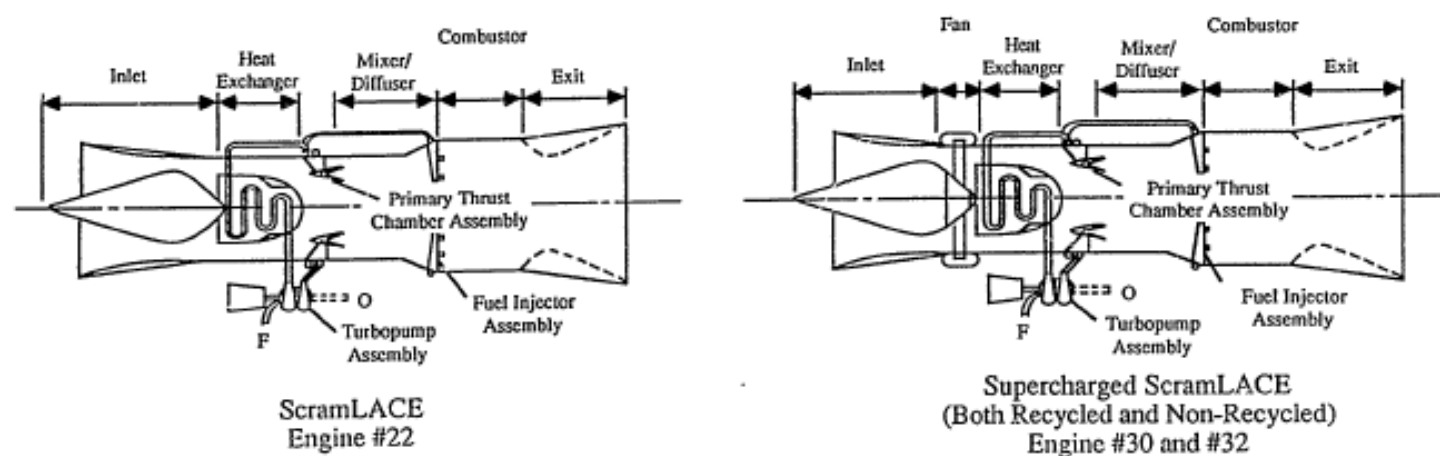

Supercharged ScramLACE (Both Recycled and Non-Recycled) Engine \#30 and \#32

Figure 3: RBCC Variations (6)

This research will focus on the AAR mode of the simplest case of an RBCC, the Ejector Scramjet.

\subsection{Air Augment Rocket Research}

Since the 1950s there have been a variety of theoretical and experimental investigations into the performance of AARs. The most comprehensive AAR experimental research was conducted in the mid 1960s as part of an RBCC development program. This research was summarized and expanded on in a study by Foster, Escher, and Robinson in 1988. 


\subsubsection{RBCC Concept Research}

Foster, Escher, and Robinson researched varying RBCC concepts for their effectiveness as a propulsion system in a single stage to orbit (SSTO) vehicle. (6) This research in 1988 was a further research on RBCC propulsion concepts put forth by Escher and Flornes in 1966 regarding RBCC concepts for advanced launch vehicles, specifically two stage vehicles. Foster, Escher, and Robinson summarized previous experimental AAR research carried out by the Martin Marieta Aerospace Group (MMAG) and the Marquardt Corporation in the 1950s and 60s. MMAG and the Marquardt Corporation examined five AAR concepts at low entrainment ratios for their influence on thrust and Isp: Rocket Ejector, Rocket Engine Nozzle Ejector (RENE), Simultaneous Mixing and Combustion (SMC), Diffusion and Afterburning (DAB), and AAR with thermal choke. All of the AAR concepts can be seen in Figure 4. Rocket ejector is the simplest form of AAR possible, a rocket enclosed in a mixing duct. MMAG tested a rocket ejector from static conditions up to Mach 1, resulting in an increase in static thrust of 14\%. RENE utilized a diverging mixing duct and secondary combustor with excess fuel injected into the secondary flow. RENE resulted in an increase in thrust and Isp of 55\%. SMC, DAB, and AAR with thermal choke all incorporate ram technologies which require flight speeds greater than Mach 1 to operate efficiently; therefore they were not examined in this research. 


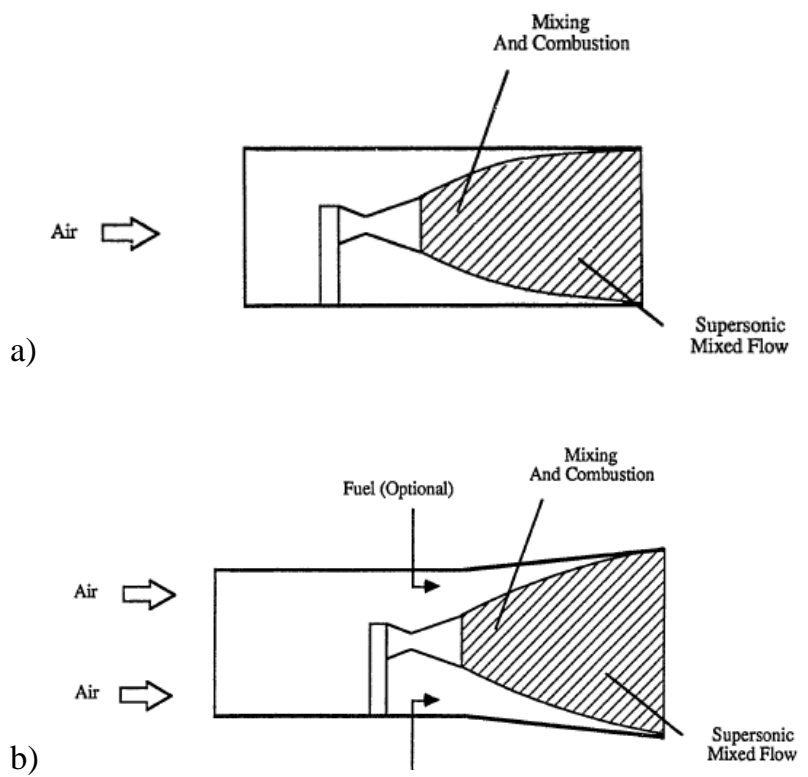

c)

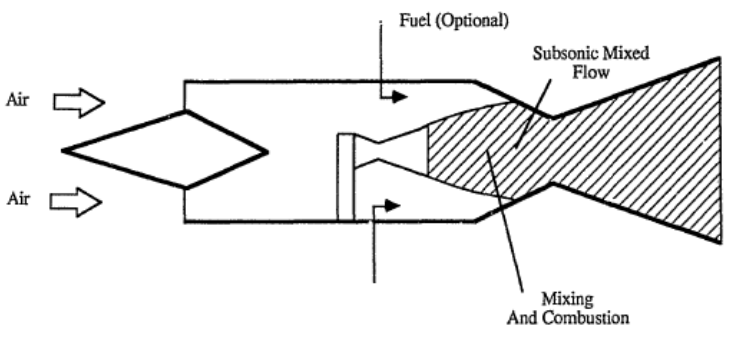

d)
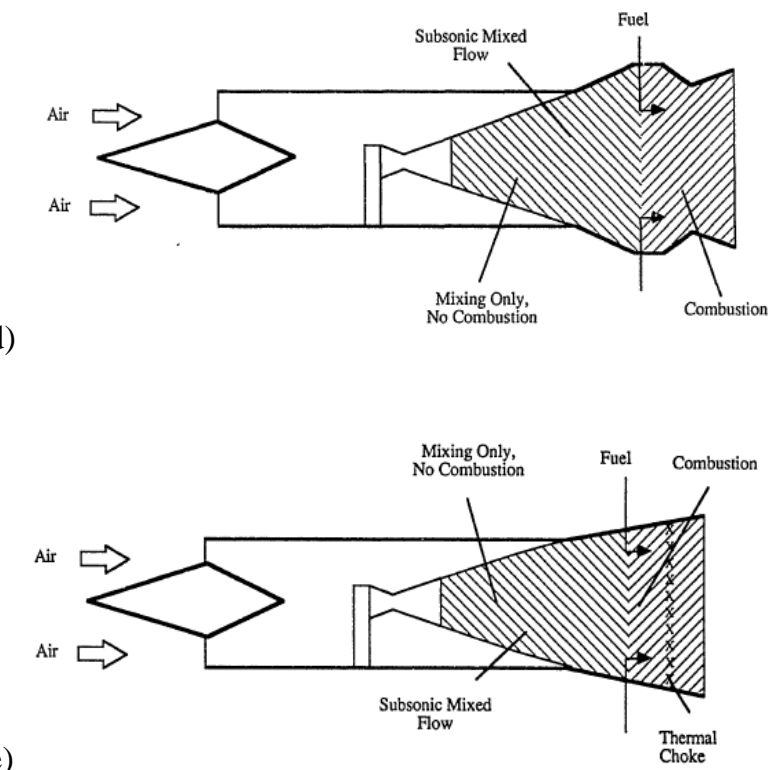

Figure 4: AAR Variations a) Rocket Ejector b) RENE c) SMC d) DAB e) AAR with thermal choke 


\section{Previous Cal Poly Experimental Research}

Multiple investigations into AAR flow phenomena have taken place at Cal Poly. AAR experimental research has taken place using variations of a single AAR test apparatus.

\subsubsection{Fabri Choking}

Trevor Foster developed an AAR experimental test apparatus capable of both hot fire and cold gas testing focusing on the expansion of the primary flow into the secondary flow field. (13) Fosters test apparatus operated as a 2-D planar flow with pressure and temperature measurement along the length of the mixing duct and primary chamber to examine flow field characteristics. Specifically the apparatus was meant to examine high pressure ratio cases where an under expanded primary flow would restrict secondary flow entrainment. When primary flow is under expanded the expansion of the primary flow downstream of the nozzle exit creates a virtual throat between the primary plume and the secondary flow, Figure 5.

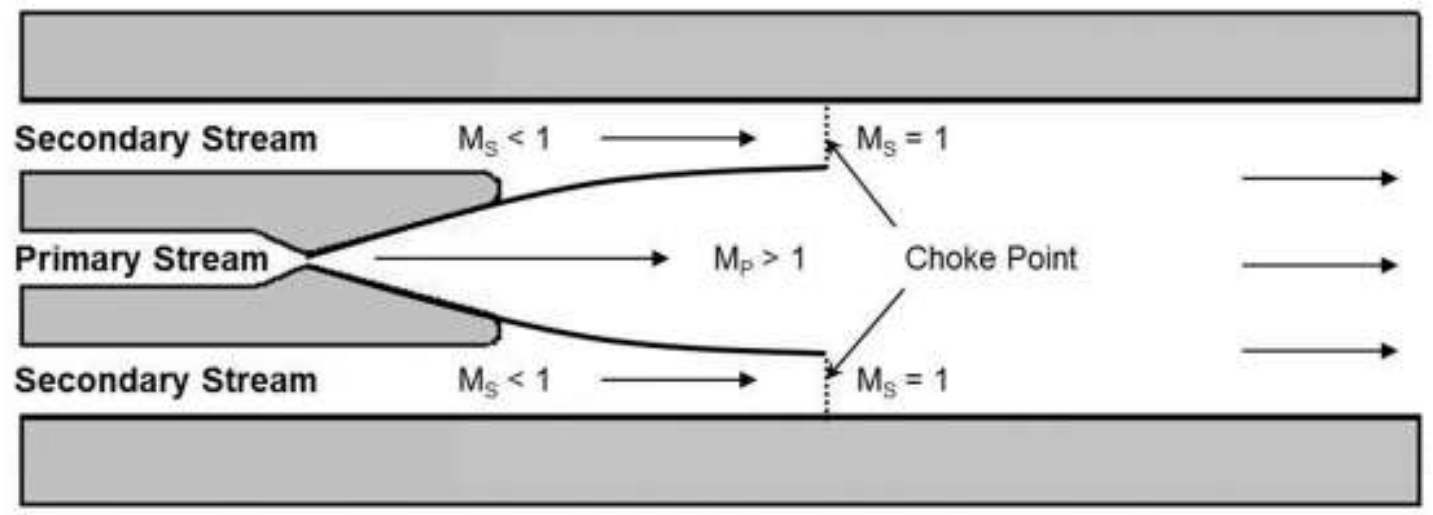

Figure 5: Fabri Choke (7)

At this point the secondary flow chokes and the secondary mass flow rate is limited by the pressure ratio between the primary and secondary flows. This is known as Fabri choke named after the French scientist who first published this theory. Conclusions drawn from Fosters testing were as follows. Cold flow was more effective than hot flow at secondary entrainment. Secondary flow restriction location is independent of primary flow temperature and primary pressure. Foster achieved a maximum primary to secondary pressure ratio of 74 with indications of the secondary flow nearing the Fabri limit but was unable to reduce secondary flow entrainment. 


\subsubsection{High Pressure Ratio AAR}

Ryan Gist further developed the 2-D apparatus constructed by Foster for higher pressure ratio cold flow testing. Gist used an upgraded Nitrogen supply system to produce a chamber pressure of up to 1690psi resulting in a maximum pressure ratio of 115 . Maximum primary mass flow rate was $2.81 \mathrm{bm} / \mathrm{s}$ with secondary flow based on the entrainment from ambient air. Fabri choking was achieved at pressure ratios greater than 80.(14)

\subsubsection{Fabri Blocking}

Josef Sanchez expanded on the high pressure ratio research of Gist and Foster. Using the same 2-D AAR test apparatus Sanchez added a constant volume plenum chamber which reduced the secondary stagnation pressure to as low as 3.3 psia. With a maximum primary pressure of 1758 psia the apparatus was now capable of examining extreme primary to secondary pressure ratios. Over the course of testing a maximum pressure ratio of 221 was achieved. At extreme pressure ratios a variation of the Fabri choke case is possible. If the primary pressure is high enough the primary flow field expands to the mixing duct wall blocking the secondary flow and reducing secondary entrainment to zero. This is called the Fabri block case. Fabri blocking was not achieved but the secondary flow was reduced to $5 \%$ of the primary flow. (15)

\subsubsection{Nozzle Lip Thickness Affects}

Trevor Montre varied the geometry and lip thickness of the primary nozzle utilizing the 2-D AAR test apparatus. Maximum pressure ratio achieved through testing was 160 . The primary nozzle was varied between a conical nozzle and bell nozzle with different nozzle lip thicknesses to examine the affects of lip thickness and geometry on secondary entrainment. Secondary flow Fabri choking was found to be inversely proportional to nozzle lip thickness indicating that Fabri choking is primarily an inviscid phenomenon. Entrainment was found to increase with increasing nozzle lip thickness due to turbulent recirculation at the nozzle lip. Bell nozzles decreased secondary entrainment compared to conical nozzles. Increases in flow efficiency from a bell nozzle were less than the increases in efficiency due to increased entrainment of a conical nozzle. (7) 


\section{Research Objective}

In order to further develop the AAR testing capabilities of Cal Poly and enhance the understanding of the full AAR system a new research focus was desired. Where the previous Cal Poly AAR experiments had examined the flow physics, Fabri phenomena, and mixing; it was noted that performance parameters such as thrust and Isp were not able to be measured on the current AAR experimental apparatus. Previous Cal Poly research concentrated on high pressure ratio transient operation of a primarily cold flow AAR. Therefore, development of an AAR test apparatus capable of steady state hot fire testing with measurement of thrust and Isp was desired. An axisymmetric flow case was chosen for its manufacturing simplicity and readily available rocket analysis tools. Based on a recommendation of Dr. Sadatake Tomioka, of JAXA, the forces on the mixing duct would be examined. The new test apparatus is to be capable of independent mixing duct axial force measurement, variable mixing duct geometries, adjustable primary mixture ratios, and primary flow rates. 


\section{Experiment Design}

While performance values for an AAR had not been developed at Cal Poly, rocket performance had seen recent examination in the form of senior projects. Specifically, there had been an examination of liquid bipropellant rockets developed from a rocket design guide by a researcher named Leroy Krzycki published in 1967. (16) Krzycki provided simple guidelines and design criteria for small reusable test stand rocket engines. These engines were not capable of flight and their thrust to weight ratio is very poor compared to typical rocket engines but they were able to be reused many times without exotic materials or complex coolant systems. The Krzycki liquid rocket engine design (SMORE) that was developed into the AAR test apparatus will be examined.

\subsection{Static Methanol/Oxygen Rocket Engine (SMORE)}

Developed by Chaz Morantz and Josef Sanchez the Static Methanol/Oxygen Rocket Engine (SMORE) was chosen to use as a starting point in designing an AAR test apparatus for a variety of reasons. The size of the rocket engine and the thrust were both reasonable for incorporation into the existing Cal Poly test facilities. It is a simple rugged design that provides an axisymmetric test case with the ability to take thrust measurements.

SMORE is a regulated pressure fed rocket with a liquid fuel (methanol) and gaseous oxidizer (oxygen), it has a theoretical chamber pressure of 300psi and thrust of 20lbf. (17) Copper is used for the combustion chamber and injector due to its high thermal conductivity which allows for the rapid extraction of heat to keep the components from melting under the high combustion temperatures. A stainless steel coolant jacket surrounds the combustion chamber, a constant supply of water pumped through the coolant jacket to maintain the combustion chamber wall temperatures at reasonable values. The original SMORE was controlled via manual ball valves in the fuel and oxidizer lines with extended control handles through a blast wall to an observation room. The main components of the SMORE thruster can be seen in Figure 6 . 


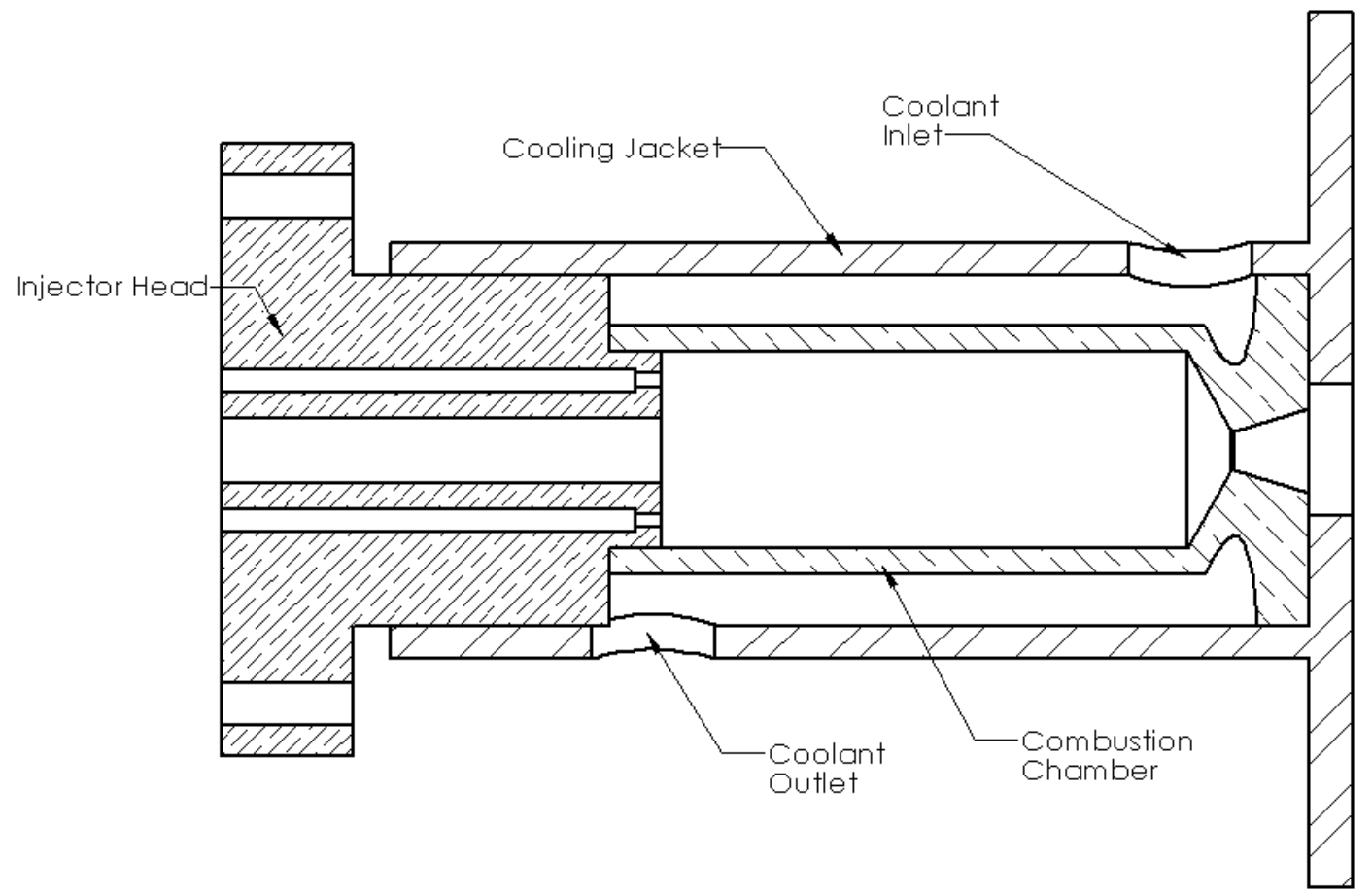

\section{Figure 6: SMORE Thruster Components}

Thrust measurement was recorded by mounting the rocket chamber on a pivot arm with a counterweight and taking readings of the change in force on a load cell by calculating the sum of the moments around the main pivot point seen in Figure 7. While the SMORE is a satisfactory rocket demonstrator, it lacked the measurement tools required to calculate important performance characteristics such as fuel and oxidizer flow rates. 


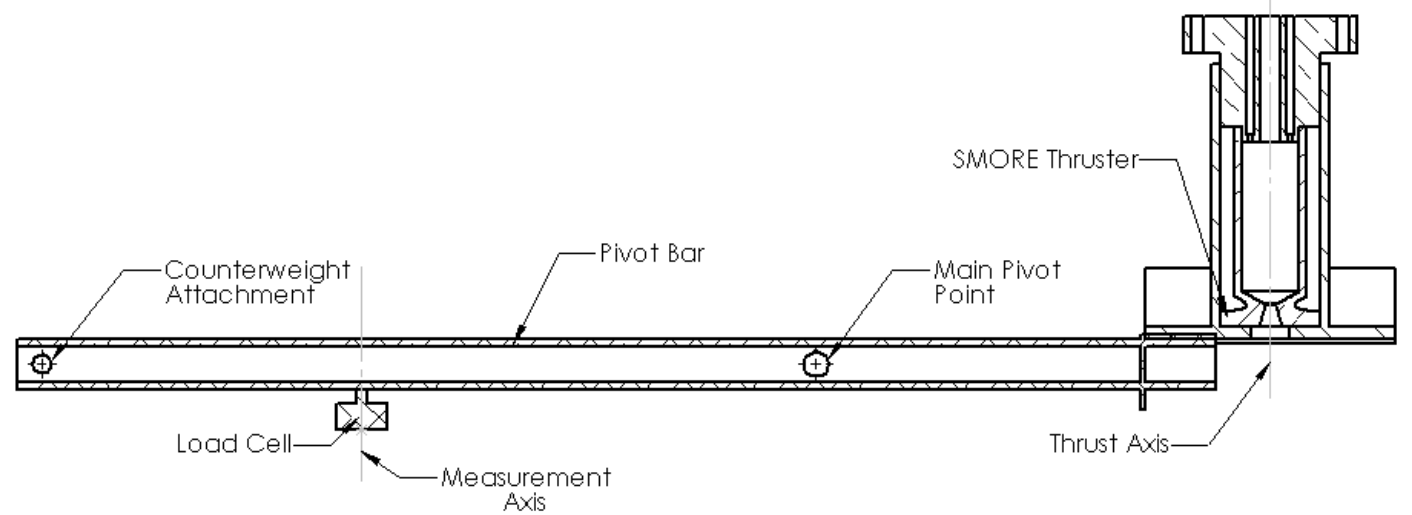

Figure 7: SMORE Counterweight Thrust Measurement

\subsection{SMORE Progression}

Continued improvements to the SMORE have been implemented through senior projects since Morantz and Sanchez completed the initial construction and testing. The first improvement was addition of remotely operated solenoid valves to control the flow of fuel and oxidizer without the use of manual ball valves. In conjunction with the solenoid valves the ignition system of the SMORE was changed. Morantz and Sanchez ignited the SMORE outside of the chamber using a magneto arc, then through intricate manipulation of the fuel and oxidizer flow using the manual ball valves allowed combustion to travel back into the chamber. This process required knowledge of how the system worked and practice operating the valve controls to achieve sustained combustion in the chamber. Even with experience successful combustion was a challenge. (17) To improve ignition Christian Soria taped the positive and negative leads of the magneto together such that there was a small air gap between the two leads with the overall diameter of the leads smaller than the SMORE chamber throat diameter. These leads were then inserted through the throat and into the chamber to act as a temporary spark plug to start ignition and then be blown out when combustion started. This method was suggested by Krzycki and can be seen in Figure 8 . The only deviation from the system shown in Figure 8 is that cotton was not used to maintain the spark gap. Using this ignition method Soria's tests showed more consistent ignition than Morantz and Sanchez. When there was successful ignition no additional manipulation was required to obtain chamber combustion. 


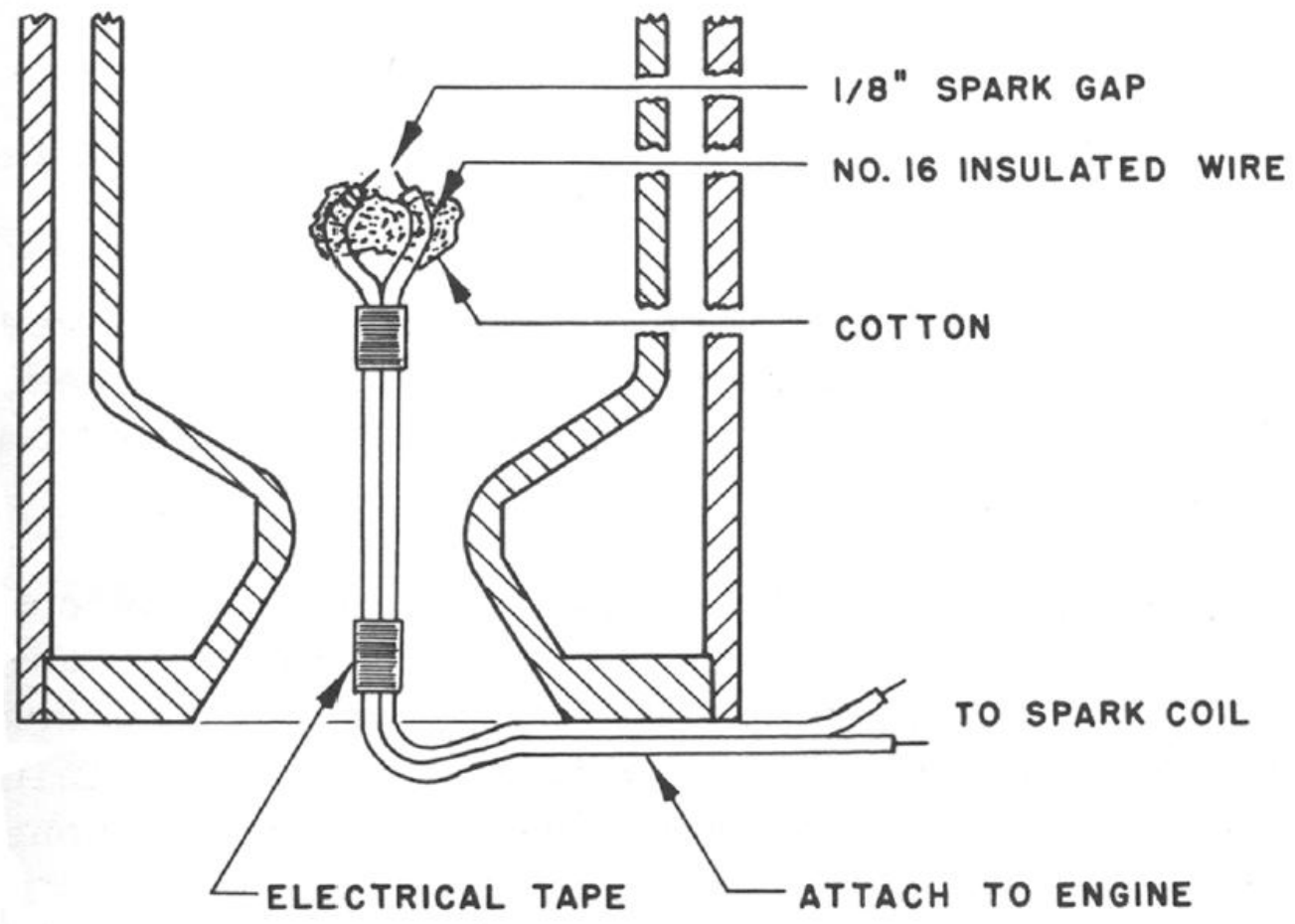

Figure 8: SMORE Igniter Diagram (16)

The SMORE was a small rocket demonstrator with simple thrust measurement; it was also unable to move from the test cell it was originally constructed in due to safety and control issues. Control issues arise from the continued inclusion of the manual ball valves. While Soria added solenoid valves the manual ball valves were still in the propellant feed lines. Manual ball valves required holes through a protective blast wall in order to extend the handles to a location where the operators could safely handle them. In order to use the SMORE as a bipropellant demonstrator in the Cal Poly propulsion lab an update to the test frame and fuel system was required. A suitable frame was constructed to mount the SMORE and its components in a single mobile unit. The fuel system was updated to provide a drain and purge capability using a certified double ended high pressure tank, maintaining the original blow down pressure fed system of the SMORE. The inner frame of the new SMORE stand was suspended from a pivot bar and constrained by guide rails to allow for thrust measurement. Counterweights were used to negate the weight of the SMORE thruster and frame in thrust measurement. (18) The final SMORE test frame and apparatus is shown in Figure 9. 


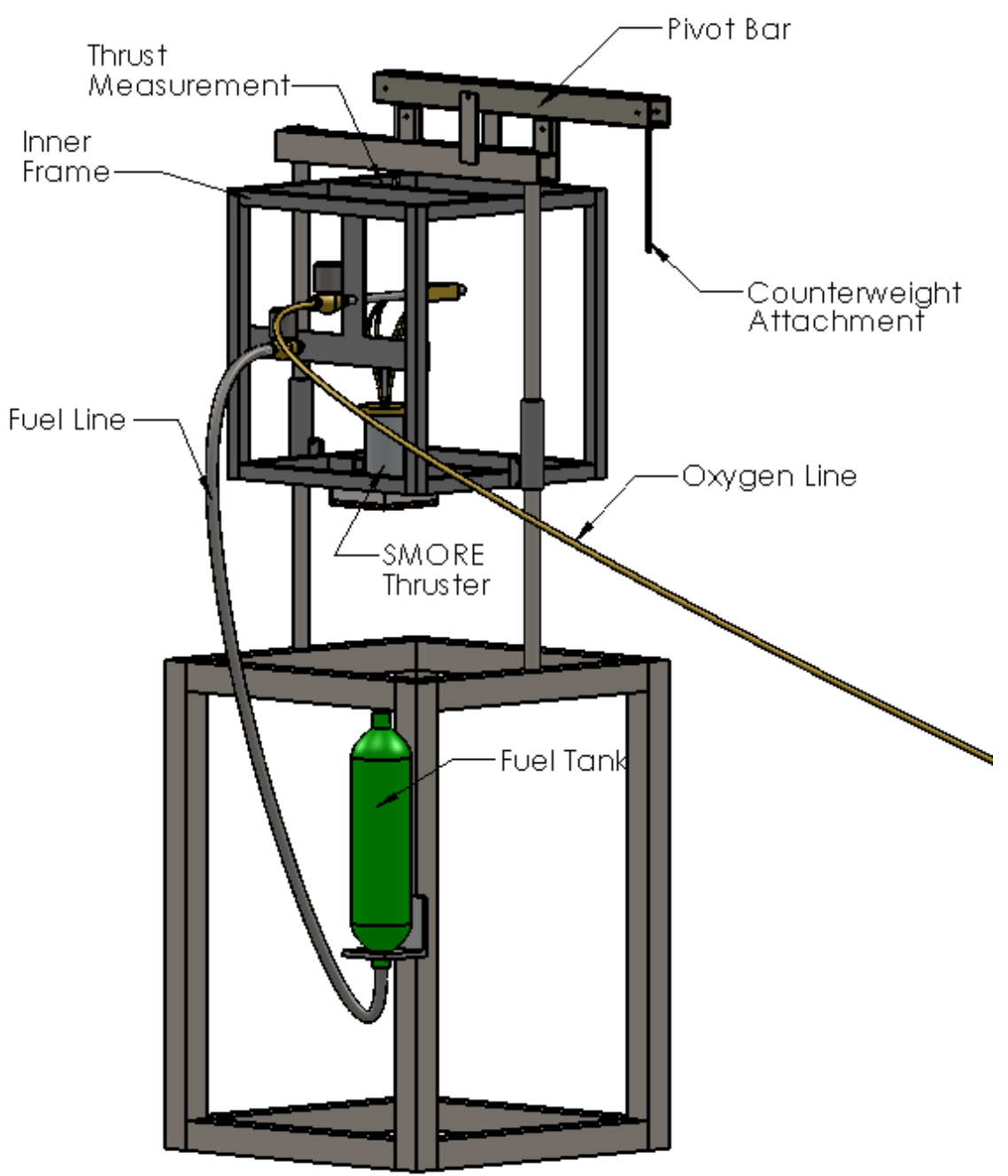

Figure 9: Final SMORE test frame 


\section{Final Design}

Even with improvements to the SMORE system AAR performance parameters were still unattainable due to instrumentation and physical limitations. Therefore a redesign of the SMORE had to be undertaken to implement instrumentation improvements and address the physical constraints that made AAR integration impossible. The test hardware must be able to determine the thrust and Isp of an AAR and measure forces on the mixing duct and total assembly separately. Initially the SMORE was examined for the possibility of mixing duct integration as shown in Figure 10.

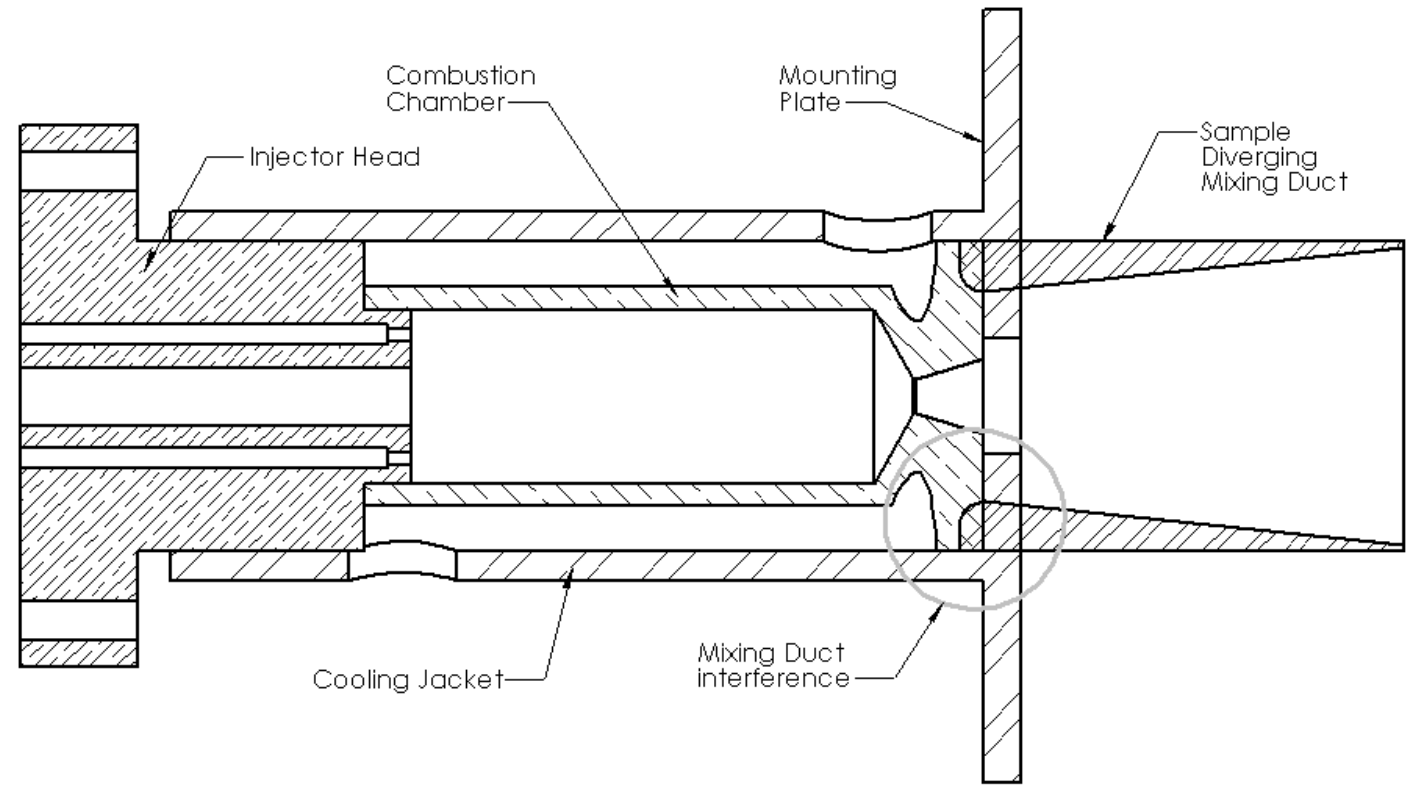

Figure 10: Attempt at SMORE mixing duct integration

The mixing duct could not be placed at the rocket nozzle exit without completely blocking the secondary flow. A change in the primary components of the SMORE had to be examined. In Figure 6 and Figure 10 the internal components of the original SMORE thruster can be seen in a cutaway view. The combustion chamber and nozzle have a wide base to allow for the use of a simple circular pipe as a coolant jacket. This simplified manufacturing and assembly. Mounting of the original SMORE was achieved through a square plate at the base of the thruster assembly seen in Figure 10. This plate was inhibiting the integration of a mixing duct around the rocket exhaust. Along with the physical issues was the lack of accurate mass flow 
readings of the fuel and oxidizer, which would be required to measure the specific impulse of the different rocket configurations. The only piece of thruster hardware to not require a redesign was the injector head. Therefore, all new components had to be designed to be compatible with the injector head. Due to the large differences between the SMORE and the new design; a new designation is given to the apparatus Static Condition Air Augmented Rocket Demonstrator (SCAARD). Henceforth in this report when discussing the current apparatus it will be labeled the SCAARD.

\subsection{Instrumentation}

Instrument improvement is essential to acquiring accurate mass flow rate measurement and thrust for calculation of Isp. Steps were taken in the design and construction of the SCAARD to make mass flow rate readings and thrust measurement.

\subsubsection{Oxygen}

Multiple steps were taken in the SCAARD to address the instrumentation deficiencies. In the SMORE oxygen was tied directly into the oxygen distribution manifold which split into four separate injection lines attached to the injector head. Oxygen orifice holes into the combustion chamber were sized based on Krzycki's guide for small rocket engines to produce the correct injection speed. (17) (16) Throughout previous testing there was very little indication of combustion sensitivity to oxygen injection velocity due to regulated pressure. (17) Therefore the orifice injection was deemed satisfactory and a method of measuring the mass flow rate of gaseous oxygen had to be devised. Multiple options were available at various levels of investment. Due to the compressible nature of gaseous oxygen and the unknown pressure conditions in the combustion chamber, the simplest most inexpensive method of mass flow measurement was found to be a sonic nozzle. Sonic nozzles, also known as critical flow nozzles, (19) provide mass flow rate control and measurement due to the choking of the fluid at the sonic nozzle throat. This means that the mass flow rate is determined by inlet pressure and temperature and is independent of downstream conditions. Based on the design oxygen mass flow rate calculations of the SMORE, a sonic nozzle with a throat diameter of $0.088 "$ from Flow Systems Inc. was chosen due to its ability to span the mass flow rate requirements over the desired pressure ranges. In order for the measurements to be accurate the flow of oxygen before the sonic nozzle must be brought to stagnation pressures and temperatures. Figure 11 shows 
the physical apparatus that connects the sonic nozzle into the oxygen feed line as well as the location of pressure and temperature measurement. Upstream of the sonic nozzle the diameter is 0.87 " which is nearly 10 times greater than the diameter of the sonic nozzle throat. According to Flow Systems Inc the upstream diameter must be greater than or equal to four times the throat diameter to ensure stagnation conditions before the sonic nozzle. (19)

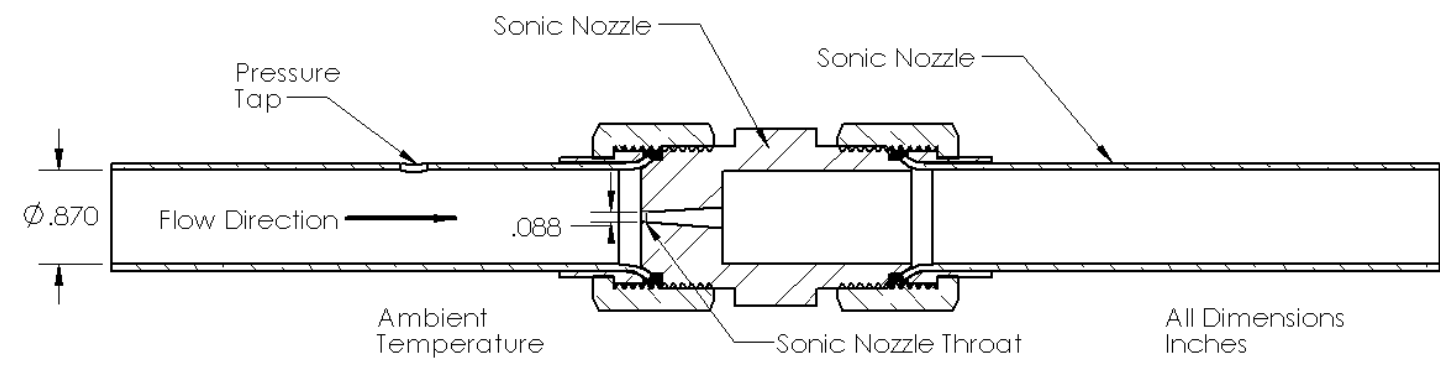

Figure 11: Sonic Nozzle Assembly

\subsubsection{Fuel}

Using the original injector manifold from the SMORE meant that the original fuel injection system was to be reused. SMORE used a capacity 12 spray nozzle with an orifice diameter of 0.076"; (17) the manufacturer provided a stated flow capacity of 10.4 to 60 gallons per hour of water depending on the pressure drop across the nozzle. Upstream pressure can be directly measured, while chamber pressure will be discussed in a later section. Fuel line pressure measurement is shown in Figure 12 relative to the SMORE thruster assembly. This location is assumed to be stagnation pressure due to the line diameter being greater than four times the diameter of the throat of the nozzle. 


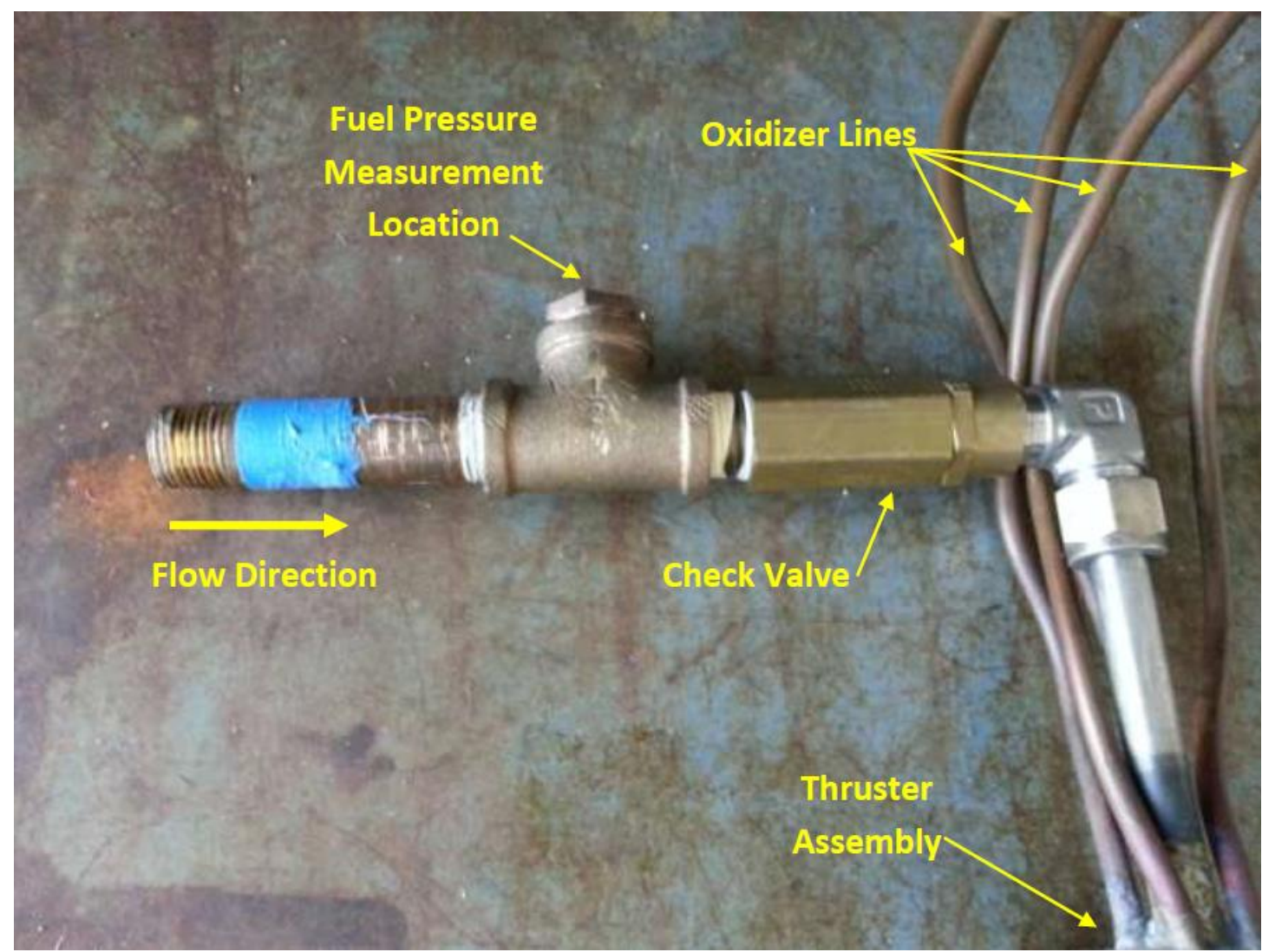

Figure 12: Fuel Line

\subsubsection{Thrust Forces}

SMORE's use of a pivot arm in thrust measurement (Figure 7) made it possible to neglect the weight of the thruster assembly and directly measure the thrust of the apparatus. With the development of a mobile test stand in the most recent version of the SMORE the counterweight pivot apparatus was modified. Phase I testing of the SCAARD used the same test stand as the SMORE (Figure 9) with a suspended inner frame containing the thruster assembly and control valves. This suspended frame was attached to a pivot bar with counterweights which brought the frame into contact with the upper cross bar. A load cell was placed between the cross bar and the frame on the same axis as the thrust chamber. This load cell measured the total thrust of the rocket at a 1:1 ratio. Phase II testing of the SCAARD transitioned to a different total thrust measurement. Suspending the inner frame from a pivot bar was replaced with a single high capacity 
load cell. The inner frame was modified such that everything was centered and a single LC101-100 S-Beam load cell with a 100lbf capacity from Omega Engineering was used to suspend the entire inner frame and its components. (20) Thrust was calculated through the change in weight recorded by the load cell due to the inner frame and its components weight being much greater than the total thrust force of the system.

Air Augmented Rockets operate with the primary flow contained in a mixing duct. One of the main aspects of this research is to separate the forces acting on the mixing duct from the total force of the AAR. To do that a second load cell was used to suspend the mixing duct from the inner frame. An Omega LCFD-25 tension/compression load cell with a 25lbf load capacity was used to measure the axial forces on the mixing duct.

All four pieces of instrumentation are routed through a shielded splitter box that splits the excitation voltage of the instruments from the signal leads. SCAARD's splitter box with the associated wire labels and locations is shown in Table 1. 

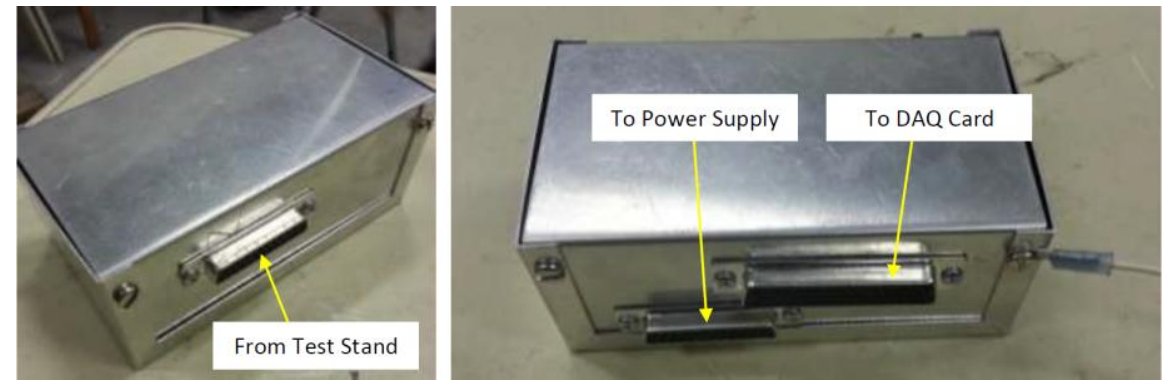

Table 1: Splitter Box and Data Pin Labels

\begin{tabular}{|c|c|c|c|c|c|c|}
\hline \multicolumn{4}{|c|}{ From Test Stand } & \multicolumn{3}{|c|}{ To Power Supply } \\
\hline Pin \# & Instrument & Function & Wire Color & Pin \# & Instrument & $\begin{array}{l}\text { Power Supply } \\
\text { End Location }\end{array}$ \\
\hline 1 & Mx Load Cell & Ex+ & Red & 1 & Mx Load Cell & $10 \mathrm{~V}$ \\
\hline 2 & Mx Load Cell & Ex- & Black & 3 & Mx Load Cell & Ground \\
\hline 3 & Mx Load Cell & $\mathrm{VO}+$ & White & 4 & Fuel Pressure & $10 \mathrm{~V}$ \\
\hline 4 & Mx Load Cell & VO - & Green & 5 & Fuel Pressure & Ground \\
\hline 5 & Fuel Pressure & Ex+ & Red & 6 & Oxygen Pressure & $10 \mathrm{~V}$ \\
\hline 6 & Fuel Pressure & Ex- & Black & 7 & Oxygen Pressure & Ground \\
\hline 7 & Fuel Pressure & $\mathrm{VO}+$ & White & 8 & Total Load Cell & $10 \mathrm{~V}$ \\
\hline 8 & Fuel Pressure & VO - & Green & 9 & Total Load Cell & Ground \\
\hline 9 & Oxygen Pressure & Ex+ & Red & & & \\
\hline 10 & Oxygen Pressure & Ex- & Black & & & \\
\hline 11 & Oxygen Pressure & $\mathrm{VO}+$ & Green & & & \\
\hline 12 & Oxygen Pressure & VO - & White & & & \\
\hline 13 & Total Load Cell & Ex + & Red & & & \\
\hline 14 & Total Load Cell & Ex- & Black & & & \\
\hline 15 & Total Load Cell & $\mathrm{VO}+$ & Green & & & \\
\hline 16 & Total Load Cell & VO - & White & & & \\
\hline
\end{tabular}

\begin{tabular}{|c|c|c|}
\hline \multicolumn{3}{|c|}{ To DAQ Card } \\
\hline $\begin{array}{c}\text { Pin } \\
\#\end{array}$ & Instrument & Function \\
\hline 1 & Mx Load Cell & VO + \\
\hline 2 & Mx Load Cell & VO - \\
\hline 3 & Fuel Pressure & VO + \\
\hline 4 & Fuel Pressure & VO - \\
\hline 5 & Oxygen Pressure & VO + \\
\hline 6 & Oxygen Pressure & VO - \\
\hline 7 & Total Load Cell & VO + \\
\hline 8 & Total Load Cell & VO - \\
\hline
\end{tabular}

\begin{tabular}{|c|c|}
\hline \multicolumn{2}{|c|}{ Legend } \\
\hline Symbol & Description \\
\hline$E x+$ & Voltage Excitation + \\
\hline$E x-$ & Voltage Excitation Ground \\
\hline VO + & Voltage Output + \\
\hline VO - & Voltage Output Ground \\
\hline$M x$ & Mixing Duct \\
\hline
\end{tabular}


All signals are routed into the control room and fed into a National Instruments SCB-68 DAQ card attached to the provided desktop computer. LabView is used to process and record the data. A LabView Graphical User Interface was developed to provide simple data acquisition with the appropriate inputs required to analyze the data. LabView exports the recorded data to a Microsoft Excel file for further analysis. Table 2 shows the LabView inputs and recorded data.

Table 2: LabView Data

\begin{tabular}{|c|}
\hline User Inputs \\
\hline Regulated Fuel Pressure (psig) \\
\hline $\begin{array}{c}\text { Regulated Oxygen Pressure } \\
(\mathrm{psig})\end{array}$ \\
\hline Ambient Temperature $\left({ }^{\circ} \mathrm{F}\right)$ \\
\hline Barometric Pressure (psi) \\
\hline
\end{tabular}

\begin{tabular}{|c|c|c|}
\hline \multicolumn{3}{|c|}{ Recorded Data } \\
\hline Label & $\begin{array}{c}\text { Measurement } \\
\text { Device }\end{array}$ & $\begin{array}{c}\text { Model } \\
\text { Number }\end{array}$ \\
\hline $\begin{array}{c}\text { Mixing Duct Thrust } \\
\text { (lbf) }\end{array}$ & Load Cell & LCFD-25 \\
\hline $\begin{array}{c}\text { Fuel Pressure (psig) } \\
\begin{array}{c}\text { Oxygen Pressure } \\
\text { (psig) }\end{array}\end{array}$ & $\begin{array}{c}\text { Pressure } \\
\text { Pransducer }\end{array}$ & PX302-3KGV \\
\hline Total Thrust (Ibf) & S-Beam Load Cell & LC101-100 \\
\hline
\end{tabular}

\subsection{Chamber}

As previously stated the SMORE combustion chamber was constructed from a single piece of copper bar stock. In the SCAARD an updated chamber was designed and constructed to reduce the base area of the combustion chamber as much as possible to allow for the integration of mixing ducts. Copper was again the chosen material for the chamber because of its relatively inexpensive procurement cost, machinability, and most importantly its very high thermal conductivity. Copper has also been proven to show almost no signs of degradation due to heat when used in conjunction with a constant supply of coolant. (17) (16) Due to the reuse of the SMORE injector manifold the inner diameter of the SCAARD chamber was fixed to be the same as that of the SMORE, corresponding to a drill bit size of $11 / 8$ " (1.125"). One of the purposes of the original SMORE was to demonstrate stable sustained combustion due to the longer characteristic chamber length of the SMORE compared to previous Cal Poly bipropellant rocket research. (17) Characteristic chamber length is defined in equation 5-1 where $V_{C}$ is the chamber volume and $A_{t}$ is the throat area. This can be used in lieu of calculating the residence time of propellants in the combustion chamber. (16) 


$$
\operatorname{ch} L=\frac{V_{C}}{A_{t}}
$$

Longer characteristic chamber length was proven to be beneficial in aiding combustion stability and as such a long characteristic chamber length of 80in is retained in the design of the SCAARD chamber. However, convergence angle, nozzle half angle, and nozzle area ratio of the SMORE are not retained in the SCAARD. These decisions were due to manufacturing constraints. Convergence angle was determined by the tip angle of the bit used to bore out the chamber resulting in a $59^{\circ}$ convergence half angle. Convergence angle has very little affect on pressure loss or flow separation due to the low speeds in the combustion chamber and favorable pressure gradients. In order to provide the smoothest surface finish for the SCAARD the throat diameter was selected to be as close to the SMORE as possible with the available standard drill bit sizes. Nozzle half angle was selected to be $15^{\circ}$ because this is a very common angle for rocket nozzle divergence and it provides high pressure recovery with a very minimal loss of thrust radially. (3) A $15^{\circ}$ nozzle is $98.3 \%$ efficient in recapturing momentum thrust and sits in the middle of the optimum conical nozzle shape and length ranges prescribed by Sutton. (3) A $15^{\circ}$ Divergence also makes it possible to expand the flow quickly without a long nozzle. Nozzle exit area was selected to be 3.6 times the throat area which provides full expansion of the combustion products to atmospheric pressure conditions. (16) Figure 13 shows the original SMORE combustion chamber and the SCAARD chamber with associated dimensions. 

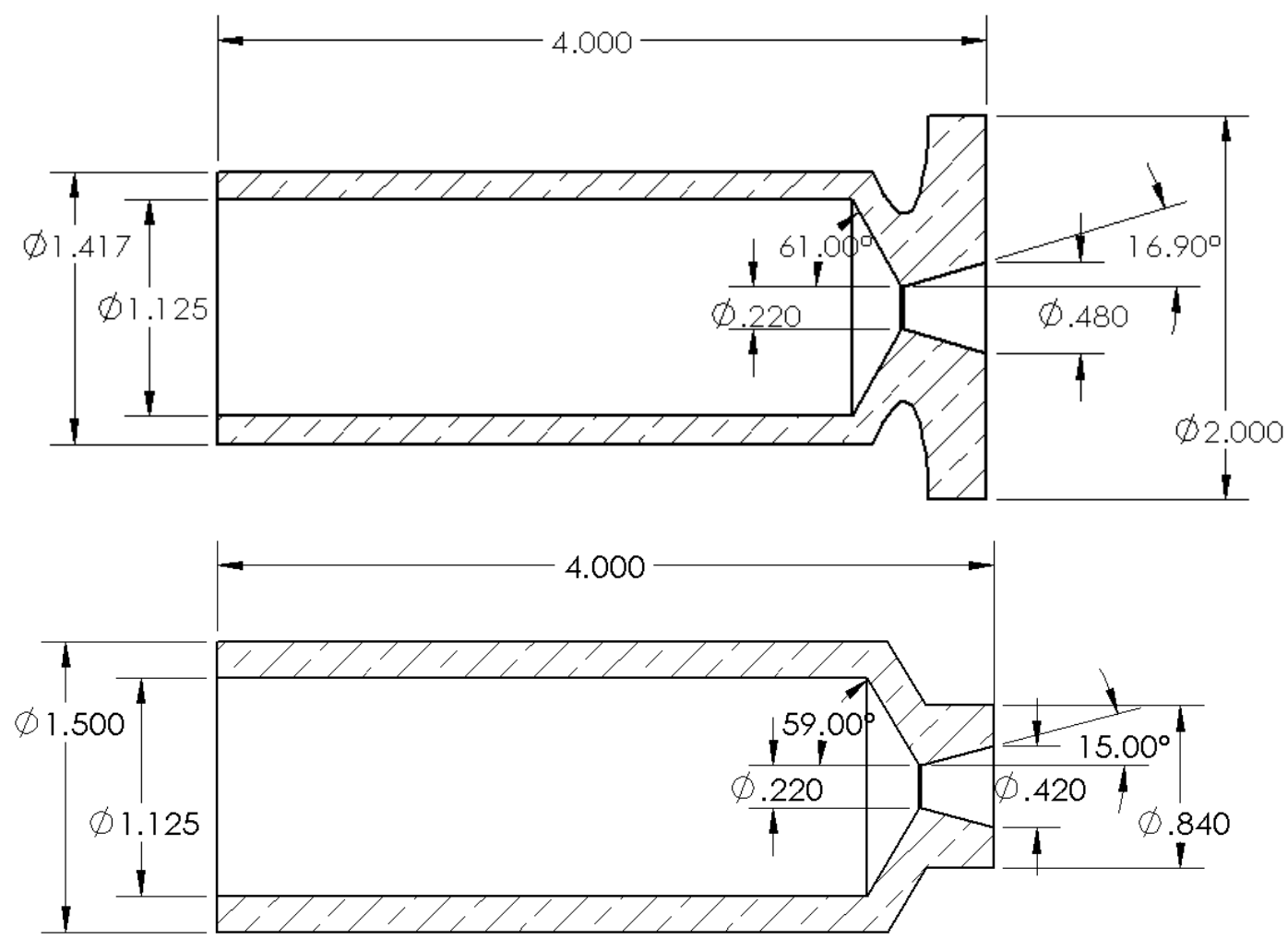

All Dimensions Inches

Figure 13: Top, SMORE Chamber; Bottom, SCAARD Chamber

\subsection{Cooling Jacket}

Any combustion under pressure produces extreme temperatures. Internal combustion engines such as those in a car produce temperatures greater than $4900^{\circ} \mathrm{F}$ every time there is combustion in a cylinder. (21) Compare this temperature to the $2800^{\circ} \mathrm{F}$ melting point of the steel that makes up the cylinder heads and walls and the problem becomes apparent. (22) Clearly every internal combustion engine doesn't break down, and the cylinders don't melt. There are two reasons for this, combustion duration and coolant. Combustion duration is a major factor when determining the operating temperatures of a system, for example in a standard four stroke internal combustion engine at 400RPM, when combustion duration would be longest, combustion only lasts for about 0.02 seconds. (21) This is specific to a single engine but the order of magnitude of combustion is generally the same, in four stroke engines combustion occurs every two revolutions per cylinder or every 0.3 seconds at 400RPM. Because the combustion duration is so 
small compared to the total cycle time, the heat capacity of the cylinder head and engine block is able to absorb that heat without melting due to their high thermal mass and coolant. Coolant plays another large role in maintaining sustainable engine operating temperatures. While the thermal mass of an engine block can take numerous cycles of a piston firing, it cannot withstand continued operations without some way to keep the heat from building up in the engine block. Coolant in the form of water or some other liquid is pumped through the engine block and the fed through a heat exchanger (radiator) to dissipate the waste heat into ambient air. This coolant maintains the engine at optimal operating temperatures. Rockets operate on a continuous combustion basis, meaning there is one sustained explosion going on in the chamber. This eliminates one of the reasons that internal combustion engines are able to remain cool. Combustion duration is no longer an order of magnitude less than the cycle length. Material selection and coolant become much more important when dealing with rocket combustion and thermal management. Table 3 and

Table 4 show the melting points of a variety of different metals along with their thermal conductivity, as well as the combustion temperatures of a variety of different products. (22) (16)

Table 3: Metal Properties

\begin{tabular}{|c|c|c|}
\hline Material & $\begin{array}{c}\text { Metal Properties } \\
\text { Temperature } \\
\left({ }^{\circ} \mathbf{F}\right)\end{array}$ & $\begin{array}{c}\text { Thermal } \\
\text { Conductivity } \\
\left(\text { Btu/(hr }{ }^{\circ} \mathbf{F ~ f t}\right)\end{array}$ \\
\hline $\begin{array}{c}\text { Aluminum } \\
2024\end{array}$ & $935-1180$ & 70 \\
\hline Copper & 1983 & 223 \\
\hline Steel & $2600-2800$ & 21 \\
\hline Titanium & 3040 & 11 \\
\hline Tungsten & 6150 & 94 \\
\hline
\end{tabular}


Table 4: Combustion Properties (16)

\begin{tabular}{|c|c|c|c|}
\hline \multicolumn{4}{|c|}{ Combustion Properties } \\
\hline $\begin{array}{c}\text { Propellant } \\
\text { Fuel/Oxidizer }\end{array}$ & $\begin{array}{c}\text { Chamber Pressure } \\
\text { (psi) }\end{array}$ & $\begin{array}{c}\text { Flame Temperature } \\
\text { (F) }\end{array}$ & Mixture Ratio \\
\hline Gasoline/GOX & 300 & 5862 & 2.5 \\
\hline Hydrogen/LOX & 500 & 4500 & 3.5 \\
\hline Methanol/GOX & 300 & 5220 & 1.2 \\
\hline Jet Fuel/GOX & 500 & 5880 & 2.2 \\
\hline
\end{tabular}

Clearly the melting point of each of these materials except Tungsten is lower than the flame temperature of the combustion reactants. Tungsten is not used in this research due to its very high cost and poor machinability. Rockets can use a variety of different thermal management techniques to keep the combustion chamber and nozzle from reaching the melting point of the chosen material. Ablative cooling uses a thick wall that absorbs the heat of combustion while it slowly burns away keeping the stress bearing outside walls from heating up. (3) This is used extensively in solid rocket motors. Ablative cooling is very effective and simple since it does not have any working fluid that must be pumped around the chamber. However, the ablative material must be replaced frequently. Therefore, it is not used in the SCAARD or the SMORE. Regenerative cooling pumps a working fluid, usually the cryogenic fuel, around the chamber, throat, and nozzle of the rocket before injecting it into the chamber. This keeps the walls at a low temperature and preheats the fuel before combustion. Regenerative cooling is very efficient, compact, and used on large bi-propellant rocket motors, but it is also complex and very difficult to manufacture. (3) Since the SMORE and the SCAARD do not require a flight worthy coolant system and manufacturing complexity and operation is a concern, regenerative cooling is not used. Another method of cooling is the use of a cooling jacket where the coolant fluid is not recycled or used in combustion. This method is very simple and effective but it is heavy and does not work for a system that is designed to fly. Since both the SMORE and SCAARD are not flight rockets the simplicity and effectiveness of this design made it an obvious choice for the SMORE and SCAARD. 
A cooling jacket like the one suggested by Krzycki is designed to surround the combustion chamber with an inlet at the throat where a cold fluid is pumped in and an outlet at the top for the fluid exit. In the original SMORE a stainless steel pipe with the same inner diameter as the outside of the injector head was used as the cooling jacket. A plate was welded to the base of the cooling jacket pipe and was used as a mounting plate for the thruster assembly to the thrust measurement system. As previously discussed this plate did not allow for the incorporation of a mixing duct around the primary rocket exhaust as required. Coolant flow was supplied by standard water pressure through a garden hose at maximum flow. This coolant entered at the lower portion of the cooling jacket near the chamber throat and exited at the top near the injector head. Over the course of the extensive SMORE testing, normal tap water at ambient temperature proved more than adequate at transferring heat from the combustion chamber. No sign of thermal degradation in the chamber was shown after more than 100 successful firings. (17) (23) (18) In the SCAARD design of the cooling jacket, a much lower profile around the nozzle exit was required. With a lower profile chamber the cooling jacket could be made to taper down in the same way as the chamber (Figure 13) to make it possible to add a mixing duct around the exhaust. Mounting and assembly of the thruster components of the SCAARD was restricted to the same method used in the SMORE. In order to hold the SMORE components together threaded rods were placed in holes along the perimeter of the injector head and through the mounting plate of the cooling jacket. These were then tightened together using washers and nuts. This configuration supplied the clamping pressure to seal the chamber to the injector head as well as seal the coolant area for water flow. Moving the mounting plate to the top of the cooling jacket maintained both the clamping and mounting features present in the original SMORE. Figure 14 shows the final design of the SCAARD cooling jacket. The tapered portion of the jacket was machined out of a solid bar of stainless steel on a lathe. A groove was machined into the face of the tapered portion to coincide with a recess on a stainless steel pipe that was used for the tubular portion of the cooling jacket. These two pieces were then welded together to form a solid unit. Coolant lines were extended from the top of the cooling jacket down to the base via copper pipe to make the coolant lines lower profile and symmetrical. This can also be seen in Figure 14. Two coolant lines directed at opposite sides of the chamber throat improved the coolant distribution around the area of highest heat flux, the chamber throat. 


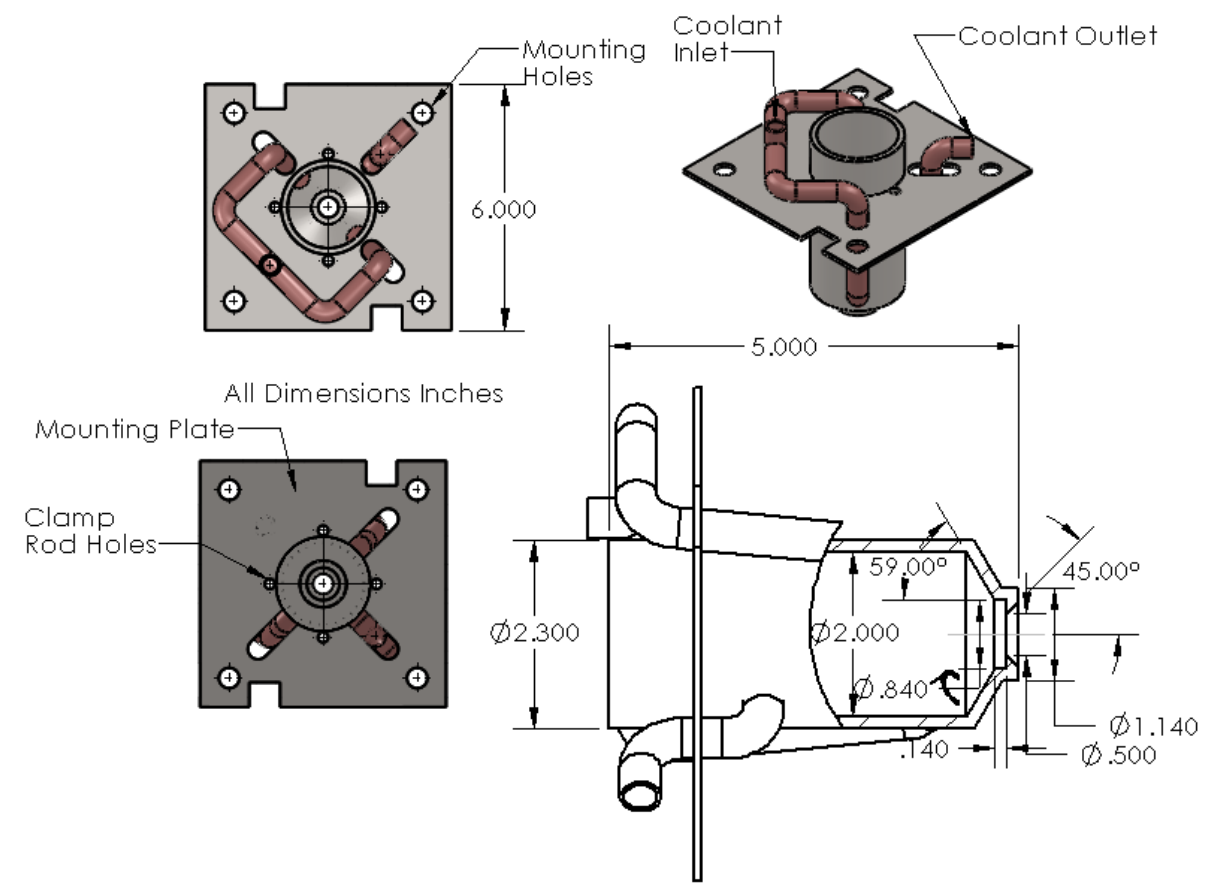

Figure 14: Cooling Jacket

After construction was completed on the SCAARD thruster components, the thruster was assembled and hydrostatically tested for both water coolant and chamber pressure leaks. Coolant flow rate was found to be greater than $1 \mathrm{lb} / \mathrm{sec}$, which was more than sufficient to maintain the chamber operating temperatures within a safe range.

\subsection{Ignition and Control System}

SCAARD's ignition system remains the same as SMORE's with the use of an MSD coil as the spark generator. MSD coils maintain a constant arc from the positive lead to ground and were very effective at establishing combustion in the final version of the SMORE. (18) To reduce the number of power supply's in the control room the SCAARD ignition is controlled remotely in a different manner than the SMORE. At the time of SCAARD design and construction the test building maintained power supplies of $5 \mathrm{~V}, 10 \mathrm{~V}$, and $12 \mathrm{~V}$ in the test area. The $12 \mathrm{~V}$ power supply was used for the MSD coil. In order to maintain control of the ignition timing a relay was placed in series between the power supply and the MSD coil. This relay was controlled by $120 \mathrm{~V}$ AC power and when activated would complete the MSD coil circuit producing the 
ignition arc. AC power was provided through the same control system used for the fuel and oxygen control. SCAARD's main control board remains in the control room with power coming from a standard 120V AC power outlet. Both the fuel and oxidizer solenoid valves are activated when $120 \mathrm{~V}$ AC is applied, the same as the ignition relay. Figure 15 shows the control system and wiring. Fuel and oxidizer solenoids can be selected before activation and can be activated individually or simultaneously. Ignition switching is controlled via a push button switch that is spring loaded. It will only remain activated as long as it is depressed. This prevents the igniter from remaining active beyond ignition.

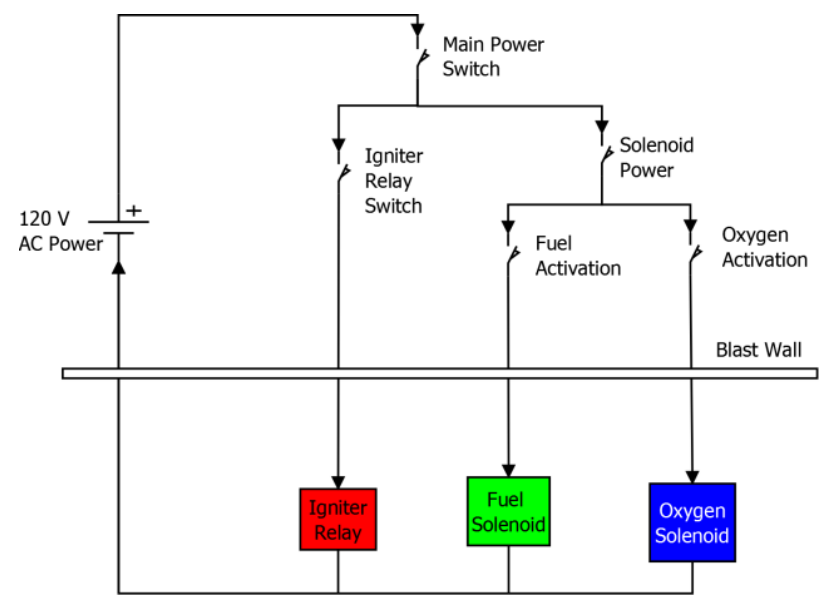

\section{Figure 15: Control System Wiring Diagram}

\subsection{Mixing Ducts}

All previous modifications for the SCAARD were implemented in order to incorporate a mixing duct around the exhaust and create an AAR. In order to achieve the goal of measuring total system thrust and mixing duct forces separately, the mixing duct design had to be somewhat unique. Mixing ducts were designed based on the area ratios used in a CFD study by NASA of an RBCC operating in rocket only mode. (11) Results and conclusions summarized in the NASA paper could not be applied to the SCAARD. This is because the SCAARD operates in the AAR mode at static conditions and the NASA study operates in high speed high altitude rocket only mode with little or no secondary flow. Even though the results could not be carried over to the SMORE, the geometries and area ratios of the mixing ducts provided a reference of what reasonable mixing duct geometry should be. Table 5 and Figure 16 give an illustration of the area ratios provided by the NASA study. The highlighted area ratios were chosen to be used in this initial 
demonstration due to the chamber pressure and rocket area ratio similarities. This mixing duct study is a simple comparison of a straight mixing duct, diverging mixing duct, and no mixing duct.

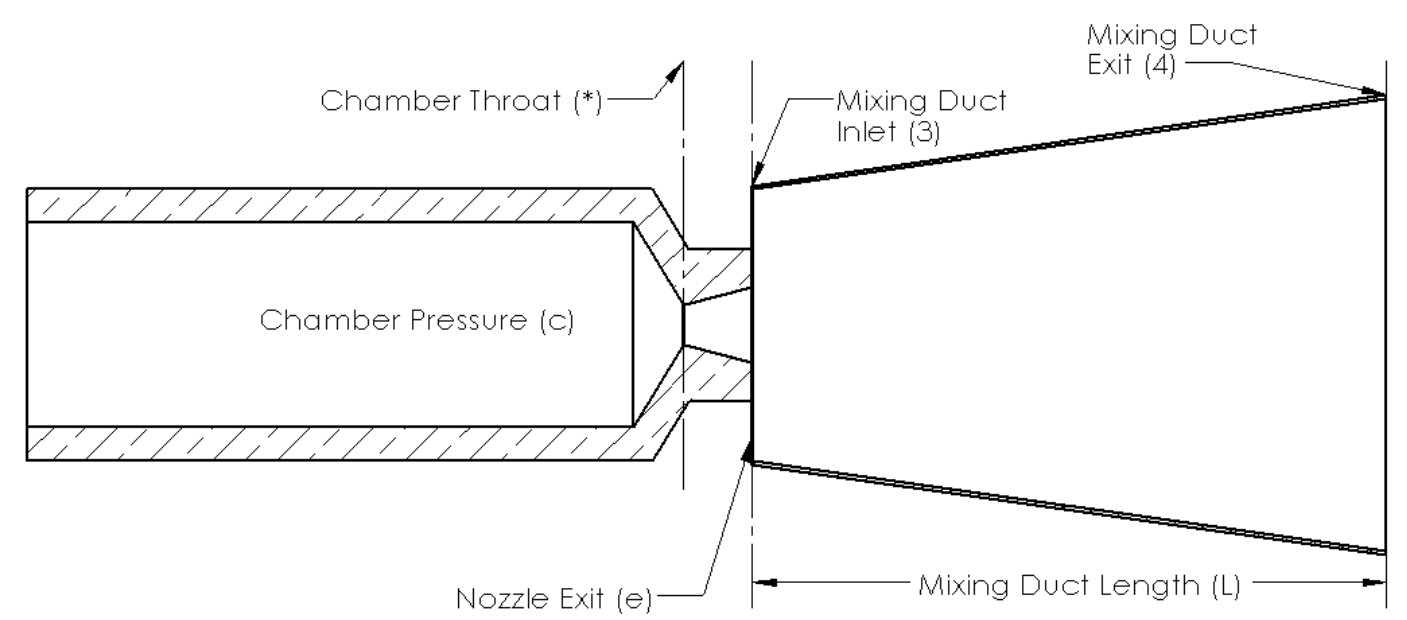

Figure 16: AAR Positions

Table 5: NASA Study Area Ratios (11)

\begin{tabular}{|c|c|c|c|c|c|}
\hline Case & $\begin{array}{c}\text { Chamber } \\
\text { Pressure }(\mathbf{p s i})\end{array}$ & $\begin{array}{c}\text { Mixer Inlet } \\
\text { Area Ratio } \\
\left(\mathbf{A}_{3} / \mathbf{A}^{*}\right)\end{array}$ & $\begin{array}{c}\text { Length to } \\
\text { Dia. Ratio } \\
\left(\mathbf{L}_{\mathbf{D}} \mathbf{D}_{3}\right)\end{array}$ & $\begin{array}{c}\text { Mixer area } \\
\text { Ratio } \\
\left(\mathbf{A}_{4} / \mathbf{A}_{3}\right)\end{array}$ & $\begin{array}{c}\text { Rocket Area } \\
\text { Ratio } \\
\left(\mathbf{A}_{\mathrm{e}} / \mathbf{A}^{*}\right)\end{array}$ \\
\hline 1 & 300 & 40 & 2 & 2 & 4 \\
\hline 2 & 300 & 40 & 5 & 2 & 20 \\
\hline 3 & 1200 & 200 & 2 & 2 & 4 \\
\hline 4 & 300 & 200 & 5 & 1 & 4 \\
\hline 5 & 300 & 200 & 2 & 1 & 20 \\
\hline 6 & 1200 & 200 & 5 & 2 & 20 \\
\hline 7 & 1200 & 40 & 5 & 1 & 4 \\
\hline 8 & 1200 & 40 & 2 & 1 & 20 \\
\hline 9 & 750 & 120 & 3.5 & 1.5 & 12 \\
\hline 10 & 300 & 40 & 2 & 1 & 4 \\
\hline
\end{tabular}

Figure 17 shows the two mixing ducts with their dimensions determined by the area ratios from the NASA study. Both mixing ducts were machined on a CNC lathe using solid 2" diameter steel bar stock. Outer 
diameter remained constant between the two mixing ducts in order to determine the effects that mixing duct internal shape had on mixing duct forces.

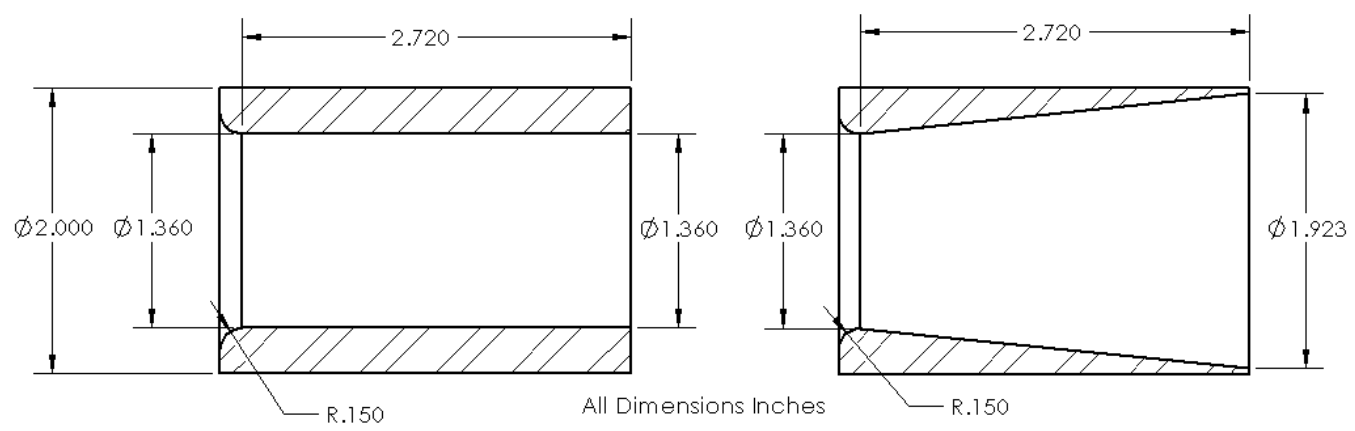

\section{Figure 17: Mixing Duct Dimensions}

Mounting the mixing ducts while maintaining mixing duct force measurement was completed using suspended mounting similar to the inner frame mounting. Mixing duct supports were designed to go around the thruster assembly to mount the mixing duct separately from the thruster assembly. Figure 18 shows the final design of the mixing duct support. Threaded 1/4"-20 rods were welded perpendicular to the ends of a $\mathrm{T}$ support. Support arms were welded to the outside of the mixing ducts using a custom designed spacer that oriented the supports at right angles to each other and perpendicular to the surface of the mixing duct. Mixing duct support arms were then trimmed such that the mixing duct was centered in the T support with the correct spacing. Steel disks with 1/4" through holes were then welded to the support arms while attached to the $\mathrm{T}$ support rods. This created a centered orientation for the mixing duct while allowing it to be removed by sliding the mixing duct off the end of the $\mathrm{T}$ support rods. This process was repeated for the second mixing duct. 


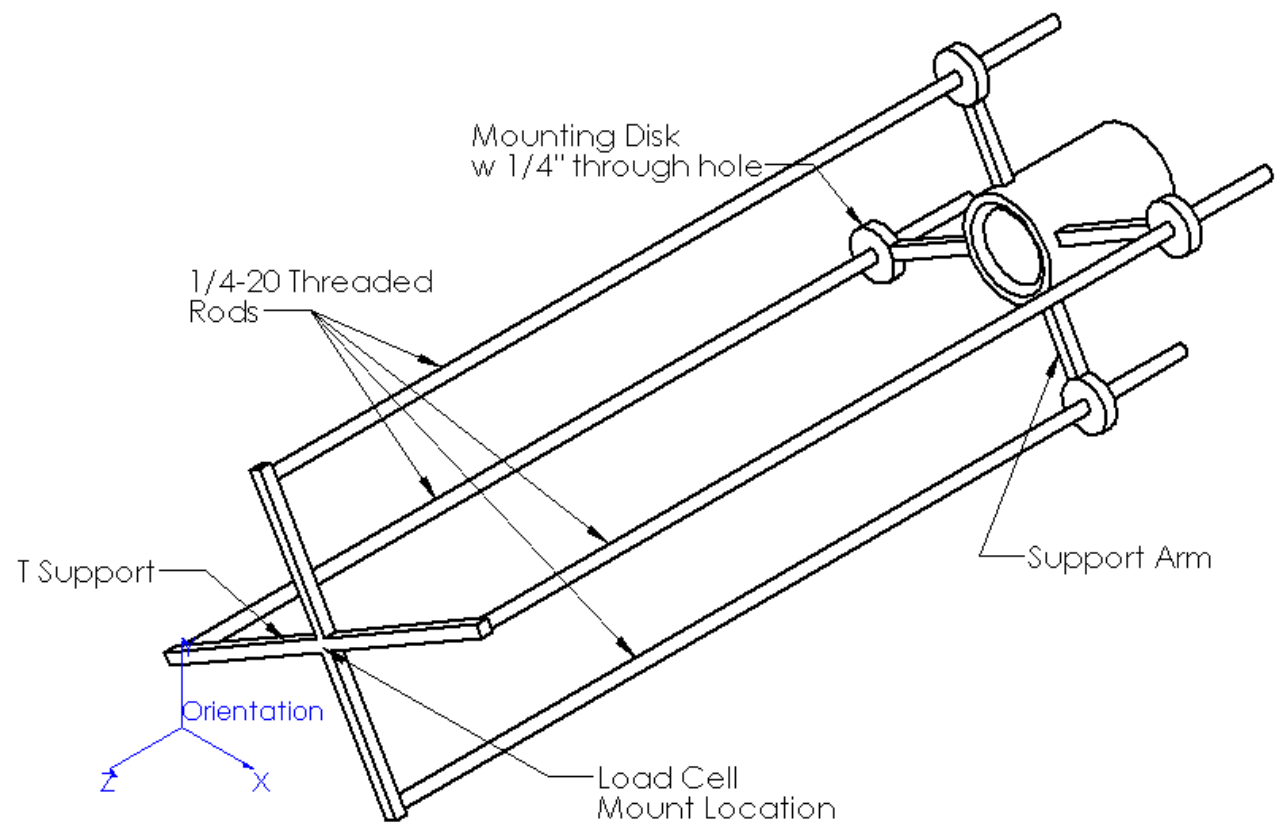

\section{Figure 18: Mixing Duct Mounting}

Figure 19 shows an orientation spacer that was made to position the mixing duct around the primary rocket exhaust such that it was concentric around the axisymmetric exhaust. It also positioned the mixing ducts the correct distance from the cooling jacket such that the minimum area for the secondary flow would occur at the exit plane of the primary rocket exhaust. Mounting the $\mathrm{T}$ support and mixing duct to the inner frame was done via a LCFD-25 25lb omega load cell with a plate attachment. This plate allowed the mixing duct to be moved in the $\mathrm{x}$ and $\mathrm{y}$ direction relative to the thruster axis to ensure the mixing duct and thruster were concentric. 


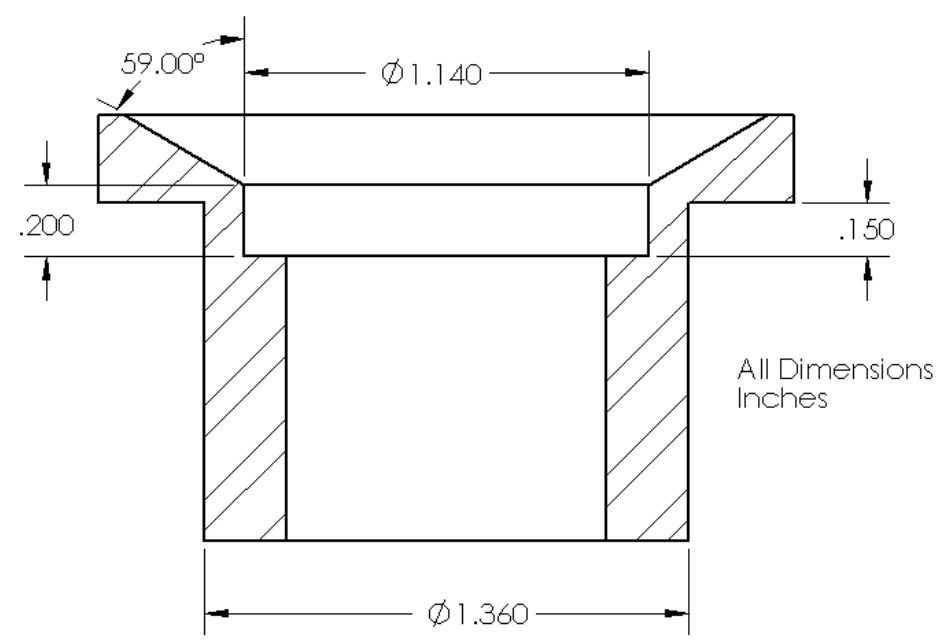

\section{Figure 19: Mixing Duct Placement Spacer}

Orientation of the mixing duct was achieved using the aforementioned spacer. The mixing duct was secured using nuts tightened down on the top and bottom of the threaded rods going through the steel disks on the end of the mixing duct supports. Once the correct orientation was achieved the top nut was held in place using locktight thread sealer. The mixing duct and spacer was removed, and then replaced in the same orientation and secured back onto the support. Initial testing with the mixing duct in this orientation showed significant movement of the mixing duct around the exhaust. This required some additional supports to be implemented. Using thin sheet metal machined to very strict tolerances, guides were created and welded onto the outside of the mixing ducts. Figure 20 shows the complete thruster assembly and mixing duct along with mixing duct guides. Four guides were welded onto each mixing duct. These guides did not physically attach to the cooling jacket but rather kept the mixing duct from straying away from its concentric orientation. Testing with the mixing ducts in this new orientation showed no discernible movement around the primary exhaust. With this mounting system mixing ducts can be easily changed out, axial forces of the mixing duct can be measured, and the total thrust of the system can be measured. 


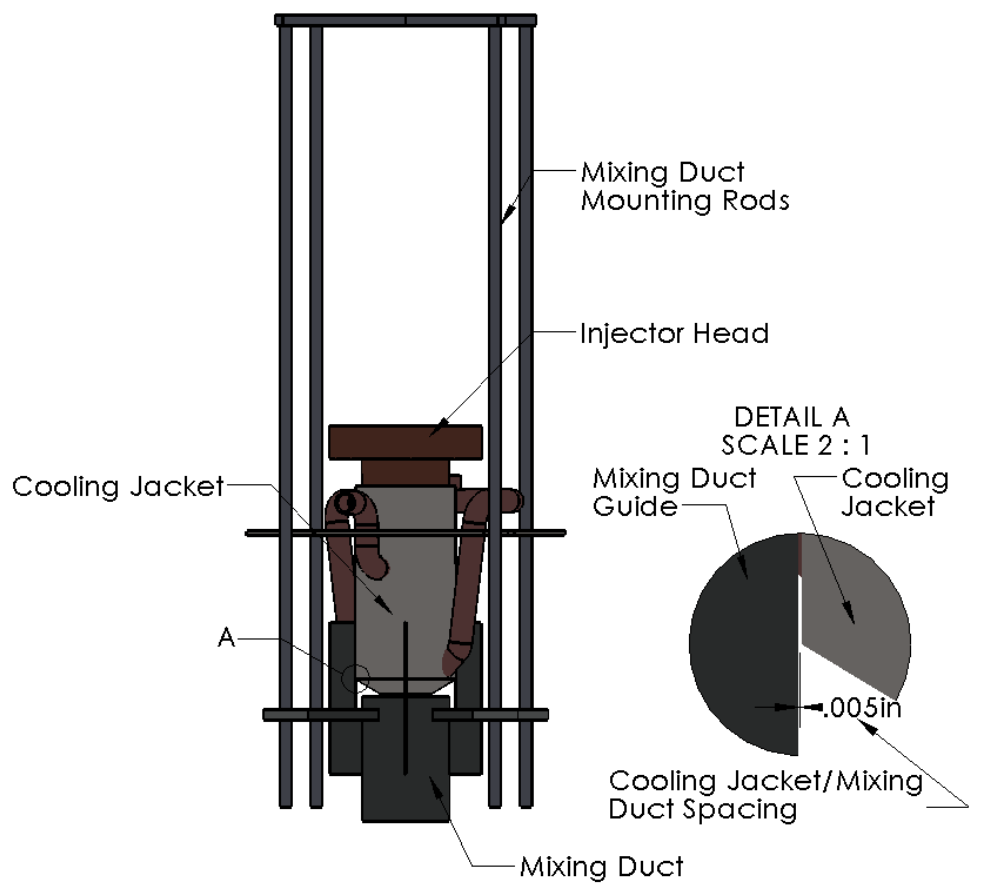

Figure 20: Thruster/Mixing Duct Assembly

\subsection{Final Configuration Overview}

The SCAARD is a combination of five different subsystems: Propellant, Control, Ignition, Thruster, and Instrumentation. Figure 21 is a diagram of the SCAARD subsystems with the exception of instrumentation. With all of these subsystems in place, the SCAARD is capable of consistent controlled operations, mass flow measurement, and independent mixing duct force measurements. 


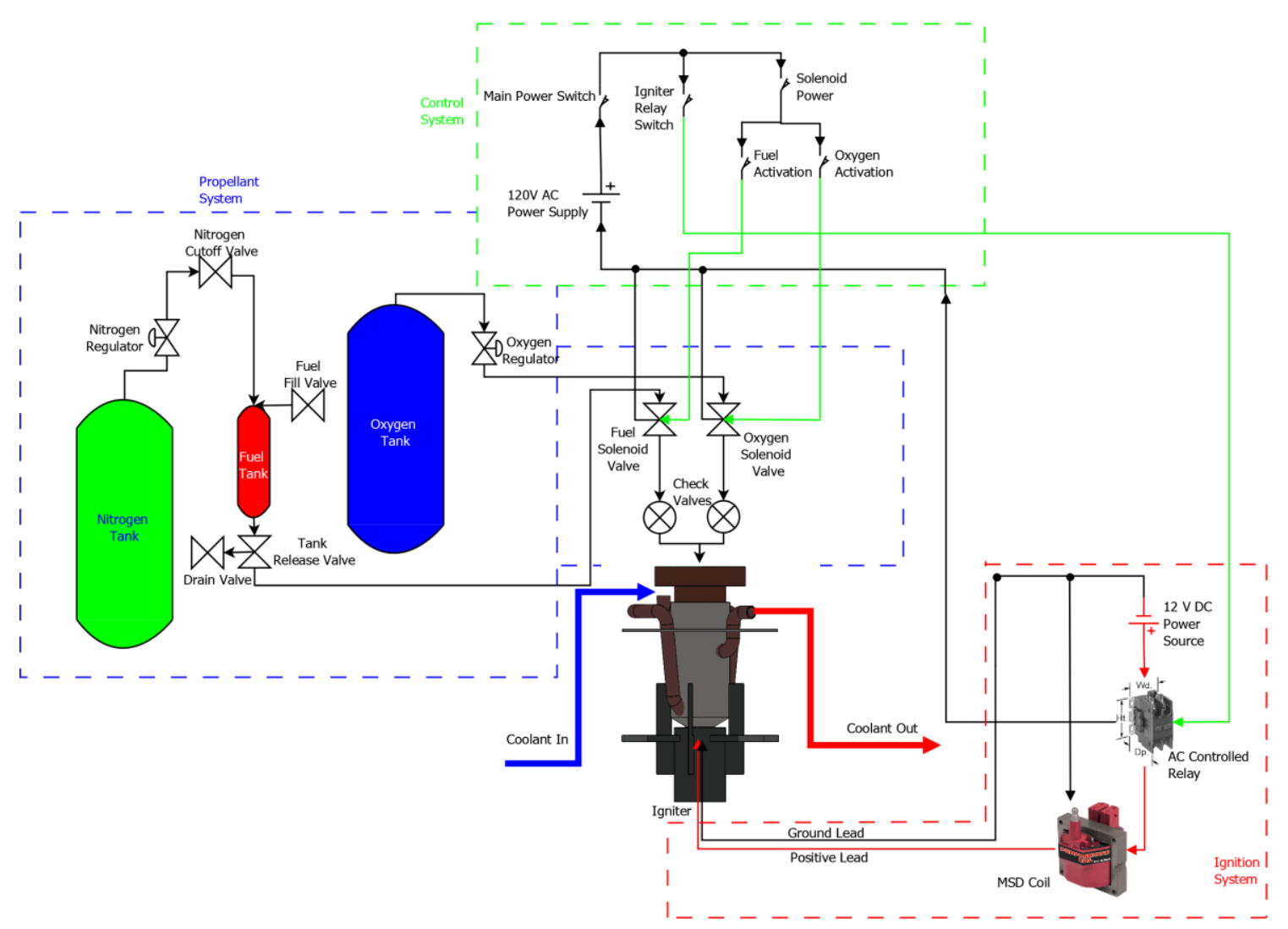

Figure 21: SCAARD Subsystems 


\section{Phase I Testing}

Phase I testing was conducted in September and October of 2012 in the Cal Poly Propulsion lab Bld 41. The SCAARD thruster assembly was used along with the counterweight type thrust measurement. No mixing duct was used in Phase I testing. Phase I was an examination of the thrust characteristics of the SCAARD thruster assembly and a confirmation that sustained repeatable combustion was achievable in the SCAARD thruster assembly. Thrust variation was achieved through varying the oxidizer and fuel regulated pressure settings. A total of 72 successful firings were conducted with varying fuel and oxidizer pressure settings, the average thrust results are summarized in Table 6 .

Table 6: Phase I Test Matrix

\begin{tabular}{|c|c|c|c|c|c|c|c|}
\hline \multicolumn{8}{|c|}{ Average Rocket Thrust (lbf) } \\
\hline & & \multicolumn{6}{|c|}{ Regulated Fuel Pressure (psig) } \\
\hline & & 330 & 350 & 370 & 390 & 410 & 430 \\
\hline \multirow{11}{*}{ 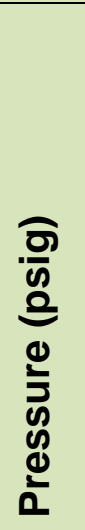 } & \multirow{4}{*}{330} & 12.80 & 14.54 & 14.48 & & & \\
\hline & & 12.73 & 14.95 & 14.52 & & & \\
\hline & & 13.49 & 13.25 & 14.50 & & & \\
\hline & & 13.28 & 13.94 & 14.09 & & & \\
\hline & \multirow{4}{*}{350} & 13.61 & 14.43 & 15.29 & & & \\
\hline & & 13.97 & 14.66 & 15.53 & & & \\
\hline & & 13.95 & 15.44 & 15.35 & & & \\
\hline & & 14.49 & 15.52 & 15.67 & & & \\
\hline & \multirow{4}{*}{370} & 15.18 & 15.71 & 16.43 & 16.47 & 15.79 & 15.71 \\
\hline & & 14.24 & 15.44 & 16.07 & 15.56 & 15.93 & 15.65 \\
\hline & & 15.14 & 15.90 & 16.23 & 15.74 & 15.55 & 15.86 \\
\hline \multirow{13}{*}{ 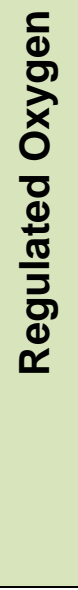 } & & 15.24 & 15.72 & 16.20 & 16.02 & 15.59 & 15.93 \\
\hline & \multirow{4}{*}{390} & 13.33 & 14.57 & & & & \\
\hline & & 14.94 & 16.33 & & & & \\
\hline & & 14.30 & 16.18 & & & & \\
\hline & & 14.97 & 16.06 & & & & \\
\hline & \multirow{4}{*}{410} & 15.32 & 16.23 & & & & \\
\hline & & 15.19 & 16.29 & & & & \\
\hline & & 15.55 & 16.22 & & & & \\
\hline & & 15.22 & 16.20 & & & & \\
\hline & \multirow{4}{*}{430} & 14.96 & 16.01 & & & & \\
\hline & & 14.64 & 16.25 & & & & \\
\hline & & 14.43 & 16.15 & & & & \\
\hline & & 13.69 & 16.03 & & & & \\
\hline
\end{tabular}


Numerous other firings were conducted but due to inconsistent pressure from the regulated oxygen and nitrogen, the data from those firings was thrown out. Inconsistent regulated pressure is caused when the supply nitrogen or oxygen pressure is reduced to the point where supply pressure is about twice the regulated pressure. When supply pressure is this low the supply cannot maintain enough volumetric flow rate to maintain steady regulated pressure. Figure 22 shows a typical thrust and pressure profile of a successful steady run, Figure 23 shows a thrust and pressure profile of an unsteady run with low pressure supply.
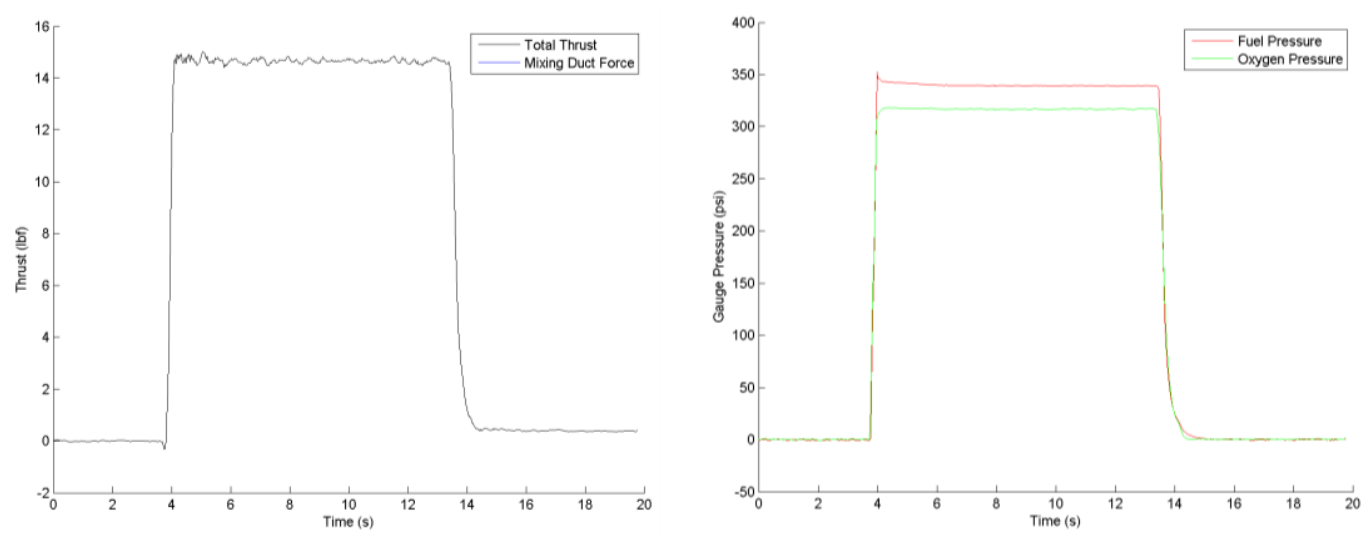

Figure 22: Steady Run: Regulated Fuel Pressure 350psi, Regulated Oxygen Pressure 350psi
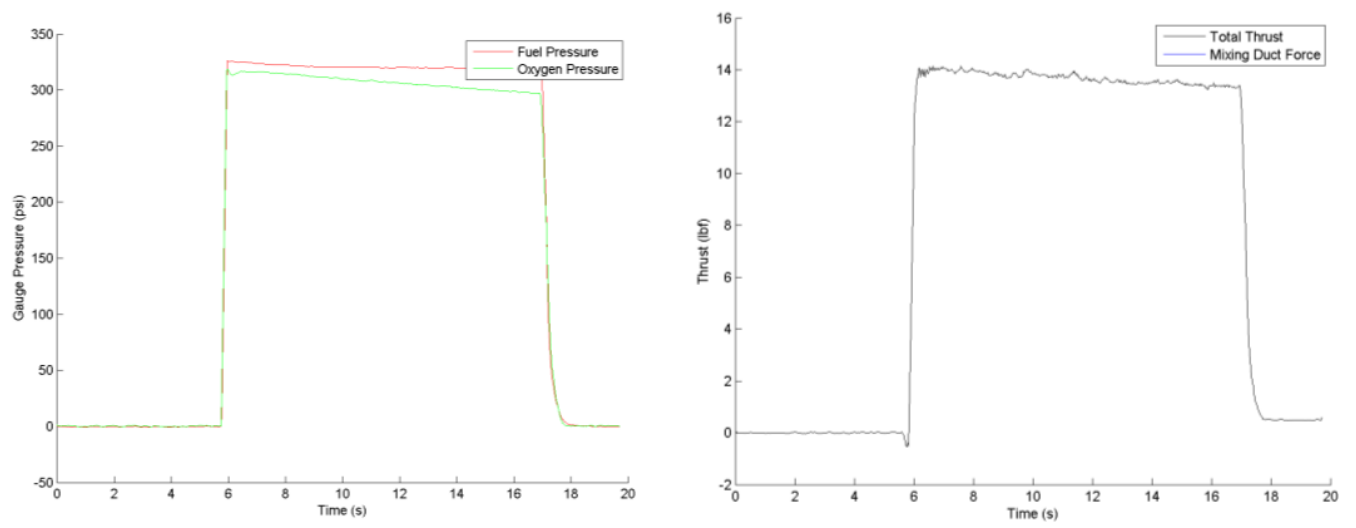

Figure 23: Unsteady Run: Regulated Fuel Pressure 330psi, Regulated Oxygen Pressure 430psi 
When viewing the thrust traces and summarized data of the Phase I testing, some irregularities became apparent and needed to be addressed. Again Phase I used the counterweight thrust measurement system described in Figure 9. When this system was used over a variety of test conditions summarized in Table 6, the repeatability at each condition became an issue. The procedures for firing the SCAARD are displayed in Appendix A. During each set of four tests at a single oxidizer and fuel pressure setting, the regulators remained untouched and a single tank of fuel was used in order to minimize inconsistencies in the data. Regulated pressure was not very accurate due to the screw control and low resolution of the dial. Therefore, regulated pressure is a rough reading of the actual pressure in the fuel and oxidizer lines. Regulated pressure is used to set the inlet pressure but the pressure transducer readings are used in all calculations and give a much more accurate picture of the true conditions in the fuel and oxidizer lines. After the initial Phase I testing was conducted the observed thrust data did not consistently match for a given fuel and oxidizer pressure setting. In a given pressure setting the thrust values could vary anywhere from 0.2 to over $1 \mathrm{lbf}$ which did not provide consistent thrust measurement. Repeatability issues were narrowed down to inconsistent forces on the load cell due to friction in the system and high hysteresis in the load cell. Figure 24 shows some of the hysteresis issues between multiple Phase I thrust traces. The largest problem with the hysteresis is that it was not consistent through each run. Some would have no hysteresis and others would show a multiple lbf offset after the completion of a firing. 
a.)

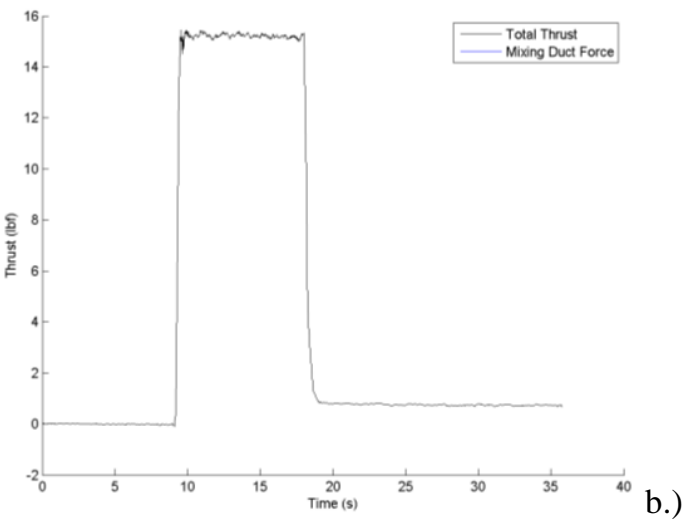

c.)

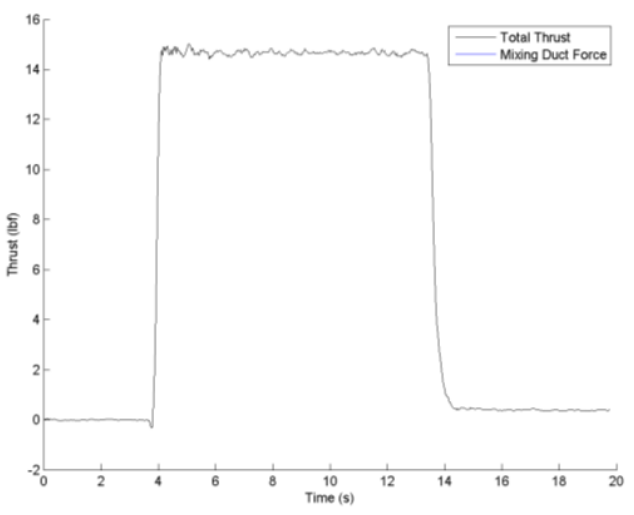

d.)

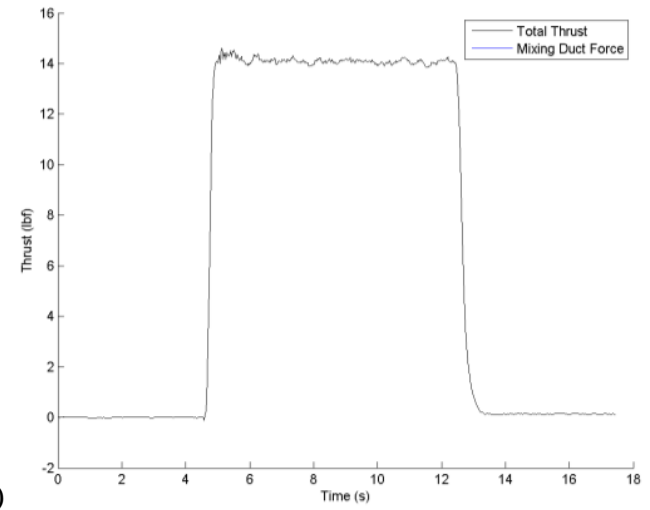

\section{Figure 24: Hysteresis Comparison}

In order to solve the issue of thrust repeatability the counterweight thrust measurement system was discarded. SCAARD's inner frame was adjusted so that the thruster assembly was located in the exact center of the inner frame and a LC101-100 100lbf S-Beam load cell was placed directly over the thruster assembly in the thrust axis. This load cell suspended the inner frame from the upper crossbar, the only object restraining the inner frame in the $\mathrm{Z}$ axis was the load cell. Therefore any thrust would be recorded as a change in force acting on the load cell, this became the total thrust measurement. 


\section{Phase II Testing}

Phase II consisted of performance testing the SCAARD with attached mixing ducts and mixing duct force measurement. Initial tests were conducted to confirm the correct operation of the SCAARD with attached mixing ducts and instrumentation. This initial test stage is where the movement issue of the mixing ducts was discovered as discussed in the mixing duct section. Once the guide fins on the mixing ducts were installed to correct the mixing duct stability, it was confirmed that mixing duct and total thrust measurements were operating properly.

\subsection{Formal Testing}

At this point formal testing began and the SCAARD apparatus was considered complete for the purpose of this research. No further changes to the SCAARD apparatus or instrumentation were carried out in order to make comparisons between formal test data sets possible. During formal testing at each fuel and oxidizer pressure setting, three steady state firings would take place for each configuration of the SCAARD:

- $\quad$ No mixing duct

- $\quad$ Straight mixing duct

- Diverging mixing duct

Throughout this report a case refers to a single fuel and oxidizer pressure setting. A run or firing is a single test of the SCAARD. Therefore each case has 9 firings, 3 for each configuration. In order for run data to be considered acceptable, some basic criteria had to be fulfilled. Ignition had to be maintained through the entire desired test period. If the methanol fuel level was low combustion would become unsteady which would reduce the average thrust value of the run resulting in unusable data. Pressure measured by the fuel and oxidizer pressure transducers must be constant throughout the desired run. If the pressure in the oxygen or nitrogen supply was less than two times the desired regulated pressure, the stagnation pressure in the lines would be constantly decreasing resulting in unsteady thrust. If either of these criteria was not satisfied the run data was thrown out and the desired case and configuration was rerun with a full methanol tank or a replaced oxygen or nitrogen bottle. Formal testing procedures followed the Rocket Activity procedures in Appendix A. In order to keep data between the different configurations in the same case as comparable as 
possible a specific fueling procedure was developed. This was due to the fact that one tank of methanol fuel could not be used for the full 9 runs of each case. In order to maintain continuity between SCAARD configurations once a desired case was applied, the regulators were not touched again until a new case was desired. In conjunction with the regulators, pressure bottles were not closed until a new case was desired. As previously shown in Figure 21 the fuel line has a cutoff valve upstream of the fuel tank as well as a tank release valve at the bottom of the fuel tank. Closing these two valves isolated the fuel tank from the rest of the system allowing it to be depressurized and refueled without adjusting or shutting off the nitrogen pressure supply. Every three successful runs the methanol tank would be refueled and the SCAARD configuration would be changed. As stated in the mixing duct section a spacer was used to orient each mixing duct in the same location, and the mounting nuts were adjusted to lock the mixing duct in place. Top nuts were fixed in place and the spacer was then taken out leaving the mixing duct in the correct orientation. Each run had an average duration of 10 seconds, this allowed for steady state thrust to be achieved and sustained. Through the formal testing 9 separate pressure settings were examined to develop trends as the mixture ratio was varied. Over the course of formal testing over 140 firings took place with 81 considered acceptable for use in comparison and analysis. Table 7 provides a summary of the successful test cases carried out.

Table 7: Formal Test Cases

\begin{tabular}{|c|c|c|c|c|c|c|c|c|c|}
\hline & \multicolumn{8}{|c|}{ Regulated Fuel Pressure (psig) } \\
\hline & & 330 & 340 & 350 & 360 & 370 & 380 & 390 & 400 \\
\hline \multirow{11}{*}{ 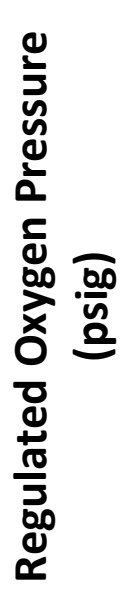 } & 330 & & & & & & & & \\
\hline & 340 & & & & & & & & \\
\hline & 350 & & & & & & & & \\
\hline & 360 & & & & & & & & \\
\hline & 370 & & & & & & & & \\
\hline & 380 & & & & & & & & \\
\hline & 390 & & & & & & & & \\
\hline & 400 & & & & & & & & \\
\hline & 410 & & & & & & & & \\
\hline & 420 & & & & & & & & \\
\hline & 430 & & & & & & & & \\
\hline
\end{tabular}




\subsection{External Combustion}

External combustion was a flow condition that disqualified a test from being successful. Sustained external combustion was only observed in a mixing duct configuration. It was never obtained in a no-mixing duct configuration. External combustion occurred when successful ignition would fail to begin inside the chamber and instead would occur inside the mixing duct. Un-combusted fuel and oxidizer would be provided from the chamber nozzle exit and due to the high flow rate of fuel and oxidizer combustion would not propagate into the chamber. Visually the external combustion exhaust was much larger in both length and width compared to successful chamber combustion. No visible shock diamonds were present indicating that external combustion exhaust is subsonic. Figure 25 a) shows successful chamber combustion while Figure 25 b) shows sustained external combustion.

a)

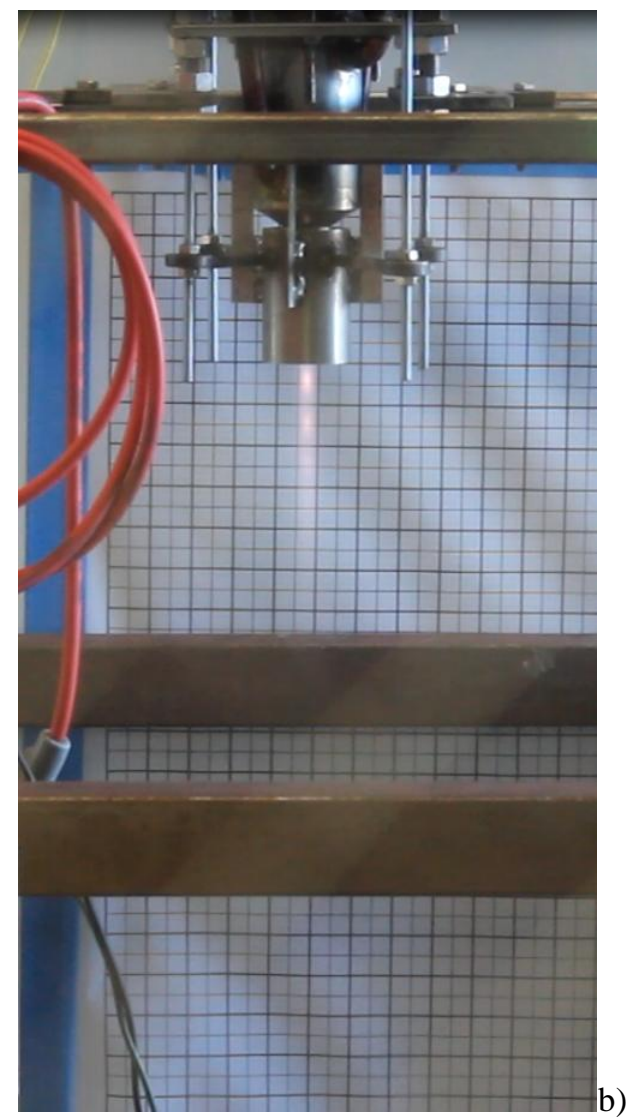

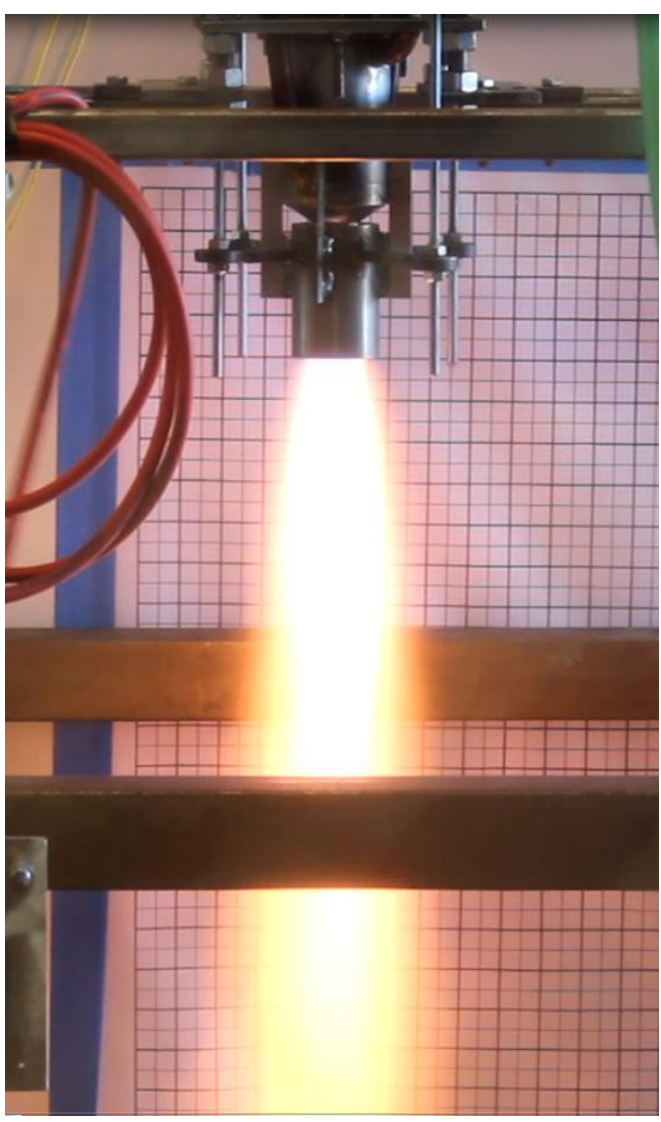

Figure 25: a) Internal Combustion b) External Combustion 
Both of the pictures in Figure 25 were taken from video recordings of the same case and straight mixing duct configuration. This is a very lean mixture with an oxidizer to fuel ratio of 2.3. Stoichiometric mixture ratio for these products is 1.5 . When chamber combustion is achieved at a lean mixture ratio the exhaust and shock diamond train is barely visible. This indicates complete combustion since Methanol should burn almost invisibly with visible shock diamonds due to the alcohol nature of the fuel. (3) As the mixture ratio becomes richer the rocket exhaust becomes more and more visible. In the case of external combustion the pressure in the chamber is much lower. Therefore, the pressure drop across the fuel nozzle is greater resulting in much higher fuel flow rates. In essence external combustion acts as an afterburner with a very rich mixture ratio. When the recorded data is examined the difference in total thrust between external and in chamber combustion is clearly shown in Figure 26. External combustion produces around 2.5lbf of thrust while chamber combustion at the same setting results in nearly $16 \mathrm{lbf}$ of thrust. External combustion can be intentionally created by placing the ignition wires at the throat of the chamber instead of inside the chamber.

a)
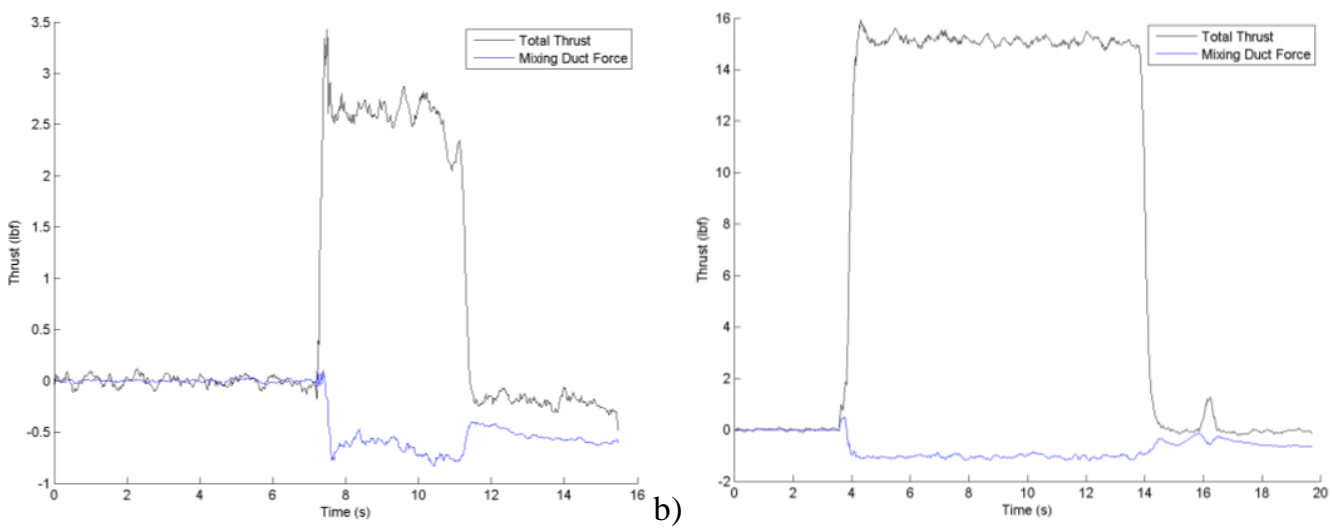

Figure 26: Regulated Fuel Pressure 350psi, Regulated Oxygen Pressure 370psi: a) External Combustion, b) Chamber Combustion

\subsection{Data Post-Processing}

In each run data is recorded via LabView and exported to Microsoft Excel for further analysis. Matlab is used to read in the excel data for analysis and plotting. Data was recorded simultaneously on 4 channels, two thrust measurements as well as the fuel and oxidizer pressure measurements, at a rate of $50 \mathrm{~Hz}$. After 
reading data into Matlab a smoothing function was used to reduce the amount of noise in the data. Smoothing the data reduces the resolution of the transients because it takes a local average around each point to filter out noise. This results in a cleaner signal to be used for calculation. Figure 27 shows a thrust trace before and after the smoothing function is used. Since all analysis in this thesis is done at steady state the loss in resolution in the transient portion is deemed acceptable.

a)

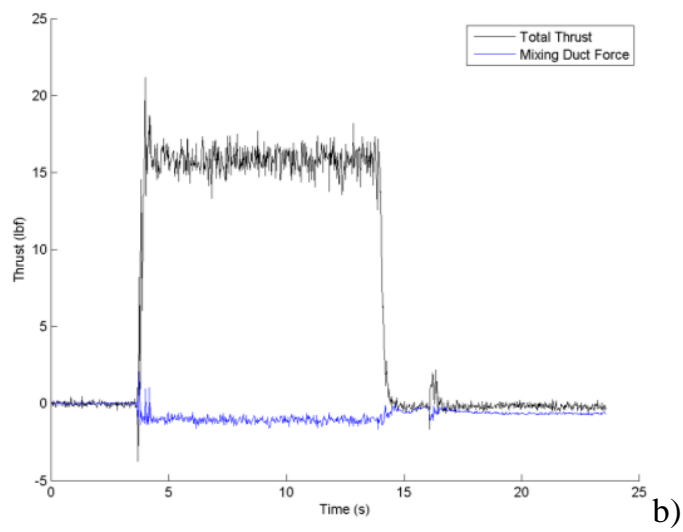

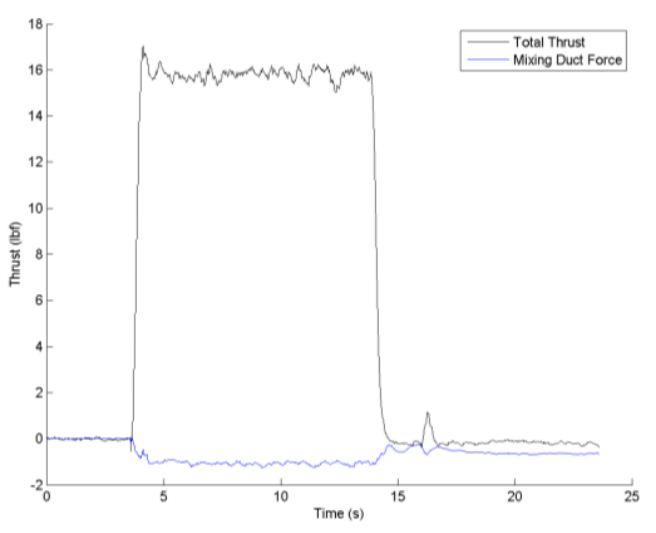

Figure 27: Smoothing Example

In the Matlab script, trigger recognition is implemented by sensing the activation and deactivation of the fuel and oxidizer pressures. Oxidizer and fuel were chosen as the triggers due to their clean and steady profile. Transients in the pressure data are minimal. The oxygen and fuel is either on or off and it remains steady throughout the entire run. In each firing the oxidizer and fuel are turned on together and remain on until the run is over. Oxidizer may be pulsed to evacuate the combustion chamber after a run but these activations are not recognized as a trigger. Using the trigger locations the data can then be cropped to include only steady state operation. For each run $15 \%$ of both the beginning and end of a run is cropped out to get rid of any transient conditions. Cropping $15 \%$ corresponds to approximately 1.5 seconds off of the beginning and end of each run leaving approximately 7 seconds of steady state data to be used in analysis. Transient conditions typically exist for less than 0.5 seconds, therefore cropping approximately 1.5 seconds from the run time ensures that the analyzed data is steady state. Both the total thrust load cell as well as the mixing duct load cell operate in tension. Therefore, a decrease in load on the load cell corresponds to positive thrust. Total thrust is calculated by the change in force on the total thrust load cell. The negative of 
this difference is used in the thrust traces. Thrust measurements are adjusted based on the average initial reading of the load cell before the test is initiated allowing the thrust traces to start at $0 \mathrm{lbf}$ and have a positive thrust measurement. Mixing duct thrust is not multiplied by -1 . Therefore, a negative mixing duct thrust corresponds to a force in the positive $\mathrm{z}$ direction. Fuel and oxidizer pressure data is recorded with gauge pressure transducers which are then adjusted with the ambient barometric pressure when required to obtain absolute pressure.

\subsection{Performance Calculations}

After the data is processed and steady state conditions are established performance results can be calculated. Thrust values for both total thrust and mixing duct thrusts are straight forward and were previously explained in the data post processing section. Oxygen mass flow rate and fuel mass flow rate are not as simple to calculate.

\subsubsection{Oxygen Mass Flow Rate}

As previously stated oxygen mass flow rate is controlled and measured using a sonic nozzle. The following flow rate calculation procedure is from the sonic nozzle manufacturer Flow Systems Inc. The critical flow equation that governs mass flow through a choked nozzle is written as.

$$
\dot{m}_{x}=P_{o} A_{n t} C^{*} C d \sqrt{\frac{g_{c} M w}{R T}}
$$

Measured values are stagnation temperature $T$ and stagnation Pressure $P$. Throat area $A_{t}$ is prescribed by the manufacturer. Oxygen is assumed to act as an ideal gas, therefore $\mathrm{C}^{*}$ is a function of the ratio of specific heats shown in equation 7-2.

$$
C^{*}=\sqrt{\gamma\left(\frac{2}{\gamma+1}\right)^{\left(\frac{\gamma+1}{\gamma-1}\right)}}
$$


$C_{d}$ is a function of the throat Reynolds number (shown in equation 7-3) which in turn is a function of the mass flow rate equation (7-1). Using an iterative solver a solution can be converged on within a $C_{d}$ tolerance of $0.0001(19)$.

$$
\begin{gathered}
R_{d}=\frac{48 m_{x}}{\pi D_{n t} \mu} \\
R_{d}<100,000 \\
C_{d}=\frac{0.99738-3.053}{R_{d}{ }^{5}} \\
R_{d}>100,000 \\
C_{d}=\frac{0.9935-1.525}{R_{d}{ }^{.5}}
\end{gathered}
$$

At this point the mass flow rate is converged and the value is used for further calculation.

\subsubsection{Fuel Flow Rate and Chamber Conditions}

Neither SMORE's nor SCAARD's design was capable of direct chamber pressure measurement. The area of the injector head is simply too constricted to allow for a pressure port into the combustion chamber. All other areas of the combustion chamber are surrounded by the cooling jacket and coolant making a pressure port infeasible in those areas. According to Krzycki's guide the combustion pressure of methanol and gaseous oxygen is $300 \mathrm{psi}$ at stoichiometric mixture ratio and optimum design conditions. (16) With the intended variation of mixture ratios, it is evident that a more robust method of determining chamber conditions is required. To that end an iterative method for determining chamber conditions based on the input pressures was determined. Measured values are the Oxygen line stagnation pressure, and fuel line stagnation pressure. Oxygen mass flow rate is calculated using the aforementioned sonic nozzle mass flow method. Fuel mass flow rate is a function of the pressure drop between the fuel line and chamber pressure. Fuel mass flow rate is given by the manufacturer in gallons per hour of water for a given pressure drop. Fitting a curve to the fuel data provides an equation for fuel flow rate. Using methanol's specific gravity and the mass of a gallon of water, equation 7-5 produces the methanol mass flow rate in $1 \mathrm{bm} / \mathrm{s}$.

$$
\dot{m}_{f}=2.411 *\left(P_{f}-P_{c}\right)^{4988} * S G_{f} * G W * \frac{1}{60^{2}}
$$


Initial guesses at chamber pressure and temperature are used to start the iteration process. Chamber pressure initial guess is 10psi lower than the lowest propellant line stagnation pressure. Chamber temperature guess is arbitrary since it is updated through each iteration. Fuel mass flow rate is calculated and oxygen mass flow rate is known and independent of downstream pressure as long as the downstream pressure is less than $90 \%$ of the upstream pressure. (19) If the upstream to downstream pressure ratio in the oxygen line is greater than $90 \%$ the mass flow rate decreases based on the pressure ratio. Based on the manufacturer specifications and a study done on backpressure ratio influence, a mass flow relationship for high back pressures can be developed as a ratio of the critical flow seen in Figure 28. (19) (24)

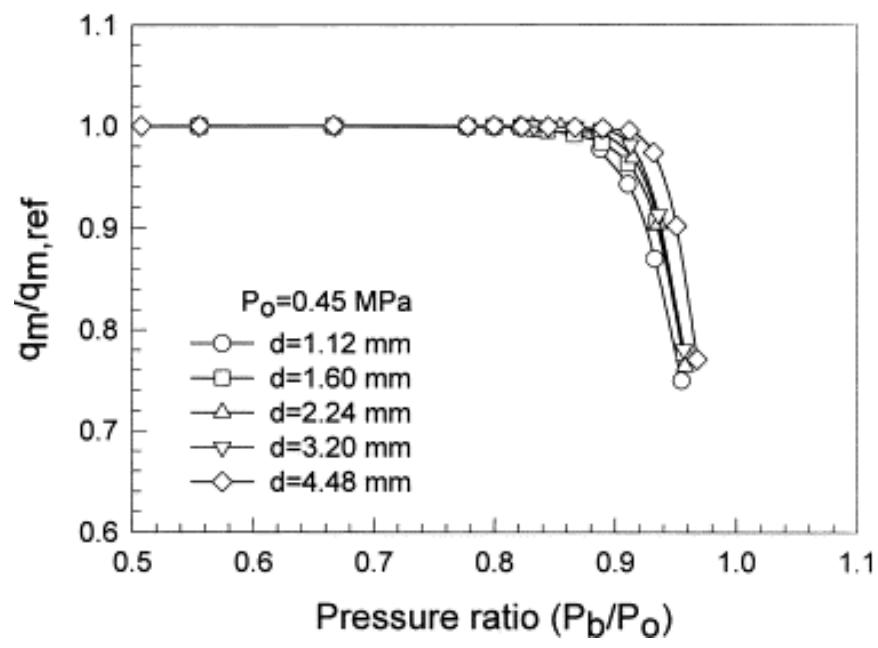

Figure 28: Sonic Nozzle Relationship past Critical Pressure Ratio (24)

Residence time of the chamber is calculated based on the, mass flow rate, chamber dimensions and specific volume of the reactants equation 7-6. (3)

$$
r t=\frac{V_{c} P_{c} M w}{\dot{m} R T_{c}}
$$


Flow rates and residence time provides the moles of combustion reactants in the chamber. Fuel available for combustion is determined by the fuel efficiency multiplied by the total fuel amount. Assuming complete combustion of the available products to $\mathrm{H}_{2} \mathrm{O}$ and $\mathrm{CO}_{2}$ with excess fuel or oxidizer remaining uncombusted the molar values of the products can be determined using equation 7-7 through 7-13.

$$
\begin{array}{lc} 
& a=a_{\text {total }} * \mathrm{FE} \\
& a \mathrm{CH}_{3} \mathrm{OH}+b \mathrm{O}_{2} \stackrel{\text { yields }}{\longrightarrow} \mathrm{cH}_{2} \mathrm{O}+d \mathrm{CO}_{2}+e \mathrm{CH}_{3} \mathrm{OH}+\mathrm{fO}_{2} \\
c=2 a & \text { if } b \leq \frac{3}{2} a \\
d=a & c=\frac{4}{3} b \\
e=a_{\text {total }}-a & d=\frac{2}{3} b \\
f=b-\frac{3}{2} a & e=\left(a_{\text {total }}-\frac{2}{3} b\right) \\
& f=0
\end{array}
$$

Stoichiometrically equation $7-8$ is balanced when $b=1.5 a$. This differs from the mixture ratio of 1.2 provided by Krzycki. (16) It is probable that Krzycki used a slightly fuel rich mixture ratio to reduce chamber temperature and pressure. Equation 7-14 and heat of formation data from thermochemcial tables results in the enthalpy released by the reaction. (25) (26)

$$
\Delta H=\sum_{p r} n_{p r} \Delta H_{f T_{d}}^{o}-\sum_{R} n_{R} \Delta H_{f T_{d}}^{o}
$$

Equation 7-15 calculates the enthalpy required to raise the products to a certain temperature, when equation 7-14 equals 7-15 the temperature $T_{c}$ specified by equation 7-15 is the combustion temperature.

$$
\Delta H=\sum_{p} n_{p r}\left(H_{T_{c}}-T_{T_{d}}\right)
$$

Enthalpy data used in equation 7-15 was readily available for all combustion products over the desired temperature range except for methanol. Enthalpy data was available for methanol over the temperature range of 298 to $1500^{\circ} \mathrm{K}$ from the Handbook of Chemistry and Physics. (27) Full temperature range enthalpy data is available for methane $\left(\mathrm{CH}_{4}\right)$ which is very similar to methanol $\left(\mathrm{CH}_{4} \mathrm{O}\right)$. It is also observed that 
oxygen, water, carbon dioxide, and methane all follow a linear enthalpy trend from 1200 to $5000^{\circ} \mathrm{K}$. Therefore, a linear extrapolation of the provided methanol data using the data points between 1200 and $1500^{\circ} \mathrm{K}$ is created to account for methanol enthalpy data at the higher temperature ranges. Figure 29 shows the methanol data with trend lines as well as methane, oxygen, water, and carbon dioxide. Enthalpy linearity at high temperatures for all used chemical compounds is also apparent.

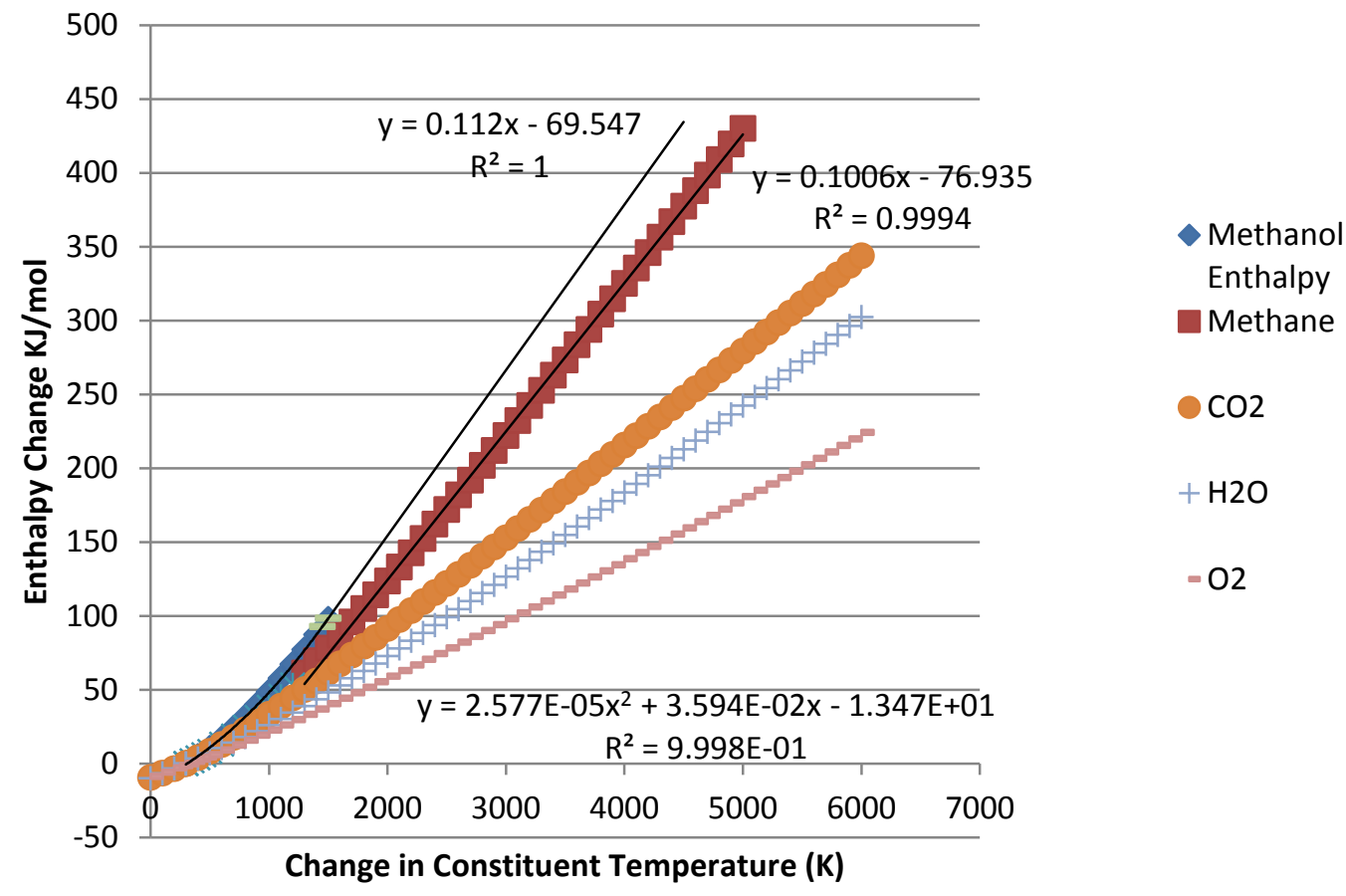

Figure 29: Enthalpy Trends of Products

Using the updated combustion temperature and the rocket mass flow equation solved for pressure, equation 7-16, a new combustion pressure is calculated.

$$
P_{c}=\frac{\dot{m} \sqrt{T_{c}}}{A_{t} \sqrt{\frac{\gamma}{R}}}\left(\frac{\gamma+1}{2}\right)^{\frac{\gamma+1}{2(\gamma-1)}}
$$

This process is repeated until the combustion temperature and pressure converge. Chamber pressure guess is reduced by 0.5 psi until the difference between the calculated chamber pressure and the chamber pressure 
guess changes sign. Using this process a more reasonable fuel mass flow rate can be calculated due to the fuel flow rate dependence on chamber pressure. Non-stoichiometric chamber conditions can also be solved.

\subsubsection{Specific Impulse}

At this point fuel mass flow rate, oxygen mass flow rate, and both total and mixing duct thrusts are known.

Thrust efficiency of a rocket is determined by its specific impulse previously stated in equation 1-1. Calculating the specific impulse of the system makes comparison between differing thrust runs possible.

\subsubsection{Error Analysis}

Each measured value has uncertainty associated with it due to level of accuracy of the instruments used. Since measured values are used in calculation of mass flow rate, chamber conditions, thrust, and Isp the uncertainty is carried through all calculations. To quantify the level of error associated with the measured and calculated values in this research an error analysis was performed. Table 8 summarizes the instruments used to record data and their total error values.

\section{Table 8: Instrument Error Values}

\begin{tabular}{|l|l|l|l|}
\hline Instrument & Model Number & Measurement Range & Total Error \\
\hline Total Thrust Load Cell & LC101-100 & $\pm 100 \mathrm{lbf}$ & $0.037 \%$ Full Scale \\
\hline Mixing Duct Load Cell & LCFD-25 & $\pm 25 \mathrm{lbf}$ & $0.15 \%$ Full Scale \\
\hline Fuel/Oxidizer Pressure & PX302-3KGV & $0-3000 \mathrm{psig}$ & $0.37 \%$ Reading \\
\hline
\end{tabular}

Measurement error propagates through all calculations conducted in the chamber conditions solver and theoretical calculations. Error is accounted for as best as possible in the chamber conditions solver but error associated with chemical composition and enthalpy calculations used to find chamber temperature and pressure are unknown. Table 9 summarizes the instrument error propagated through all calculations. Errors reported in Table 9 are averages over all cases and configurations, they also include the standard deviation between recorded run values for each case and configuration. Through error calculation the dominating error term is the standard deviation between runs for a specific case and configuration. Extreme error values of the diverging mixing ducts are quite misleading. Diverging mixing duct cases experience very minimal thrust values, less than $0.3 \mathrm{lbf}$; therefore the standard deviation between the three runs dominates 
the error of the averaged diverging mixing ducts even more than the other readings. The high errors of the diverging mixing duct occur when the mixing duct produces average thrust values very close to zero. When calculating the percent error the error value is divided by the actual value, when the actual value is very close to zero the percent error becomes very large. For the purposes of this study the high percentage error seen by the mixing ducts is acceptable. In section 9.1, Figure 33 it can be shown that even with the error values of the mixing ducts a distinct differentiation between mixing ducts is clearly shown.

Table 9: Total Error

\begin{tabular}{|l|r|r|}
\hline Reading & Maximum Error & Average Error \\
\hline Total Thrust & $6.10 \%$ & $2.20 \%$ \\
\hline Straight Mixing Duct Thrust & $49.90 \%$ & $26.80 \%$ \\
\hline Diverging Mixing Duct Thrust & $2604 \%$ & $679 \%$ \\
\hline Mixture Ratio & $5.90 \%$ & $1.70 \%$ \\
\hline Fuel Mass Flow Rate & $1.88 \%$ & $1.10 \%$ \\
\hline Oxygen Mass Flow Rate & $5.40 \%$ & $1.15 \%$ \\
\hline Specific Impulse & $10.40 \%$ & $3.20 \%$ \\
\hline
\end{tabular}




\section{Theory}

Theoretical values are used as a check to make sure that the measured values recorded through experimentation are reasonable. Theoretical thrust of the total system and mixing ducts are examined in this section.

\subsection{Ideal Thrust}

Rocket thrust can be solved for by integrating the pressure forces acting on the combustion chamber and nozzle with the resulting force vector equaling the thrust force. (3) Figure 30 is a visual representation of a simplified chamber very similar to the chamber used by the SCAARD. The lengths of the arrows represent the magnitude of the pressure force. (3)

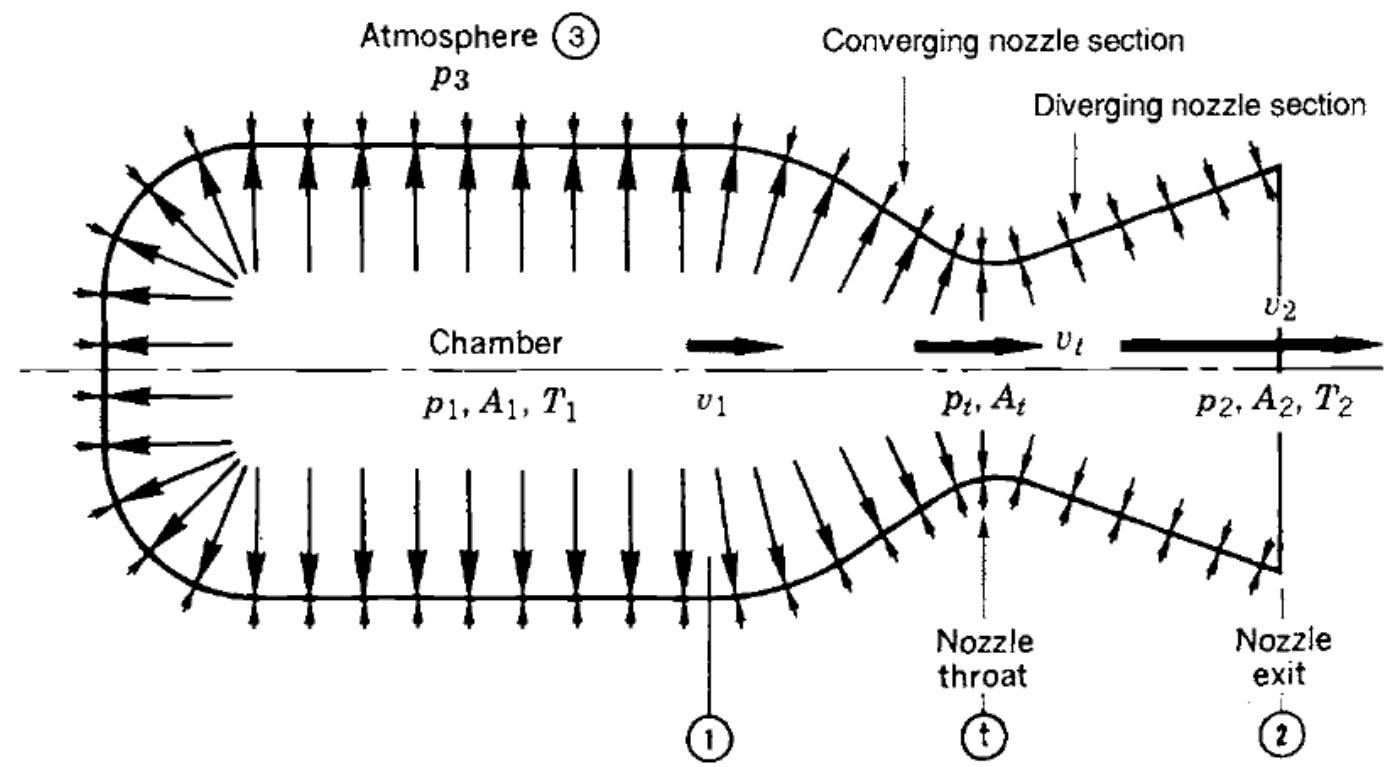

Figure 30: Chamber Pressure Diagram (3)

In order to complete the integral of pressure forces acting on the chamber, static pressure data at all points of the chamber must be known. Practically this is impossible but it demonstrates where the thrust force acting on the rocket actually comes from. Thrust is always reacted via pressure forces. In order to calculate the theoretical thrust of a rocket when the pressure data at all point is unknown, another method must be 
used. Conservation of momentum principle can be used to simplify the thrust calculation considerably. If the mass flow rate and exit velocity of the propellants are known the momentum of the propellants can be calculated. Acting opposite of the propellant direction is the reaction force which is equal to the force imparted to the rocket, its thrust. One other term is also included in the momentum thrust equation; the pressure force acting on the rocket nozzle when the nozzle exit pressure is not equal to ambient pressure. This results in thrust changing with altitude as the ambient pressure changes. Pressure thrust is not accounted for in this study because the nozzle exit pressure is assumed to be expanded to ambient pressure. Equation 8-1 is the equation for rocket thrust based on the momentum of the propellant gases. (3)

$$
F=\dot{m} v_{e}+\left(p_{e}-p_{a}\right) A_{e}
$$

Mass flow rate of the primary flow is provided through experimental data and the iterative chamber conditions solver. Exhaust velocity is dependent on the calculated chamber pressure, temperature, and the propellant chemical composition equation 8-2.(3)

$$
v_{e}=\sqrt{\frac{2 \gamma}{\gamma-1} \frac{R T_{c}}{M w}\left[1-\left(\frac{P_{e}}{P_{c}}\right)^{(\gamma-1) / \gamma}\right]}
$$

\subsection{Mixing Duct Lip Thrust and Incompressible Theory}

Examining mixing duct geometries such as those used in this research raises the question of where mixing duct thrust is formed. Figure 17 previously showed the two mixing ducts used in this study. If friction were the only force accounted for, both mixing ducts should experience a net drag force and detract from the total thrust of the system. Yet experimentally and theoretically this is not the case. Mixing ducts have been researched for jet noise reduction and thrust augmentation. A lobed mixing duct was used to augment the primary exhaust of a Gulfstream GIIB aircraft and was found to increase static thrust of the system by $7 \%$. (28) The same study also hypothesized that a well designed, lobed, multi-stage mixing duct could augment the static thrust of a rocket by up to $25 \%$. Mixing ducts behave the same as inlets. Therefore, the equations regarding inlets can be applied to mixing ducts. Assuming incompressible constant density flow a simple control volume approach can be used to approximate the forces acting on an inlet. (29) Figure 31 taken from Internal Flow Concepts depicts two cases of an inlet: take-off conditions, and cruise conditions with aerodynamic forces acting on the inlet. 
(a)

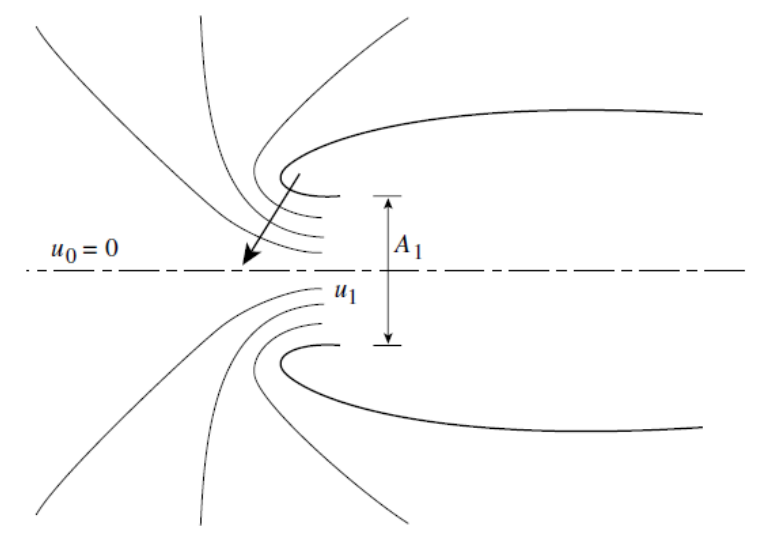

(b)

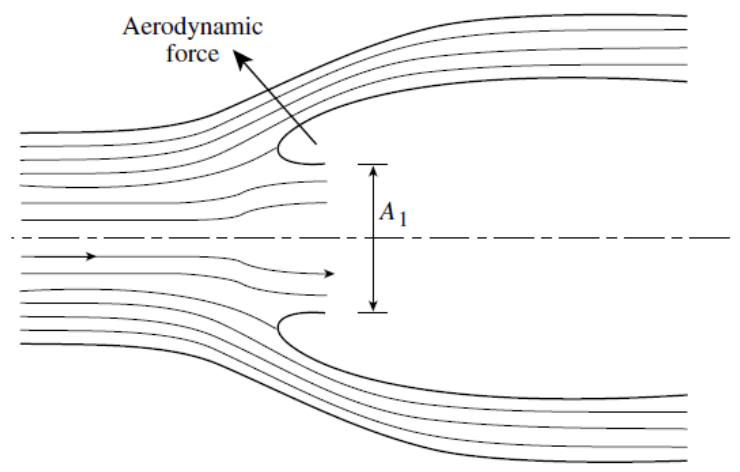

Figure 31: Forces on an Inlet (29)

In each case the aerodynamic force acts in the opposite direction of the flow. This phenomenon is again shown through equation 8-3 and Figure 32. Figure 32 gives the physical references for equation 8-3.

$$
\frac{F}{\frac{1}{2} \rho u_{1}^{2} A_{1}}=\frac{\int_{A_{N}}\left(p_{0}-p\right) d A_{N}}{\frac{1}{2} \rho u_{1}^{2} A_{1}}=\left(\frac{u_{o}}{u_{1}}-1\right)^{2}
$$




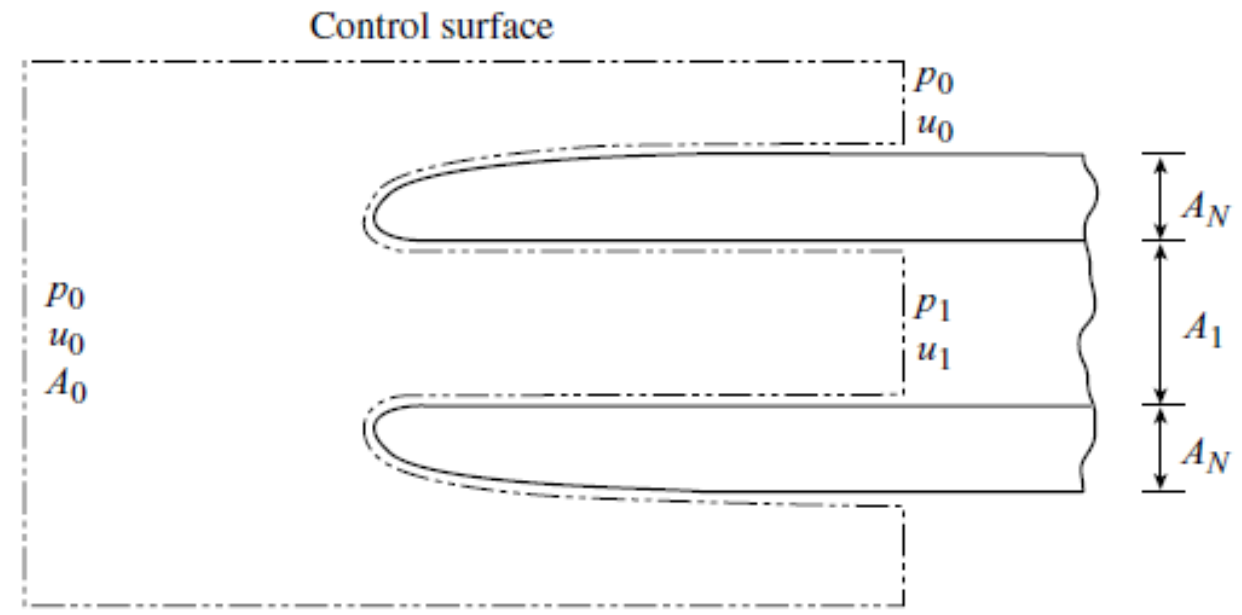

Figure 32: Inlet Diagram (29)

Equation 8-3 assumes that the rear of the inlet cross section is exposed to ambient pressure. According to equation 8-3 the thrust on an inlet is positive for all cases except when flow velocity inside and outside the inlet is equal. (29) Based on the study done on the Gulfstream IIB aircraft, density, molecular weight, and temperature effects do not play a major role in the physics of ejectors (AAR). With that knowledge incompressible parameters can be used to solve for the ideal secondary mass flow rates which are solely based on the area ratio of the secondary to primary flow fields, equation 8-4. (28)

$$
\left(\frac{\dot{m}_{s}}{\dot{m}_{p}}\right)^{2}\left[\left(\frac{A_{p}}{A_{s}}\right)^{2}+1\right]+4\left(\frac{\dot{m}_{s}}{\dot{m}_{p}}\right)-2\left(\frac{A_{s}}{A_{p}}\right)=0
$$

Once the ideal secondary mass flow rate is known the theoretical mixing duct thrust can be calculated using either equation 8-3 or 8-4. Equation 8-5 defines thrust augmentation as the ratio of thrust with a mixing duct compared to the same system without a mixing duct. (28)

$$
\emptyset=\frac{\left(\frac{\dot{m}_{s}}{\dot{m}_{p}}+1\right)^{2}}{\left(\frac{A_{s}}{A_{p}}+1\right)\left[1-\left(\frac{\dot{m}_{s}^{2}}{\dot{m}_{p}^{2}}\right)\left(\frac{A_{p}^{2}}{A_{s}^{2}}\right)\right]^{\frac{1}{2}}}
$$


Calculating mixing duct thrust in this fashion is highly idealized and only good for a sanity check of the experimental values. It also assumes that a straight wall mixing duct is used and complete mixing occurs before the exit of the duct. 


\section{Results}

The goal for this research has been to develop hot flow, axisymmetric, AAR test capability and examine differing mixing ducts at static conditions. By measuring the mixing duct forces separately from total thrust, the affects of differing mixing ducts can be examined; specifically, a diverging and straight mixing duct with the same length and initial inner diameter. Mixing duct forces were measured experimentally and then compared to theoretical mixing duct thrust presented in section 8.2. To increase the accuracy of the theoretical mixing duct calculations a fuel efficiency study was conducted. Fuel efficiency affects chamber conditions which are used in mixing duct calculations. It was expected that a diverging mixing duct would have greater thrust forces due to the larger amount of area exposed to the flow with a normal component in the axial direction. This expectation is also supported by the experimental tests carried out by the Marquardt Corporation in the 60s on their diverging duct RENE AAR where the total system thrust and Isp was augmented by 55\% with a diverging duct. (6) Over the course of SCAARD formal testing it was found that at static conditions without secondary fuel injection, a straight mixing duct produces greater thrust forces than a diverging mixing duct.

\subsection{Measured Mixing Duct Forces}

Mixing duct axial forces of both the diverging and straight mixing ducts were measured for all cases. Figure 33 summarizes the mixing duct axial forces. A positive number corresponds to the positive $\mathrm{Z}$ direction, the same direction as thrust force. 


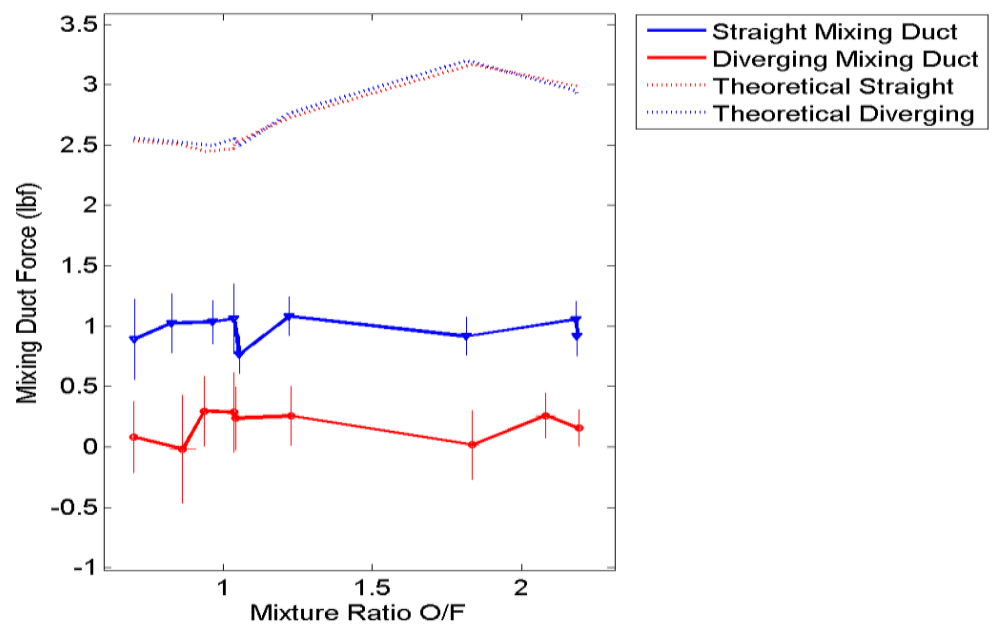

Figure 33: Mixing Duct Axial Force

Figure 33 indicates that the mixture ratio has very little affect on the mixing duct axial force. Calculation of the theoretical mixing duct thrust value was completed using equation 8-4, 8-5 and primary mass flow for each case. Theoretical mixing duct thrust is a function of primary mass flow rate and secondary to primary area ratio but does not account for differences in mixing duct geometry. Similarities between the straight and diverging mixing duct theoretical thrusts are also due to consistency in primary mass flow rates between configurations. Secondary area was reduced by the lip thickness area due to the theory requiring mass flow along the entire control volume surface. (28) The theoretical analysis increase in thrust as mixture ratio increases is due to the primary mass flow rate increases in those cases. A possible explanation for the larger theoretical thrust is the assumption that the flow is completely mixed at the exit of the mixing duct. Through visible flow comparison it is readily apparent that the primary and secondary flows are not completely mixed due to the small change in plume behavior and the visibility of shock diamonds in the lean case. Incomplete mixing of the primary and secondary flows would result in reduced entrainment which reduces the thrust augmentation (equation 8-5). In every case the diverging mixing duct experiences a greatly reduced thrust force when compared to the straight mixing duct. Experimental results carried out in this study do not show an increase in mixing duct thrust for the diverging case compared to the straight mixing duct or no mixing duct. On average the straight mixing duct produced $0.97 \mathrm{lbf}$ of thrust while the diverging mixing duct produced $0.18 \mathrm{lbf}$. Summaries of the thrust values for each case and configuration are 
shown in Table 10. All thrust values are directly measured by the experimental apparatus. Mass flow rates, mixture ratio, theoretical mixing duct thrust, and secondary flow velocity are all results of the chamber conditions solver. Table 10 demonstrates the consistency of primary mass flow rates between configurations for each case. Primary mass flow rates have an average error of $\pm 1.6 \%$ and an average standard deviation of $0.000341 \mathrm{bm} / \mathrm{s}$ between configurations. This consistency allows for the comparison of configurations within each case and demonstrates the repeatability of the SCAARD test apparatus. 


\begin{tabular}{|c|c|c|c|c|c|c|c|c|c|c|c|}
\hline \multicolumn{3}{|c|}{ Case Number and Conditions } & \multicolumn{3}{|c|}{ No Mixing Duct Total Thrust } & \multicolumn{3}{|c|}{ Straight Mixing Duct Total Thrust } & \multicolumn{3}{|c|}{ Diverging Mixing Duct Total Thrust } \\
\hline \# & $\begin{array}{l}\text { Regulated } \\
\text { Fuel } \\
\text { Pressure } \\
\text { (psig) }\end{array}$ & $\begin{array}{c}\text { Regulated } \\
\text { Oxygen } \\
\text { Pressure } \\
\text { (psig) }\end{array}$ & $\begin{array}{l}\text { Mixture } \\
\text { Ratio }\end{array}$ & $\begin{array}{l}\text { Measured } \\
\text { Thrust (lbf) }\end{array}$ & $\begin{array}{c}\text { Primary Mass } \\
\text { Flow Rate } \\
\text { (lbm/s) }\end{array}$ & $\begin{array}{c}\text { Mixture } \\
\text { Ratio }\end{array}$ & $\begin{array}{l}\text { Measured } \\
\text { Thrust (lbf) }\end{array}$ & $\begin{array}{c}\text { Primary Mass } \\
\text { Flow Rate } \\
\text { (lbm/s) }\end{array}$ & $\begin{array}{l}\text { Mixture } \\
\text { Ratio }\end{array}$ & $\begin{array}{l}\text { Measured } \\
\text { Thrust (lbf) }\end{array}$ & $\begin{array}{c}\text { Primary Mass } \\
\text { Flow Rate } \\
\text { (lbm/s) }\end{array}$ \\
\hline 1 & 390 & 350 & 0.71 & 14.45 & 0.0812 & 0.7 & 13.75 & 0.0814 & 0.7 & 13.63 & 0.0815 \\
\hline 2 & 380 & 350 & 0.82 & 14 & 0.0742 & 0.83 & 13.61 & 0.0746 & 0.86 & 13.45 & 0.076 \\
\hline 3 & 350 & 350 & 0.95 & 13.74 & 0.074 & 0.97 & 13.42 & 0.0735 & 0.94 & 13.15 & 0.0745 \\
\hline 4 & 340 & 350 & 1.03 & 13.98 & 0.0709 & 1.05 & 13.42 & 0.0701 & 1.04 & 13.29 & 0.0707 \\
\hline 5 & 370 & 350 & 1.04 & 14.41 & 0.071 & 1.04 & 13.74 & 0.0709 & 1.04 & 13.56 & 0.071 \\
\hline 6 & 350 & 370 & 1.21 & 15.41 & 0.0703 & 1.22 & 14.85 & 0.0705 & 1.23 & 14.7 & 0.0701 \\
\hline 7 & 380 & 430 & 1.82 & 17.92 & 0.0851 & 1.82 & 17.2 & 0.0854 & 1.84 & 17.04 & 0.0849 \\
\hline 8 & 350 & 430 & 2.13 & 16.61 & 0.082 & 2.18 & 15.54 & 0.0824 & 2.08 & 16.34 & 0.0816 \\
\hline 9 & 350 & 410 & 2.21 & 16.21 & 0.0811 & 2.19 & 15.66 & 0.0813 & 2.19 & 16.04 & 0.0814 \\
\hline
\end{tabular}

\begin{tabular}{|c|c|c|c|c|c|c|c|c|}
\hline \multirow[b]{2}{*}{$\#$} & \multicolumn{2}{|c|}{ Theoretical Mixing Duct Thrust (Ibf) } & \multirow{2}{*}{$\begin{array}{c}\text { Measured } \\
\text { Straight Mixing } \\
\text { Duct Thrust (lbf) }\end{array}$} & \multirow{2}{*}{$\begin{array}{c}\text { Measured } \\
\text { Diverging Mixing } \\
\text { Duct Thrust (lbf) }\end{array}$} & \multicolumn{2}{|c|}{$\begin{array}{l}\text { Ideal Secondary Mass } \\
\text { flow Rate (lbm/s) }\end{array}$} & \multicolumn{2}{|c|}{$\begin{array}{c}\text { Ideal Secondary Flow Velocity } \\
\text { at Minimum area (ft/s) }\end{array}$} \\
\hline & Straight & Diverging & & & Straight & Diverging & Straight & Diverging \\
\hline 1 & 2.56 & 2.53 & 0.89 & 0.081 & 0.069 & 0.069 & 445 & 445 \\
\hline 2 & 2.53 & 2.5 & 1.02 & -0.02 & 0.063 & 0.064 & 401 & 409 \\
\hline 3 & 2.49 & 2.44 & 1.03 & 0.3 & 0.062 & 0.063 & 401 & 407 \\
\hline 4 & 2.5 & 2.47 & 0.76 & 0.29 & 0.059 & 0.06 & 383 & 386 \\
\hline 5 & 2.55 & 2.52 & 1.06 & 0.24 & 0.06 & 0.06 & 383 & 383 \\
\hline 6 & 2.76 & 2.73 & 1.08 & 0.26 & 0.059 & 0.059 & 385 & 383 \\
\hline 7 & 3.2 & 3.17 & 0.92 & 0.02 & 0.072 & 0.072 & 466 & 464 \\
\hline 8 & 2.94 & 3.04 & 1.06 & 0.26 & 0.069 & 0.069 & 448 & 444 \\
\hline 9 & 2.91 & 2.98 & 0.916 & 0.155 & 0.068 & 0.068 & 440 & 441 \\
\hline
\end{tabular}


Examining the theory of mixing duct thrust provides some insight into why the diverging mixing duct produces less thrust than the straight duct. Thrust of a mixing duct is reacted through the pressure difference between the lip and the exit section 8.2. (29) Lower than ambient static pressure is also maintained on the inside wall of the mixing duct due to high velocity flow. Inner wall pressure makes no difference to the axial thrust in the straight duct because there is no axial component to that pressure force. In the diverging mixing duct there is an axial component to the low pressure on the inside wall, this results in a decreased axial thrust for the SCAARD case. Reduction in base area also plays a role in decreased diverging mixing duct thrust due to a reduction in pressure differential area. Figure 34 demonstrates the differences in general pressure distribution between a straight wall and diverging mixing duct for the SCAARD case. In the study conducted by the Marquardt Corporation, extra fuel was introduced into the secondary flow to utilize the oxidizer that is entrained for secondary combustion. The ambient velocity of the 55\% augmentation case was also unspecified. If secondary combustion occurred utilizing ram compression the static pressure of the mixing duct inner wall could be increased which would result in an increase in thrust for the diverging duct. This trend of increased thrust for higher flow velocities is supported in Figure 2 from the Foster Escher and Robinson research. (6)

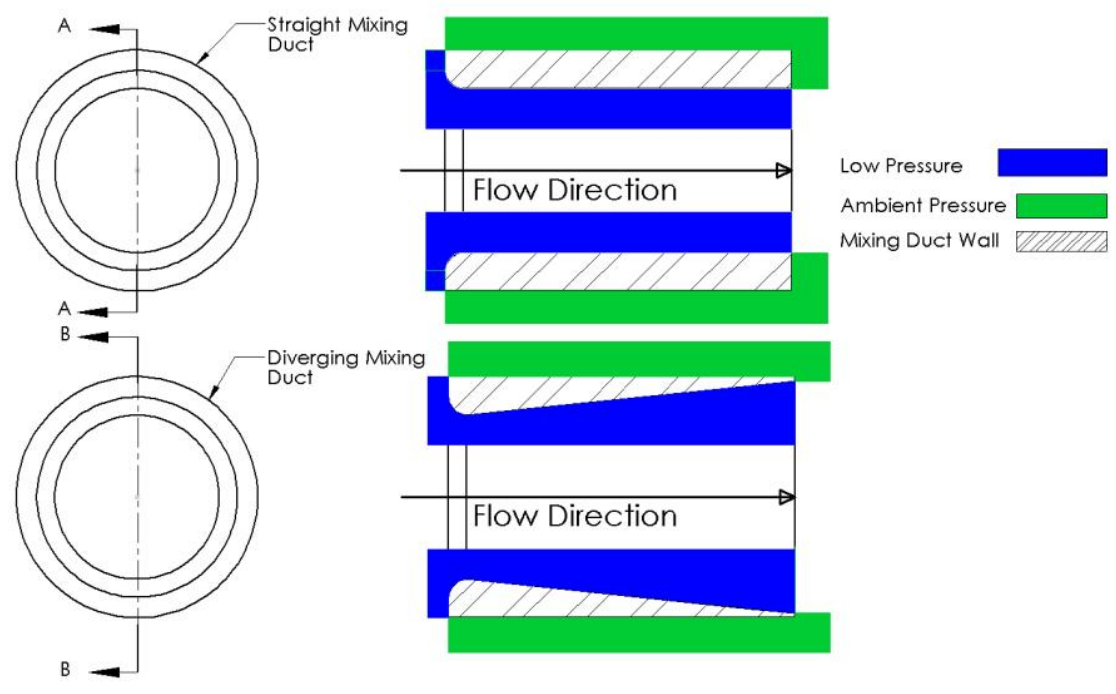

Figure 34: Mixing Duct Wall Pressure Explanation 


\subsection{Fuel Efficiency Study}

Theoretical mixing duct thrust, ideal secondary entrainment, and secondary flow velocity are functions of area ratio and primary mass flow rate. In order to obtain a more accurate primary mass flow rate the fuel efficiency factor of the iterative chamber condition solver must be addressed to avoid over or underestimation of chamber conditions. Propellant mass flow rates and chamber conditions were calculated using the iterative process described in section 7.4.2. Fuel efficiency is an integral part of the process and is effectively a user input. Fuel efficiency is the percentage of the total fuel in the reaction that can be used in a chemical reaction with the oxidizer. According to Sutton's Rocket Propulsion Elements a well designed combustion chamber and injection system can achieve combustion efficiencies anywhere from 94 to $99 \%$ indicating complete consumption of reactants. (3) However Sutton also postulates that small bipropellant thrust chambers with few injection elements like the SCAARD can have combustion efficiencies well below $95 \%$. Since chamber conditions are dependent on the combustion efficiency, or in the case of the SCAARD, fuel efficiency, an examination of the affects of fuel efficiency on chamber conditions is carried out. For this research the actual values for specific impulse and fuel ratio are not as important as the trends that develop with varying mixture ratios. Figure 35 shows SCAARD specific impulse as a function of mixture ratio for a variety of different fuel efficiency's to examine the affect of fuel efficiency on the total efficiency of the SCAARD. Figure 35 demonstrates very small changes in the trends of Isp through reasonable fuel efficiencies of $70-90 \%$. In the extreme low and high fuel efficiencies the Isp trends do change significantly. Fuel efficiency has a marked affect on the mixture ratio of a stoichiometric or lean run. As fuel efficiency decreases the mixture ratio and Isp decrease. In a fuel rich run the fuel efficiency has no impact on mixture ratio or Isp. 
a)

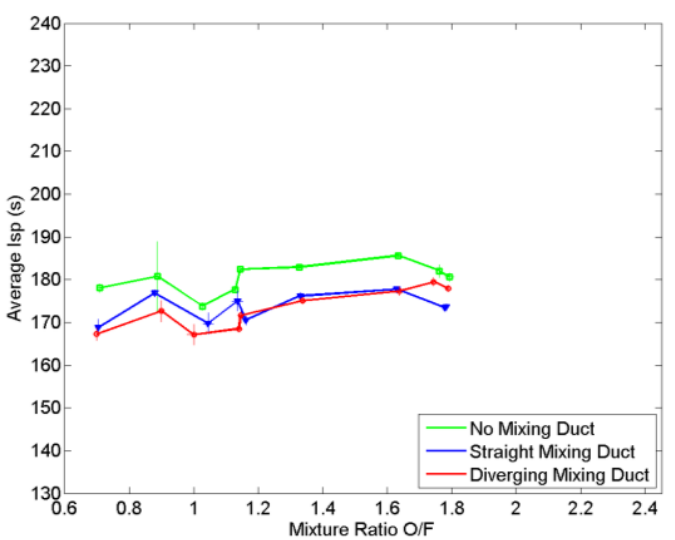

c)

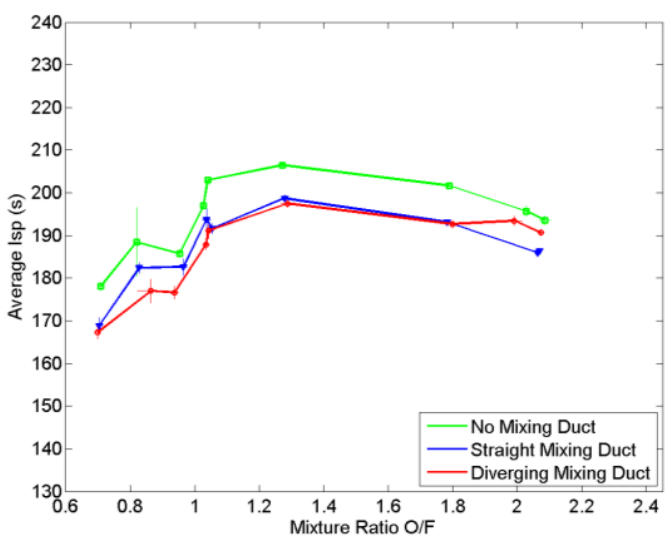

d)
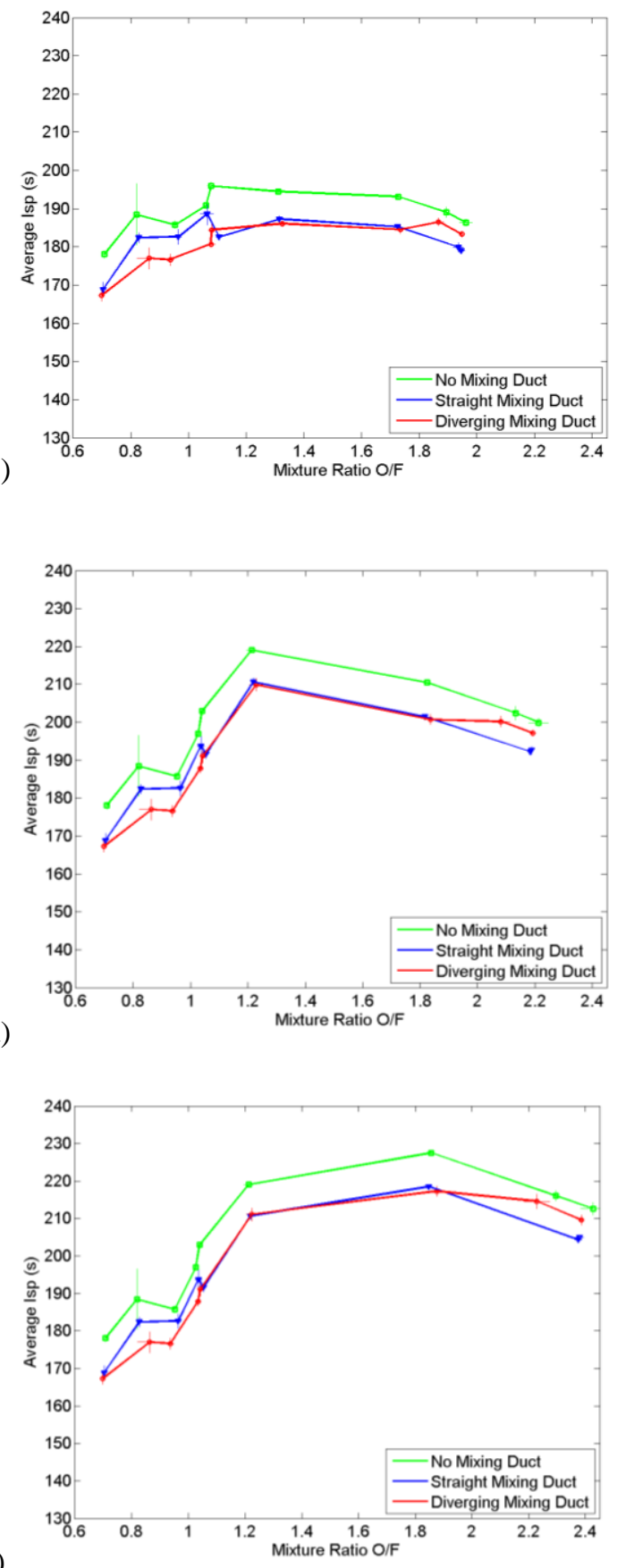

e)

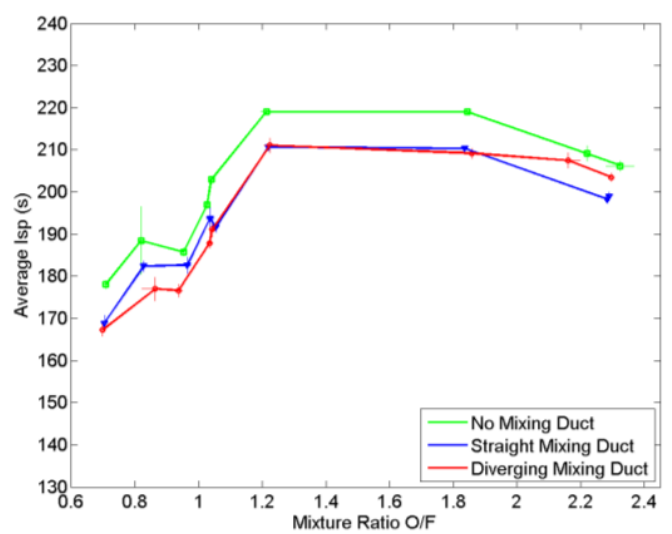

Figure 35: Variations in Fuel efficiency: a) $50 \%$ b) $60 \%$ c) $70 \%$ d) $80 \%$ e) $90 \%$ f) $100 \%$

This lack of change in the rich cases is due to an excess of fuel in the system. Therefore, adjusting the amount of fuel available for combustion does nothing to change the mixture ratio since all of the oxygen is already consumed. In a rich case, the chamber conditions are only affected when the fuel efficiency 
becomes low enough that there is stoichiometrically more oxidizer than available fuel. At this point of low fuel efficiency, the chamber pressure and temperature adjust to compensate for the decrease in enthalpy change from combustion. Decreased pressure and temperature changes the fuel flow rate, changing the mixture ratio and Isp. While the Isp values and mixture ratios change with fuel efficiency the position of each case relative to the other does not change until fuel efficiency is below $70 \%$. Though the SCAARD chamber may not be capable of efficiency in the $90 \%$ range, it is highly unlikely that the SCAARD with a characteristic chamber length of 80in would have an efficiency factor of less than $70 \%$. In order to better quantify the changes in chamber characteristics with fuel efficiency, three cases of fuel lean, mid range, and fuel rich mixture ratios are examined over a wide range of fuel efficiencies. Chamber temperature and pressure changes for said cases are shown in Figure 36.
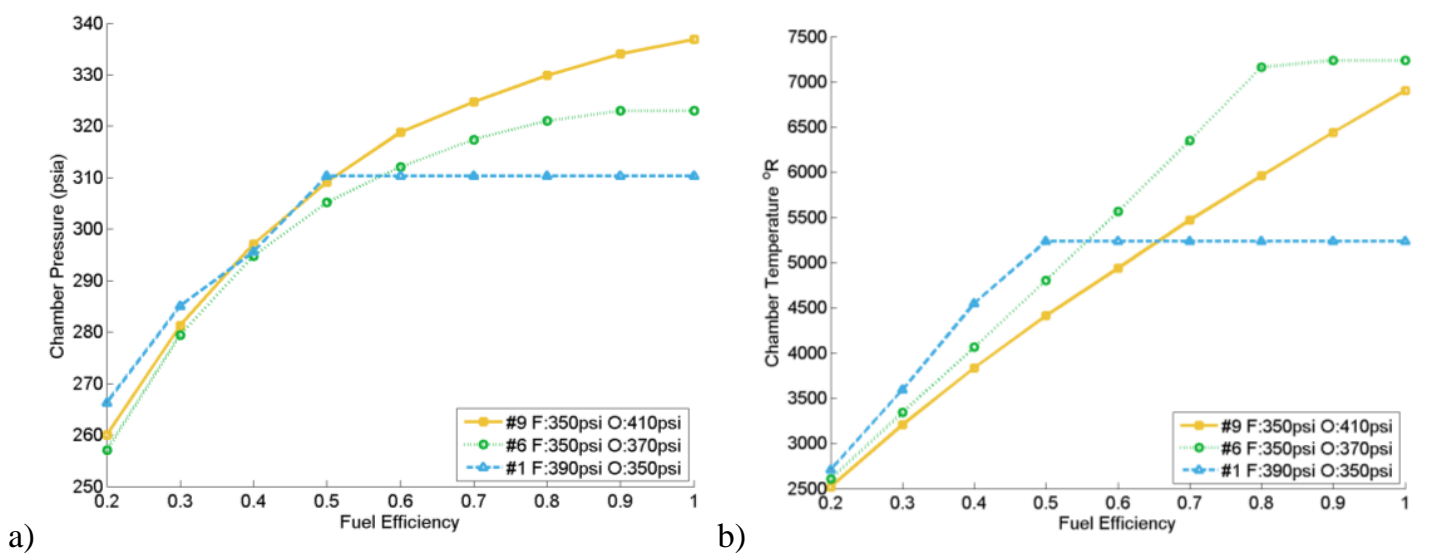

Figure 36: Effect of Fuel Efficiency on a) Chamber Pressure b) Chamber Temperature

Again the relative position of each case to the other cases does not change until fuel efficiency drops below $70 \%$. Comparing the chamber pressures and temperatures to the values provided by Kryzicki in Table 4 demonstrates that the calculated temperature is higher than Kryzicki's when the fuel efficiency is above $70 \%$. Higher pressures and temperatures are a result of increased mass flow rate relative to the size of the chamber. More propellant mass in a confined space results in higher pressures and temperatures. Another explanation for the higher temperatures could be the slope of the extrapolated methanol enthalpy line discussed in section 7.4.2. Chamber temperature is calculated by finding the temperature at which the enthalpy change of the products equals the enthalpy released by the reactants. If the enthalpy change for 
methanol is actually higher than predicted for a given temperature the resulting chamber temperature would be lower. This in turn would reduce the chamber pressure. Further manipulation of the enthalpy data would constitute pure guess work and, as shown, the trends in Isp and chamber conditions wouldn't change other than to be a slightly lower value. Changes in mixture ratio as a function of fuel efficiency for the lean, mid, and rich cases of Figure 36 are shown in Figure 37.

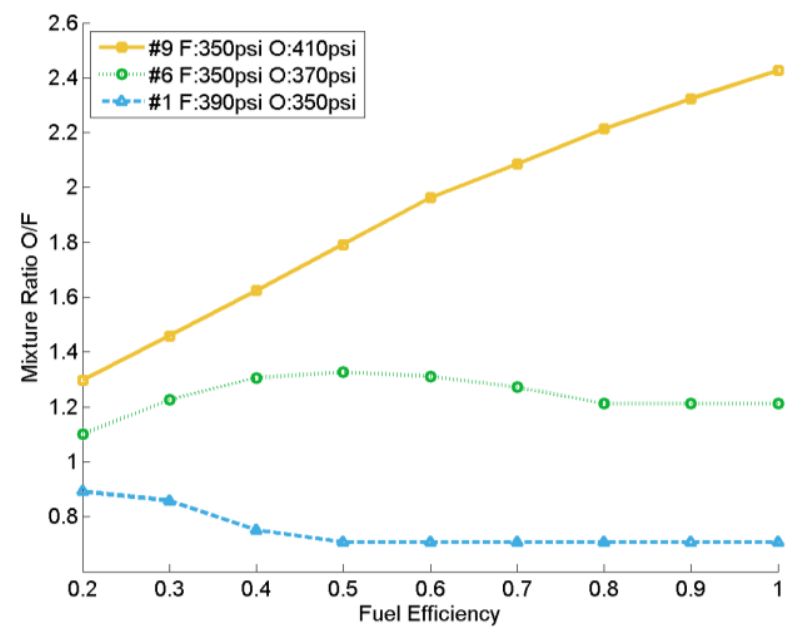

Figure 37: Effect of Fuel Efficiencv on Mixture Ratio

Ideal exhaust velocity is calculated using the chamber temperature, pressure, and mass flow rates in equation 8-2. Figure 38 demonstrates the calculated exhaust velocity variation with fuel efficiency. 


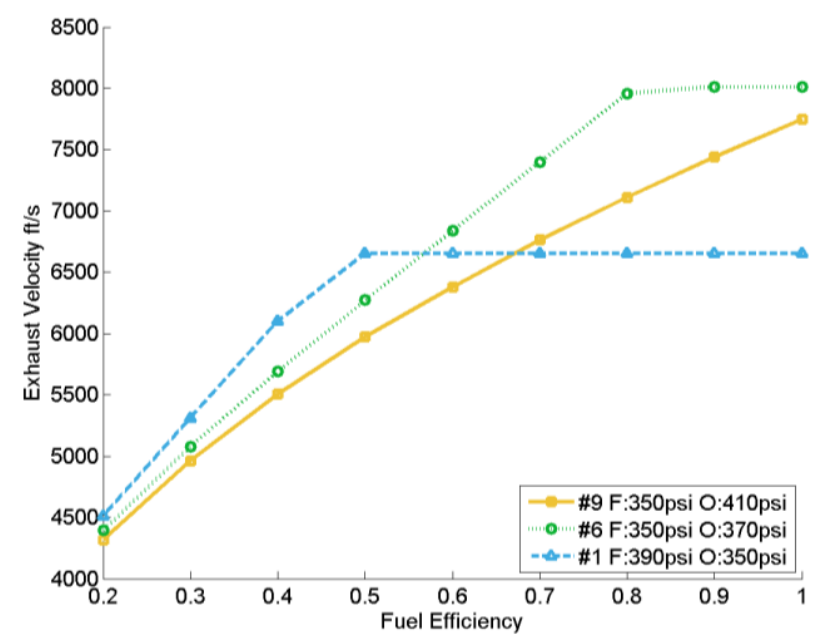

Figure 38: Ideal Exhaust Velocity Variation with Fuel Efficiency

Theoretical thrust uses the ideal exhaust velocity and primary mass flow rate in equation 8-1. Comparing the theoretical ideal thrust to the experimentally measured values produces the trends seen in Figure 39 . Experimental thrust does not change with fuel efficiency.

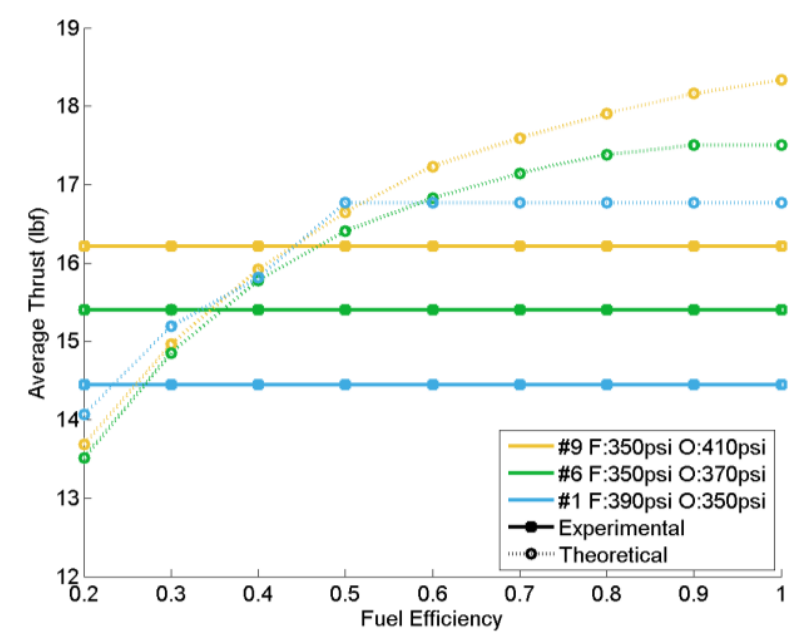

\section{Figure 39: Experimental and Ideal Thrust}

It is important to note that the theoretical thrust is ideal and does not account for any losses in expanding and accelerating the exhaust gases. Therefore, an overestimation of thrust is to be expected. The final parameter to compare with changing fuel efficiency is the specific impulse of the system. Thrust is measured experimentally with propellant flow rates calculated in the iterative combustion code. These 
values constitute experimental Isp. Theoretical Isp takes calculated chamber conditions and ideal thrust of said chamber conditions to calculate Isp. Isp values using measured thrust and ideal thrust are compared in Figure 40.

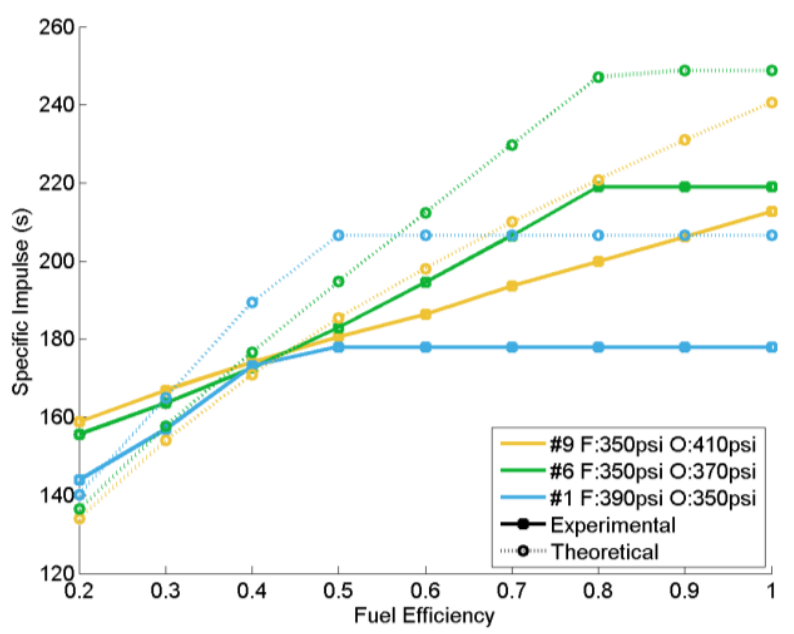

\section{Figure 40: Effect of Fuel Efficiency on Specific Impulse}

A "knee" is a point at which any value in Figure 36-Figure 40 deviates from its steady values. An example of this is the experimental specific impulse of the mid case at fuel efficiency factor of $80 \%$. A knee is formed when the limiting factor in combustion chemistry is changed. The horizontal section corresponds to a surplus of fuel in equation 7-8, while the sloped sections correspond to an oxidizer surplus. This does not indicate a lack of total fuel at a low fuel efficiency factor. It simply means there is not enough fuel available for combustion. Surplus fuel is not reacted with the available oxidizer and effectively cools the combustion chamber as well as lowering the chamber pressure. Future plots or tables in this research that do not explicitly state a fuel efficiency value will use a fuel efficiency factor of $80 \%$. This number is based on there being no variation in the relative position of the calculated data compared to $100 \%$. It is also the knee location of the mid fuel ratio case indicating a stoichiometrically balanced point. 


\subsection{Visible Flow Comparison}

A grid reference was used in the background of video recordings to compare exhaust plume shapes and sizes between configurations. Differences in exhaust plume shapes indicate the influence of mixing ducts on the primary flow field. Enhanced mixing of the primary and secondary flow streams results in a shorter exhaust plume and a shorter mixing duct required for complete mixing. (28) Figure 41 shows a fuel rich case for all three mixing duct configurations. Fuel rich and lean cases used in the visible flow comparisons correspond to the rich and lean cases used in the fuel efficiency study.
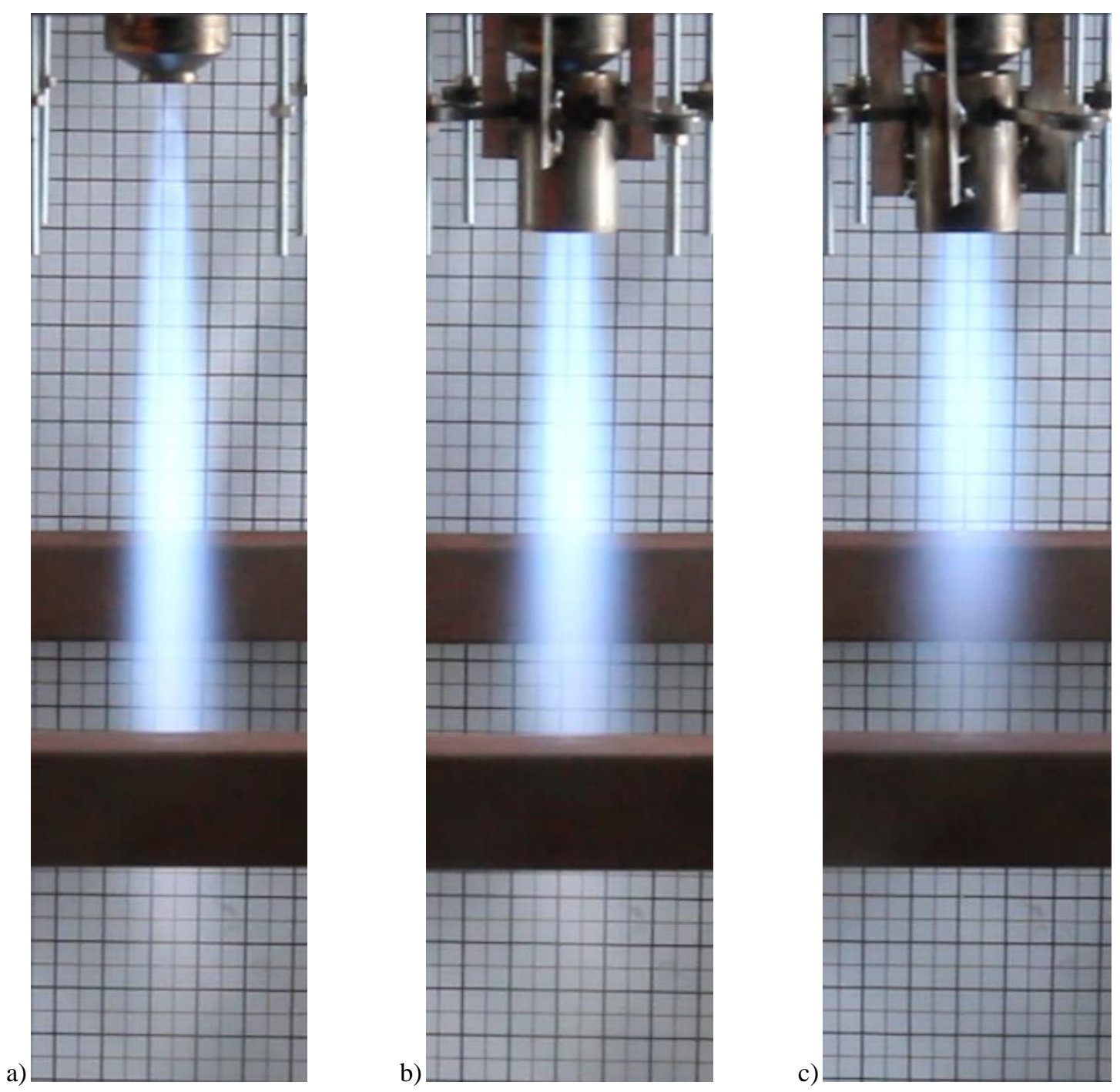

Figure 41: Rich Exhaust Visualization a) No Mixing Duct b) Straight Mixing Duct c) Diverging Mixing Duct 
The grid reference is located approximately 12 " behind the rocket exhaust, dark squares are 1" on a side while the lighter squares are $0.5 "$. Due to the distance between the reference and the exhaust plane as well as the distance between the exhaust and the video recording, the 1" reference square does not correspond to exactly $1 "$ at the exhaust plane. Even though the reference grid is not true to dimension the important factors are the changes between exhaust plumes. Because the grid, video recording, and exhaust plane remain the same through all configurations the grid is a valid reference for comparison between configurations. If true length values are required, the mixing duct diameter is known to be 2 " which can serve as a true length reference. Fuel rich exhaust is much more visible than that of a fuel lean case. However, it has been shown that a fuel rich case has the lowest chamber pressures and temperatures resulting in the lowest exhaust velocity based on mixture ratio. Straight mixing duct exhaust is approximately $94 \%$ the length of the no mixing duct case and $25 \%$ wider at the widest point. Diverging mixing duct exhaust is approximately $70 \%$ the length of the no mixing duct case and $50 \%$ wider at the widest point. Significant visible differences between the diverging mixing duct and the straight mixing duct case indicate that the diverging mixing duct has a larger affect on the primary and secondary flow field mixing. Figure 42 demonstrates the same configurations as Figure 41 for the fuel lean case. 

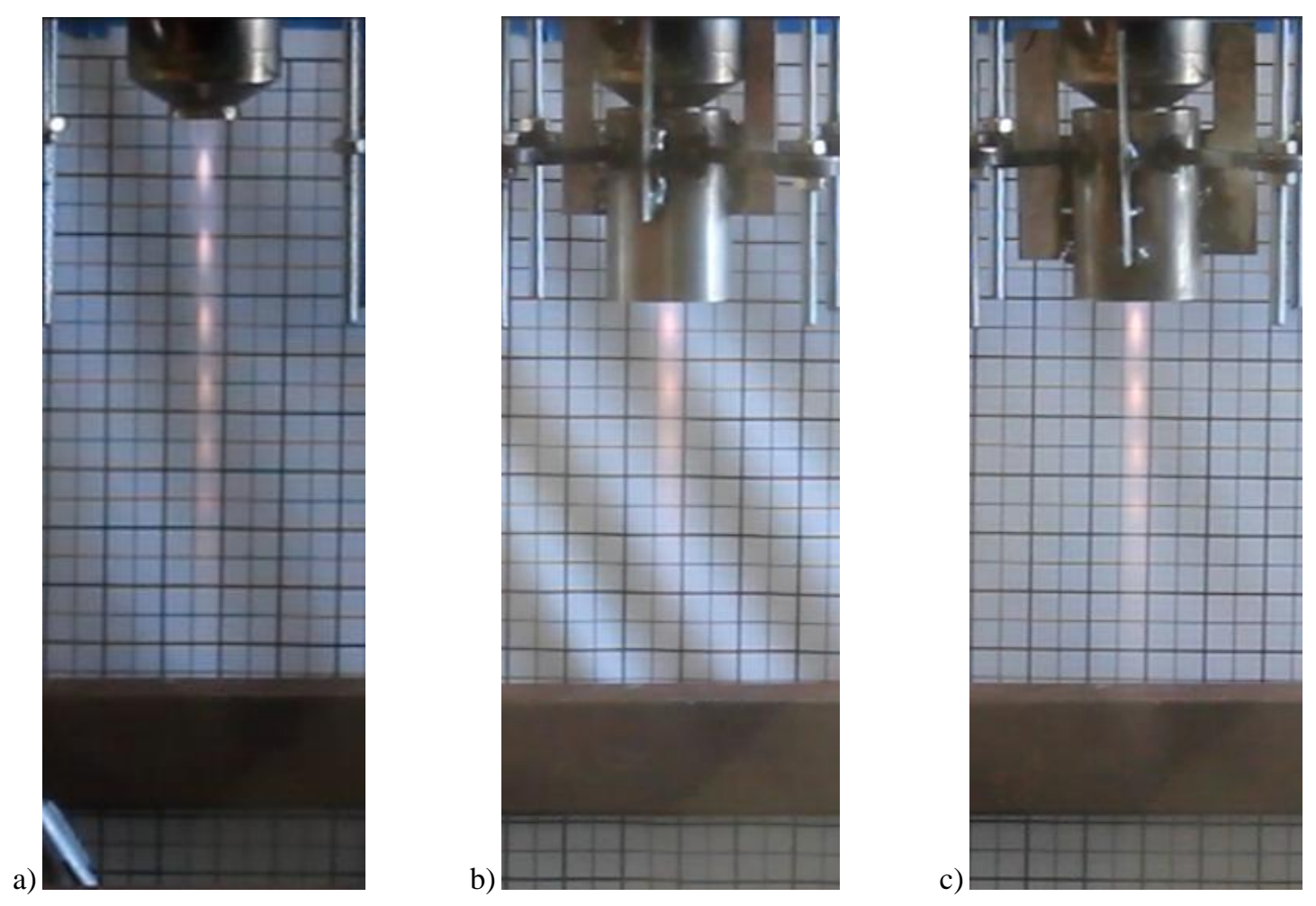

Figure 42: Lean Exhaust Visualization a) No Mixing Duct b) Straight Mixing Duct c) Diverging Mixing Duct

Examining Figure 42 the exhaust plume is drastically different from that of Figure 41 due to the change in mixture ratio. Exhaust velocity, average thrust, and Isp are all much higher in the lean case than the fuel rich case. Six shock diamonds are visible in the no mixing duct exhaust of the lean case and the visible exhaust length is approximately $37 \%$ the length of the fuel rich with case no mixing duct. Straight mixing duct exhaust of the fuel lean case is $89 \%$ of the no mixing duct configuration following the same trend as the fuel rich case. Due to the reduced visibility and narrowness of the exhaust it is difficult to discern a difference in plume width between the configurations. Contrary to the fuel rich case the diverging mixing duct configuration actually shows an increase in visible exhaust length of $14 \%$ compared to the no mixing duct configuration. The longer visible exhaust of the diverging mixing duct indicates a shift in the diverging mixing ducts influence on the primary flow field at lean mixture ratios. This trend is also reflected in the data presented in the section 9.4. 


\subsection{Combined Effects}

Even though the mixing ducts contributed a positive thrust the total thrust of the system decreased when a mixing duct was introduced (see Figure 43). Over all of the cases the straight mixing duct was on average $0.62 \mathrm{lbf}$ less than the no mixing duct case while the diverging mixing duct was $0.74 \mathrm{lbf}$ less. With positive mixing duct thrust a loss of total thrust must be occurring at some other point in the system to account for thrust decreases in the mixing duct configurations.

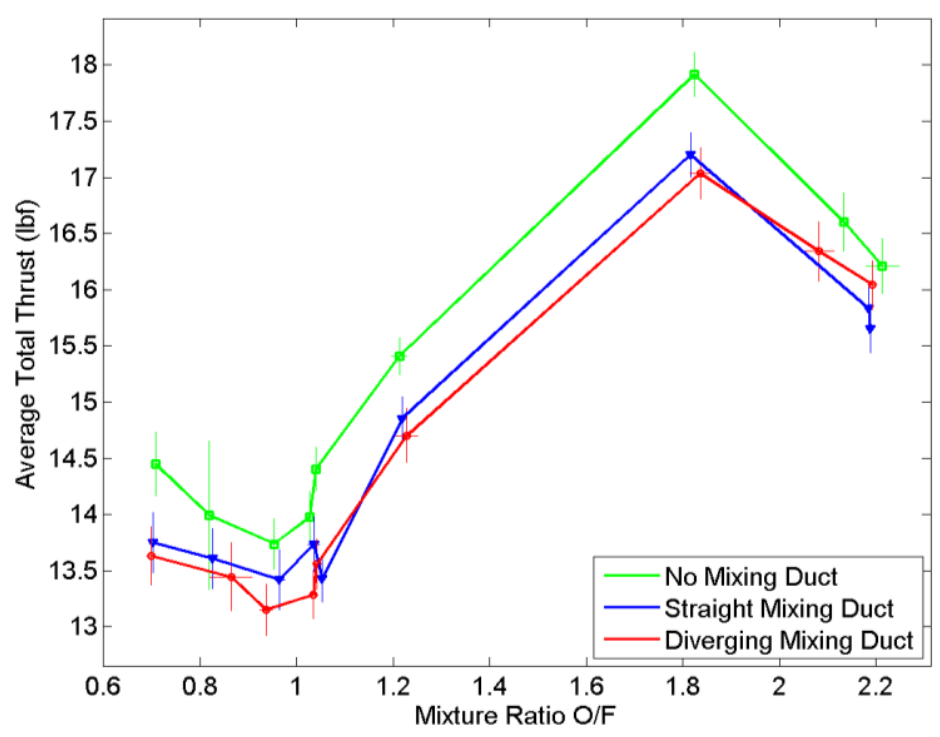

Figure 43: Total Average Thrust

A shift between the straight mixing duct and diverging mixing duct occurs at the two leanest mixture ratios compared to the rest of the data. It is hypothesized that the diverging mixing duct at these extreme lean mixture ratios decreases secondary flow entrainment resulting in a lower secondary mass flow rate and velocity. This hypothesis coincides with the visible observations of the extreme lean cases diverging mixing duct configurations. Lower velocity secondary flow reduces the static pressure drop along the wall and lip of the mixing duct. As previously shown this would decrease the already small thrust force seen by the diverging mixing duct which correlates with Figure 33. Lower static pressure drop along the lip will also decrease the total loss of thrust seen by the system as will be demonstrated. 
Due to the physical constraints of the SCAARD apparatus static pressure measurement at all points of interest is not possible. Dr. Westphal of Cal Poly's Mechanical Engineering department suggested that it is unfeasible to record the mixing duct static press with high enough resolution to experimentally integrate the pressure forces acting on the mixing duct lip as shown in section 8.2. Therefore the explanation postulated in this research is based on observing the experimental thrust data gathered and comparing it to the theory presented in section 8.2. Examining the physical setup of the SCAARD mixing duct and cooling jacket provides insight into the loss of total thrust with mixing duct implementation. Figure 43 shows the mixing duct and cooling jacket together in a cutaway view.

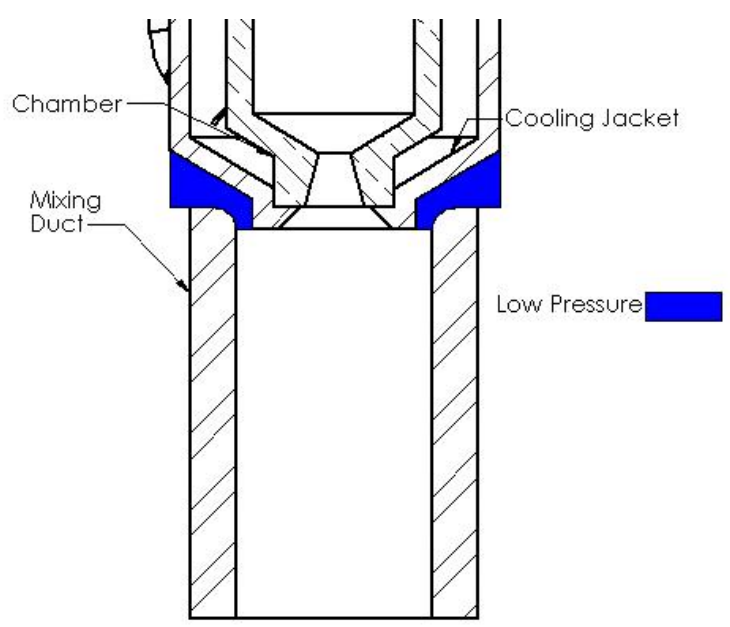

Figure 44: Low Pressure Acting on Assembly

Due to the small nature of the SCAARD, the chamber and cooling jacket diameter is much larger than the exit diameter of the nozzle. When coupled with a small diameter mixing duct the proximity of the mixing duct to the cooling jacket becomes an issue. Low pressure along the lip of the mixing duct creates the positive force seen by the mixing duct; however that same low pressure acts along the cooling jacket face as well. For example using the calculated secondary flow velocities shown in Table 10 and the Bernoulli effect the average static pressure of the secondary flow at the primary exit plane is 13.3 psi. Static wall pressure varies from ambient to $13.3 \mathrm{psi}$ along the mixing duct lip and cooling jacket face. This creates a low pressure region with a net force vector in the negative thrust direction. Since the cooling jacket has a larger surface area affected by the low pressure the total thrust of the system is decreased. This also explains the diverging mixing duct system generally producing the lowest thrust. Both the straight and diverging mixing ducts have the same inlet geometry, dimensions, and proximity to the cooling jacket. 
However, due to the diverging mixing ducts smaller amount of positive thrust, the total thrust of the diverging mixing duct configuration is generally lower. The exceptions to the diverging duct producing less thrust than the straight duct are the two extreme lean cases as previously discussed. Again the reduced pressure drop on the diverging duct lip of the extreme lean cases would result in a smaller pressure drop on the cooling jacket resulting in a decreased thrust loss for those two cases. Interaction of the mixing duct and cooling jacket should be examined in future work to determine quantitatively the mixing duct area ratio where this interaction no longer reduces total thrust.

\subsection{SCAARD Status}

Over the course of Phase I and II testing over 230 hot fire tests were conducted on the SCAARD chamber and cooling jacket. Periodically throughout testing the SCAARD chamber was disassembled and examined for signs of thermal degradation in the forms of melting or throat erosion. Figure 45 shows the inside of the SMORE chamber and nozzle at the conclusion of testing.

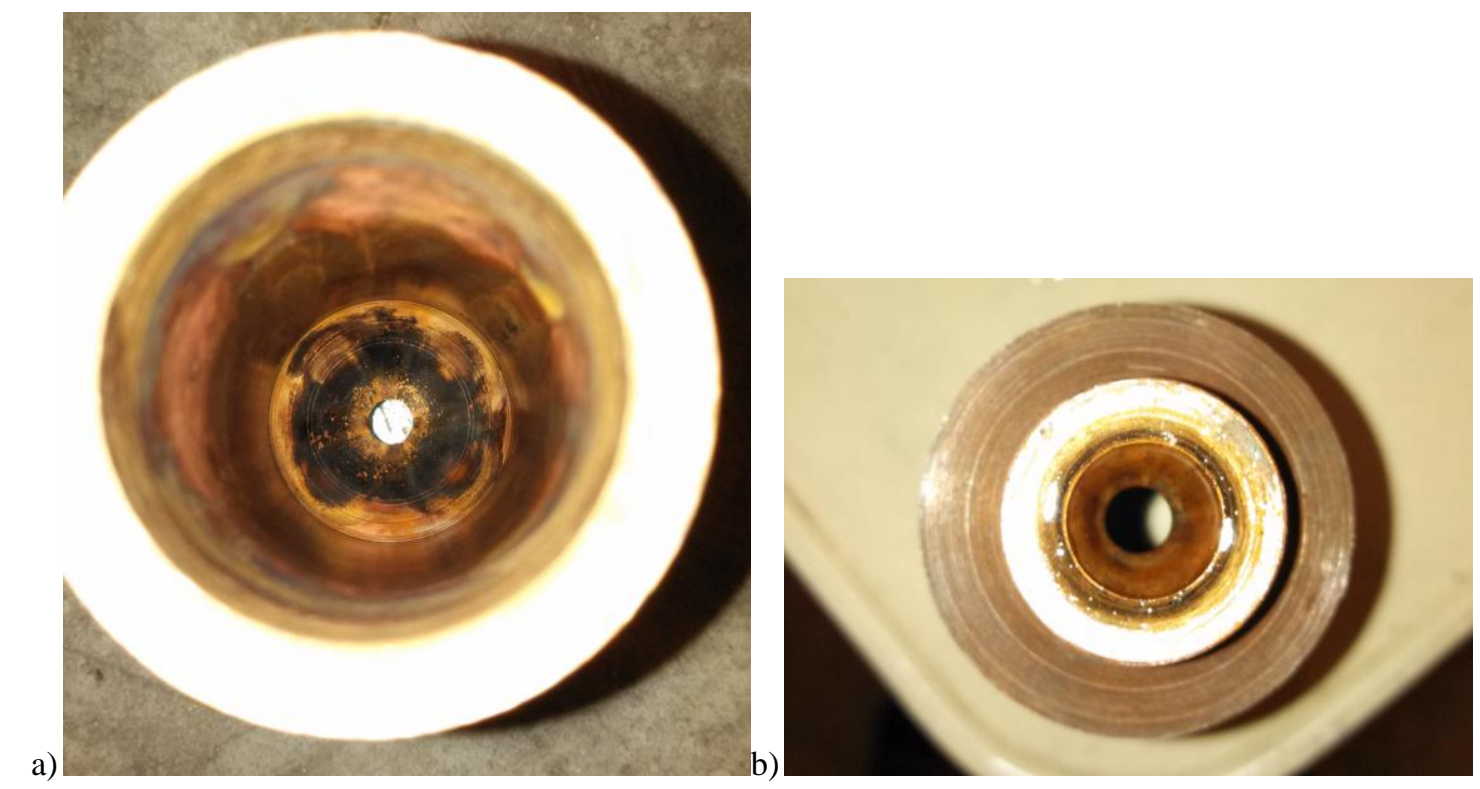

Figure 45: SCAARD Chamber: a) Combustion Chamber b) Nozzle

The SCAARD throat shows no signs of thermal erosion or asymmetry to indicate heat flux in excess of the coolant capacity. 


\section{Conclusion}

Throughout this research the goal has been to develop a hot flow, axisymmetric, static condition AAR test apparatus capable of steady state AAR testing with separate mixing duct and total thrust measurements. The SCAARD apparatus successfully operates a bipropellant rocket with independent total and mixing duct thrust measurement and propellant mass flow rate measurement.

Average positive mixing duct thrust of $0.97 \pm 0.18 \mathrm{lbf}$ was produced by the straight mixing duct while the diverging mixing duct produced an average of $0.18 \pm 0.23 \mathrm{lbf}$ of thrust. Based the RENE AAR testing performed by the Marquardt Corporation it was expected that the diverging mixing duct would produce more thrust than the straight duct.

Experimental results showed that at static conditions with small area ratio mixing ducts, a straight duct provides an average of $6.6 \%$ of the total thrust and the diverging duct provides an average of $1.2 \%$ of total thrust. However, total thrust and Isp of the system was reduced with the addition of the mixing ducts due to low pressure flow interaction with the cooling jacket.

Though the straight mixing duct provided $0.791 \mathrm{bf}$ greater thrust than the diverging duct, visual flow examination of the mixing duct exhaust showed that the diverging duct had a greater influence on the mixing of the primary and secondary flow fields. In a rich mixture ratio the diverging duct decreased visible exhaust length by $30 \%$ while in extreme lean mixture ratios the visible exhaust increased by $14 \%$ in comparison to the no mixing duct configuration. By contrast the straight duct had less than an $11 \%$ influence on the visible exhaust length in both cases.

Using pressure data from the propellant lines with known flow characteristics of the oxidizer sonic nozzle and fuel injector nozzle, as well as chamber physical characteristics, an iterative process was developed to solve for chamber conditions. The chamber condition process combined chemical composition, enthalpy

changes, and flow rates to solve for chamber pressure, chamber temperature, fuel and oxidizer mass flow rate, and molecular weight of combustion products.

A fuel efficiency study showed no change in relative chamber characteristics over fuel efficiencies of 70$90 \%$. A fuel efficiency of $80 \%$ was used in all chamber condition values and mass flow rate calculations. 
Interaction of the entrained secondary flow with the surrounding apparatus must be taken into account when designing an AAR. Proximity of the mixing duct and cooling jacket decreased the total thrust of the system by an average of $0.62 \mathrm{lbf}$ with the straight duct and $0.74 \mathrm{lbf}$ with the diverging duct. Primary nozzle lip thickness must also be taken into account when calculating the area ratio of secondary to primary flow area. Increases in lip thickness enhance flow field mixing and reduce secondary entrainment. (7)

SCAARD is an easily configurable AAR test apparatus capable of repeatable test conditions, various mixing duct configurations, and independent mixing duct thrust measurement. The tools developed in this research, specifically the chamber conditions solver enhance the accuracy of chamber conditions and mass flow rate values for non stoichiometric operations. This in turn provides better estimations of theoretical mixing duct thrusts. 


\section{Future Work}

SCAARD provides an easily modified test bed for future static AAR research. Further mixing duct studies should be conducted to examine the affect of mixing duct area on the negative interaction with the cooling jacket. Enhanced mixing studies can be undertaken by examining how axisymmeric mixing ducts of non circular cross sections influence the primary and secondary mixing. It is suggested that a thin mixing duct be constructed and tested to examine the role that mixing duct base area plays on mixing duct thrust.

Vibration reduction of the test stand should be undertaken to reduce the variation in steady state thrust data. Automation of the firing sequence via LabView could provide more consistent ignition and reduce the number of misfires due to incorrect user timing of the activation switches. Improved fuel and oxidizer pressure regulators could provide more consistent propellant pressures through multiple firings. 


\section{Bibliography}

1. Anatoly Zak R-7 ICBM. Russian Space Web. [Online] September 21, 2012. [Cited: November 4, 2012.] http://www.russianspaceweb.com/r7.html.

2.David Hitt Rocketry. NASA. [Online] NASA, September 17, 2010.

http://www.nasa.gov/audience/foreducators/rocketry/home/what-was-the-saturn-v-58.html.

3. George P. Sutton and Oscar Biblarz Rocket Propulsion Elements. New York: John Wiley \& Sons, INC, 2001. 0-471-32642-9.

4. Pratt \& Whitney Rocketdyne. Power Propulsion Optimization. [Online] Pratt \& Whitney Rocketdyne, 2010.http://www.pw.utc.com/Content/Space_Shuttle_Main_Engine/pdf/B-4-4-

1_pwr_propulsion_product_brochure.pdf.

5. Nathan Meier Civil Turbojet/Turbofan Specifications. jet-engine.net. [Online] April 03, 2005. http://www.jet-engine.net/civtfspec.html.

6. R. W. Foster, Escher, W. J. D. and J. W. Robinson Air Augmented Rocket Propulsion Concepts. Madison, WI: Astronautics Corporations of America Technology Center, 1988. F04622-86-C0094.

7. Trevor Montre Experimental Investigation of a 2-D Air Augmented Rocket: Effects of Nozzle Lip Thickness on Rocket Mixing and Entrainment. Aerospace Engineering, California Polytechnic State University. San Luis Obispo, CA: California Polytechnic State University, 2011. Master's Thesis.

8. Andrew Munoz Design of A Rocket-Based Combined Cycle Engine. Aerospace Engineering, San Jose State University. San Jose, CA: San Jose State University, 2011. Master's Thesis.

9. U.S. Air Force. X-51A Waverider. [Online] U.S. Air Force, March 23, 2011. http://www.af.mil/information/factsheets/factsheet.asp?fsID=17986.

10. Marty Curry NASA "Hyper-X" Program Demonstrates Scramjet Technologies. Dryden Flight Research Center. [Online] NASA, December 15, 2009. http://www.nasa.gov/centers/dryden/news/FactSheets/FS-040-DFRC.html.

11. Timothy D. Smith, Christopher J. Steffen Jr., Shaye Yungster, Dennis J. Keller, Performance of an Axisymmetric Rocket Based Combined Cycle Engine During Rocket Only Operation Using Linear Regression Analysis. National Aeronautics and Space Administration Lewis Research Center. 1998. NASA Technical Paper. NASA/TM-1998-206632.

12. William J. D. Escher and Bruce J. Flornes, A Study of Composite Propulsion Systems for Advance Launch Vehicle Applications. Van Nuys, California: The Marquardt Corporation, 1966. 25194.

13. Trevor Foster, Rectangular Ducted Methane/GOX Thruster. Aerspace Engineering, California Polytechnic University. San Luis Obispo: s.n., 2008. Master's Thesis.

14. D. Ryan Gist, Examination of Flow Field Charactersitics and Fabri-Choking of a 2D Air Augmented Rocket. Aerospace Engineering, California Polytechnic State University. San Luis Obispo, CA: Cal Poly, 2007. Master's Thesis.

15. Josef Salvador Sanchez, Experimental Investigation of A 2-D Air Augmented Rocket: High Pressure Ratio and Transient Flow-Fields. Aerspace Engineering, California Polytechnic State University. San Luis Obispo, CA: Cal Poly, 2012. Master's Thesis. 
16. Leroy J Krzycki, How to Design, Build and Test Small Liquid-Fuel Rocket Engines. Florence, OR: ROCKETLAB, 1967. 9600-1980-4.

17. Chaz N. Morantz, Josef S Sanchez, Design, Construction, and Testing of a Small Static Methanol/Oxygen Rocket Engine (S.M.O.R.E.). Aerospace Engineering, California Polytechnic State University. San Luis Obispo: s.n., 2009. Senior Project.

18. Kyle Johnson, Phase 3: Lab Implementation of a Static Methanol/Oxygen Rocket Engine (SMORE). Aerospace Engineering, California Polytechnic State University. San Luis Obispo: s.n., 2012. Senior Project.

19. Flow Systems Inc. Flow Calculations. Critical Flow Primer. [Online] http://www.flowsystmesinc.com.

20. Omega Engineering. omega.com. [Online] http://www.omega.com/.

21. Richard C. Flagan and John H Seinfeld, Fundamentals of Air Pollution Engineering. Englewood Cliffs: Prentice Hall, 1988.

22. Engineering ToolBox. Metals-Melting Temperature. The Engineering Toolbox. [Online] http://www.engineeringtoolbox.com/melting-temperature-metals-d_860.html.

23. Christian Soria, SMORE Phase 2: An Upgrade in Valve Systems \& Startup Procedure for a Small Methanol Oxygen Liquid Rocket Engine. Aerospace Engineering, California Polytechnic State University. San Luis Obispo: s.n., 2010. Senior Project.

24. The evaluation of critical pressure ratios of sonic nozzles at low Reynolds numbers. Park, K.A., et al. 1, Daejon, South Korea: s.n., 2001, Flow Measurement and Instrumentation, Vol. 12, pp. 37-41.

25. Gordon C Oates, Aerothermodynamics of Gas Turbine and Rocket Propulsion. Reston, VA: American Institute of Aeronautics and Astronautics, Inc., 1997. 1-56347-241-4.

26. National Institute of Standards and Technology. NIST-JANAF Tehrmochemical Tables. National Institute of Standards and Technology. [Online] 2000. http://kinetics.nist.gov/janaf/.

27. W. M. Haynes, Handbook of Chemistry and Physics 93rd Edition. Boca Raton, FL: Taylor \& Francis Group, LLC, 2012. 978-1-4398-8049-4.

28. Walter M. Presz Jr. and Michael Werle, Multi-Stage Mixer/Ejector Systems. Reston, VA: AIAA, 2002. 38th AIAA/ASME/SAE/ASEE Joint Propulsion Conference \& Exhibit. AIAA 2002-4064.

29. Edward M. Greitzer, Choon Sooi Tan and Martin B Graf, Internal Flow Concepts and Applications. New York: Cambridge University Press, 2004. 0-521-34393-3. 


\section{Appendix A: SCAARD Firing Procedures \\ Bipropellant Rocket Activity Procedure}

\section{PROCEDURE DETAILS:}

This procedure is formatted as a checklist; please print out a hardcopy and use it as such. During the lab activity, please make a hand-written note any deviations from the nominal procedure on that hardcopy.

\section{PROCEDURE CONVENTIONS:}

Buttons, switches, and other controls manipulated by an operator are highlighted in bold italicized

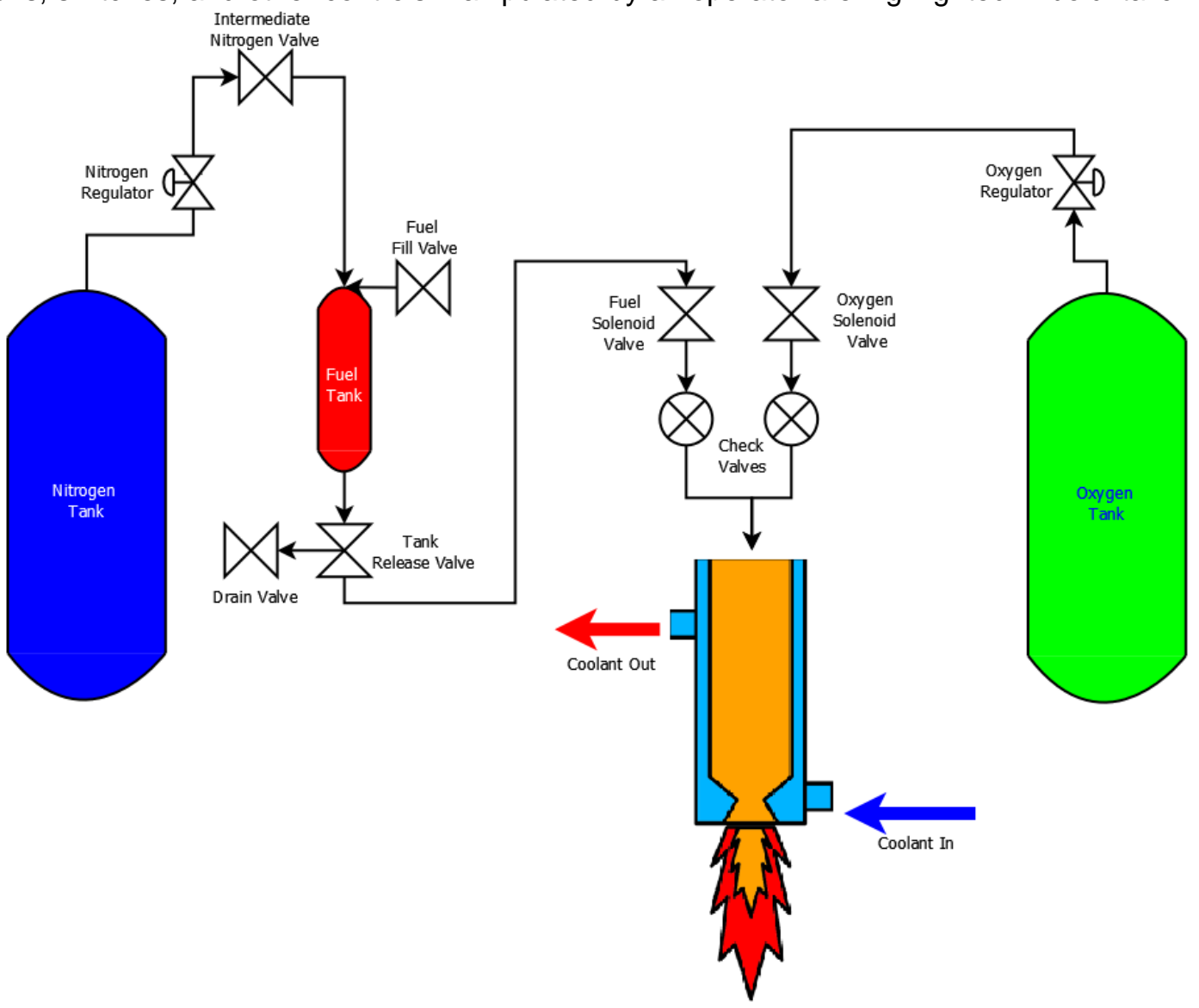

font, e.g. Fuel Boost Pump switch.

Readouts or other information displays are highlighted in italicized font, e.g. Elapsed Run Time value. 


\section{A. TEST CELL PREPARATION}

A.1. Fully open both test cell "roll-up" doors and lock in place with chains.

A.2. Clear test cell area of any loose objects near the rocket test stand (anything that may be kicked up by the rocket).

A.3. Check the test cell area for fuel spills or leaks; clean up any spills or leaks.

\section{B. PERSONNEL PREPARATION}

Please note that the bi-prop rocket engine is extremely loud; per safety regulations, ear protection is required in the control room at all times while the engine is running. Note also that while you can hear people yelling while the engine is running, you will likely only know that you are being yelled at if you're looking at the person who is yelling. As such, please coordinate with your test team how you plan to communicate while the engine is running. Make use of hand signals.

\begin{tabular}{|c|cc|}
\hline$\square$ & $\begin{array}{c}\text { B.1. Familiarize all personnel with features of the rocket apparatus, including fuel and } \\
\text { oxidizer flows, load cell, and ignition system. }\end{array}$ \\
\hline$\square$ & B.2. Review all safety information for the facility and lab \\
\hline$\square$ & B.3. Familiarize all personnel with the lab procedure and control room set up \\
\hline$\square$ & B.4. Clearly determine which personnel will execute which parts of the lab activity. \\
\hline$\square$ & $\begin{array}{c}\text { B.5. Dry-run Sections D through I of this procedure with the personnel who will execute } \\
\text { those activities prior to running the procedure "for real". }\end{array}$ \\
\hline
\end{tabular}

\section{LOAD CELL CALIBRATION}

If the load cell does not require calibration skip to section D. Inquire with the lab assistant or professor about current load cell calibration.

\begin{tabular}{|r|l|}
\hline$\square$ & C.1. Measure length of lever arms on test stand \\
\hline$\square$ & $\begin{array}{r}\text { C.2. Place weight on counterweight hook until pivot bar is balanced (should be about } 30 \\
\text { lbs) } \\
\text { a. Load cell should lightly contact the upper cross bar with very little load on it (i.e. the } \\
\text { pivot arm should be balanced }\end{array}$ \\
\hline$\square$ & C.3. Turn on Power Supply. \\
\hline$\square$ & C.4. Activate the 10V Switch for instrumentation excitation. \\
\hline$\square$ & $\begin{array}{r}\text { C.5. On the LabVIEW GUI, open the vi architecture and go to calibration tab } \\
\text { a. Click "Start a new calibration" }\end{array}$ \\
\hline$\square$ & $\begin{array}{r}\text { C.6. With a balanced pivot bar (very little to no load on load cell) enter first point in } \\
\text { calibration curve to be 0.0 lbf which will act as your zero thrust reference }\end{array}$ \\
\hline$\square$ & C.8. Odd weight to counterweight hook in 2.5 lb (5lb load) increments up to 12.5 lbs \\
\hline$\square$ & C.9. Turn off all switches on Power Supply. \\
\hline
\end{tabular}




\section{ROCKET PREPARATION}

\begin{tabular}{|c|c|}
\hline$\square$ & D.1. All personnel in test area acquire ear and eye protection. \\
\hline$\square$ & D.2. Confirm main coolant hose is connected to pressurized water supply. \\
\hline$\square$ & D.3. Close $Y$-valve fork to the rocket coolant supply. \\
\hline$\square$ & D.4. Open $\boldsymbol{Y}$-valve fork for water sprayer. \\
\hline$\square$ & D.5. Fully open coolant supply spigot. \\
\hline$\square$ & D.6. Test water sprayer hose by spraying a small amount of water outside the test cell. \\
\hline$\square$ & D.7. Place glass fuel beaker below fuel drain valve. \\
\hline$\square$ & D.8. Confirm no residual fuel in system by opening the fuel drain and fuel fill valves. \\
\hline$\square$ & D.9. Close fuel drain and fuel fill valves. \\
\hline$\square$ & $\begin{array}{l}\text { D.10. Make sure the nitrogen regulator is screwed out setting the regulated pressure to } \\
\text { zero (Do not unscrew all the way, just until no resistance is felt) }\end{array}$ \\
\hline$\square$ & D.11. Turn on Main Power on power supply. \\
\hline$\square$ & D.12. Switch on $12 \mathrm{~V}$ and $10 \mathrm{~V}$ power switches on power supply control board. \\
\hline$\square$ & $\begin{array}{l}\text { D.13. Power on the prop lab DAQ computer (dark grey Dell) and log on } \\
\text { a. Start LabVIEW } \\
\text { b. OpenLabVIEW VI }\end{array}$ \\
\hline$\square$ & $\begin{array}{l}\text { D.14. Test operation of the VI: } \\
\text { a. Click the Run button (white arrow) at top of VI window } \\
\text { b. Enter a test data file name in the prompt } \\
\text { c. Verify that the VI is operating (pressure plots should start updating) } \\
\text { d. Click the Record button on the front panel of the VI (button should switch to a brighter } \\
\text { e. Veen color) } \\
\text { f. Click the Record button a second time (to stop the recording) } \\
\text { g. Click the Stop button (red stop sign) at the top of the VI window } \\
\text { h. Open the test data file and see that all data values have been written to file. }\end{array}$ \\
\hline
\end{tabular}




\section{E. COLD GAS THRUSTER PROCEDURE}

If cold gas thruster demonstration is not required skip to fuel filling procedures section $F$.

\begin{tabular}{|c|c|}
\hline$\square$ & E.1.Confirm tank release valve is open. \\
\hline$\square$ & E.2.Slowly open the nitrogen tank. \\
\hline$\square$ & E.3.Set nitrogen pressure regulator to desired test pressure (between 330 and 420 psi) \\
\hline$\square$ & E.4. Unscrew the oxygen pressure regulator until no resistance is felt in the set screw. \\
\hline$\square$ & E.5.Slowly open the oxygen tank. \\
\hline$\square$ & E.6.Set oxygen pressure regulator to desired test pressure (between 330 and 430 psi) \\
\hline$\square$ & E.7.All personnel enter the control room and shut the doors. \\
\hline$\square$ & E.8.Plug in control board. \\
\hline$\square$ & $\begin{array}{l}\text { E.9. On the LabVIEW GUI: } \\
\text { a. Click the Run button (white arrow) at top of VI window } \\
\text { b. Enter a test data file name in the prompt } \\
\text { c. Verify that the VI is operating (pressure plots should start updating) } \\
\text { d. Click the Record button on the VI to begin cold gas thruster data recording. }\end{array}$ \\
\hline$\square$ & $\begin{array}{l}\text { E.10. On the Main Control Board } \\
\text { a. Turn on Main Power Switch } \\
\text { b. Turn on Fuel Control Switch for } 2 \text { seconds. } \\
\text { c. Turn off Fuel Control Switch. } \\
\text { d. Turn on Oxygen Control Switch for } 2 \text { seconds. } \\
\text { e. Turn off Oxygen Control Switch. } \\
\text { f. Turn on the Fuel Control Switch and the Oxygen Control Switch for } 2 \text { seconds. } \\
\text { g. Turn off all control switches and the Main Power Switch. }\end{array}$ \\
\hline$\square$ & $\begin{array}{l}\text { E.11. On the LabVIEW GUI: } \\
\text { a. Click the Record button to stop LabVIEW recording. } \\
\text { b. Click the Stop button to stop running the LabVIEW GUI. }\end{array}$ \\
\hline$\square$ & $\begin{array}{l}\text { E.12. Before entering the test area confirm proper safety equipment is worn } \\
\text { a. Ear Protection } \\
\text { b. Eye Protection }\end{array}$ \\
\hline$\square$ & E.13. Close oxygen tank. \\
\hline$\square$ & E.14. Return to control room. \\
\hline$\square$ & $\begin{array}{l}\text { E.15. Depressurize oxygen line by turning on the Main Power Switch and the Oxygen } \\
\text { Control Switch until no sound is heard. }\end{array}$ \\
\hline$\square$ & E.16. Turn off all switch on Main Control Board. \\
\hline$\square$ & E.17. Reenter the test area and close the nitrogen tank \\
\hline$\square$ & $\begin{array}{l}\text { E.18. WARNING LOUD- While watching the nitrogen pressure regulator depressurize fuel } \\
\text { line by slowly opening the fuel fill valve until the regulator shows } 50 \text { psi then close the fuel } \\
\text { fill valve. }\end{array}$ \\
\hline$\square$ & E.19. Close the tank release valve at the bottom of the fuel tank. \\
\hline & E.20. Complet \\
\hline
\end{tabular}




\section{F. FUEL FILLING PROCEDURE}

Fuel filling is a potentially dangerous procedure, Methanol is highly flammable and poisonous if ingested. Review the MSDS and use proper procedures and safety equipment when handling. Before transferring methanol from one container to another be sure to touch the two containers together to reduce the chance of a static spark. Fuel handler should be wearing gloves and grounding wrist strap. If Cold Gas Thruster procedures have already been followed skip to F.6.

\begin{tabular}{|c|c|}
\hline$\square$ & F.1.Open tank release valve. \\
\hline$\square$ & F.2.Slowly open nitrogen tank. \\
\hline$\square$ & F.3.Set nitrogen regulator to 50psi. \\
\hline$\square$ & F.4. Close tank release valve. \\
\hline$\square$ & F.5.WARNING LOUD- Depressurize fuel line by slowly opening the fuel fill valve. \\
\hline$\square$ & $\begin{array}{l}\text { F.6. On Fuel Drum } \\
\text { a. Pull out cap to deploy spout. } \\
\text { b. Tip drum over on side with spout at the top. } \\
\text { c. Touch glass beaker and fuel drum together. } \\
\text { d. Remove fuel drum cap. } \\
\text { e. Roll drum to pour up to } 1 \mathrm{~L} \text { of methanol into glass beaker. (If fuel level in drum is low it } \\
\text { may be necessary to pick up the fuel drum and pour fuel into beaker) } \\
\text { f. Replace cap on fuel drum. }\end{array}$ \\
\hline$\square$ & F.7.Place metal funnel into fuel fill spout. \\
\hline$\square$ & F.8. Open fuel fill valve. \\
\hline$\square$ & $\begin{array}{l}\text { F.9. Have someone lift the nitrogen line that feeds into the fuel tank to prevent methanol from } \\
\text { flowing back towards the nitrogen tank. }\end{array}$ \\
\hline$\square$ & $\begin{array}{l}\text { F.10. Clip fuel handlers grounding wrist strap to the metal funnel and clip grounding line from } \\
\text { funnel to frame. }\end{array}$ \\
\hline$\square$ & $\begin{array}{l}\text { F.11. Slowly pour methanol fuel into metal funnel, make sure fuel does not back up and } \\
\text { overflow fuel fill spout. }\end{array}$ \\
\hline$\square$ & F.12. Close fuel fill valve. \\
\hline$\square$ & F.13. Remove grounding lines and metal funnel from fuel fill spout. \\
\hline$\square$ & F.14. Unscrew the nitrogen and oxygen pressure regulators. \\
\hline$\square$ & F.15. Slowly open the nitrogen tank. \\
\hline$\square$ & $\begin{array}{l}\text { F.16. Set nitrogen pressure regulator to desired testing pressure (between } 330 \text { and } 430 \\
\text { psi) }\end{array}$ \\
\hline$\square$ & F.17. Slowly open fuel tank release valve. \\
\hline$\square$ & $\begin{array}{l}\text { F.18. Insert ignition wires into chamber through the nozzle throat until plug contacts the } \\
\text { nozzle. }\end{array}$ \\
\hline$\square$ & F.19. Slowly open oxygen tank. \\
\hline$\square$ & $\begin{array}{l}\text { F.20. Set oxygen pressure regulator to desired testing pressure (between } 330 \text { and } 430 \\
\text { psi) }\end{array}$ \\
\hline 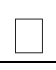 & F.21. All personnel exit the test area back to the control room. \\
\hline
\end{tabular}




\section{G. ROCKET FIRING}

Before firing the rocket with fuel it is important to make sure everyone is clear of the test area and that these procedures are strictly followed.

\begin{tabular}{|c|c|}
\hline$\square$ & G.1. Confirm all switches on control board in the "OFF" position \\
\hline$\square$ & G.2. Plug in control board to wall outlet \\
\hline$\square$ & $\begin{array}{l}\text { G.3. CRITICAL- Turn on coolant valve at } \boldsymbol{Y} \text {-valve fork and confirm good coolant flow by } \\
\text { observing water coming out of coolant exit outside the test area. }\end{array}$ \\
\hline$\square$ & G.4. Turn on Main Power Switch on control board. \\
\hline$\square$ & G.5. Confirm power supply is turned on and the $12 \mathrm{~V}$ and $10 \mathrm{~V}$ power is active. \\
\hline$\square$ & $\begin{array}{l}\text { G.6. On the LabVIEW GUI: } \\
\text { a. Click the Run button to begin LabVIEW GUI } \\
\text { b. Enter in file name when prompted. } \\
\text { c. Click the Record button on the front panel of the VI (button should switch to a } \\
\text { brighter green color) } \\
\text { d. See that the Elapsed Run Time value increments }\end{array}$ \\
\hline$\square$ & G.7. Lift and hold the SPARK switch to "ON" \\
\hline$\square$ & $\begin{array}{l}\text { G.8. Simultaneously switch the Fuel Control Switch and Oxygen Control Switch to "ON" } \\
\text { a. Assuming the rocket ignites with combustion in the chamber (you should see } \\
\text { shock diamonds in the exhaust), release the SPARK switch } \\
\text { b. If the rocket does not ignite, or ignites outside the combustion chamber, switch } \\
\text { SPARK, FUEL, and OXYGEN to "OFF" and skip to misfire procedures section H. }\end{array}$ \\
\hline$\square$ & G.9. Timer count down from run time to zero \\
\hline$\square$ & G.10. At end of run, switch Fuel Control Switch and Oxygen Control Switch to "OFF" \\
\hline$\square$ & $\begin{array}{l}\text { G.11. If flame is still seen around the nozzle exit pulse the Oxygen Control Switch until } \\
\text { flame is extinguished. }\end{array}$ \\
\hline$\square$ & $\begin{array}{l}\text { G.12. On the LabVIEW GUI } \\
\text { a. Click the Record button to stop LabVIEW data recording } \\
\text { b. Click the Stop button to stop running the LabVIEW GUI }\end{array}$ \\
\hline$\square$ & G.13. Turn all control panel switches to "OFF". \\
\hline$\square$ & G.14. Turn off coolant valve at $Y$-valve fork. \\
\hline$\square$ & $\begin{array}{l}\text { G.15. If multiple runs are required continue to section } \mathrm{H} \text {, if not skip to Rocket Safing and } \\
\text { Closeout section I. }\end{array}$ \\
\hline
\end{tabular}




\section{H. ROCKET MISFIRE/MULTIPLE RUN PROCEDURES}

\begin{tabular}{|r|ll|}
\hline$\square$ & H.1. $\quad$ Confirm all switches on Main Control Board are in the off position. \\
\hline$\square$ & H.2. & Unplug the Main Control Board from the wall. \\
\hline$\square$ & H.3. $\quad$ Confirm no residual ignition in test area by checking for flames or heat waves. \\
\hline$\square$ & H.4. $\quad$ Enter test area and check ignition wires for correct insulation degradation and position. \\
\hline$\square$ & H.5. $\quad$ Reinsert ignition wires into rocket until plug contacts the nozzle wall. \\
\hline$\square$ & H.6. Reenter control room. \\
\hline$\square$ & H.7. $\quad$ Plug Main Control Board back into wall socket. \\
\hline$\square$ & H.8. $\quad$ Go back to step G.6 and continue rocket firing procedure. \\
\hline
\end{tabular}

\section{ROCKET SAFING AND CLOSEOUT}

\begin{tabular}{|c|c|}
\hline$\square$ & $\begin{array}{l}\text { I.1. Before entering test area confirm there is no ongoing combustion or fire by checking } \\
\text { for flames or heat waves. }\end{array}$ \\
\hline$\square$ & I.2. Close oxygen tank. \\
\hline$\square$ & I.3. Close nitrogen tank. \\
\hline$\square$ & I.4. Place metal capture bucket below the rocket nozzle. \\
\hline$\square$ & I.5. Return to control room. \\
\hline$\square$ & $\begin{array}{l}\text { I.6. Depressurize oxygen line by turning on the Main Power Switch and the Oxygen } \\
\text { Control Switch until no sound is heard. }\end{array}$ \\
\hline$\square$ & I.7. Turn off Main Power Switch and Oxygen Control Switch. \\
\hline$\square$ & I.8. WARNING LOUD- Depressurize fuel line by slowly opening the fuel fill valve. \\
\hline$\square$ & I.9. Place glass fuel beaker below fuel drain valve. \\
\hline$\square$ & I.10. Drain residual fuel by opening the fuel drain valve and fuel fill valve. \\
\hline$\square$ & I.11. Close fuel drain valve and fuel fill valve. \\
\hline$\square$ & $\begin{array}{l}\text { I.12. Residual fuel in beaker can be recycled. } \\
\text { a. Place metal funnel into spout of fuel drum. } \\
\text { b. Pour residual fuel back into fuel drum. }\end{array}$ \\
\hline$\square$ & I.13. Residual fuel if capture bucket can be left it will evaporate rather quickly. \\
\hline$\square$ & I.14. Unscrew nitrogen regulator. \\
\hline$\square$ & I.15. Slowly open nitrogen tank. \\
\hline$\square$ & I.16. Set nitrogen regulator to $200 p s i$. \\
\hline$\square$ & I.17. Reenter control room. \\
\hline$\square$ & I.18. Clear fuel line by turning the Main Power Switch and Fuel Control Switch on. \\
\hline$\square$ & I.19. Pulse the Fuel Control Switch until no liquid is seen exiting the rocket nozzle. \\
\hline$\square$ & I.20. Close nitrogen tank. \\
\hline$\square$ & I.21. WARNING LOUD- Depressurize fuel line by slowly opening the fuel fill valve. \\
\hline
\end{tabular}


I.22. Unplug control board.

I.23. Close coolant water supply.

I.24. Close LabVIEW.

I.25. Turn off all switches on power supply control board.

J. LAB CLOSE-OUT

\begin{tabular}{|l|l}
\hline$\square$ & J.1. Replace ear and eye protection in the cabinet.
\end{tabular}

J.2. Close roll up doors after last run of the day. 